\title{
THE GREAT DIVIDE
}

Citizen Science in the Anthropocene

at the Columbia Icefield

\begin{abstract}
By
Andrej Iwanski

A thesis submitted to the Faculty of Graduate and Postdoctoral Affairs in partial fulfillment of the requirements for the degree of
\end{abstract}

Master of Architecture

$\ln$

Azrieli School of Architecture

Carleton University

Ottawa, Ontario

(c) 2017

Andrej Iwanski 
THE GREAT DIVIDE 
ABSTRACT

At the dawn of the Anthropocene humankind's ability to in-

fluence its geophysical surroundings through processes - often times technological and industrial - has brought to the forefront the inextricably intertwined character of the natural environment and human culture.

At the heart of this often reckless relationship stands Alberta, Canada. Located in Jasper and Banff National Park at hydrographic apex of the Rocky Mountains, the Columbia Icefield, an icon of historic "pristine" Canadian wilderness, is now undergoing immense change. The Icefield's shifting environmental systems have generated new spatial and temporal relationships between humanity and nature. As a result, a new protagonist has gained prominence: the citizen scientist.

This thesis seeks to open discussions on historical and future time, and our engagement with the earth through the speculative rediscovery of the Columbia Icefield by means of citizen science. 


\section{ACKNOWLEDGMENTS}

I would like to first thank my family, who have provided

me with unconditional support and encouragement. Thank you to my advisor Inderbir Riar, whose knowledge and guidance throughout the project has been invaluable and to Ozayr Saloojee for his thoughtful and helpful advice.

Thank you also to my fellow students and friends who have supported me throughout my education. A special thanks to Jean Olivier Larocque, Matthew Lerch, Paola Vega, and Melanie Li for their insightful comments and valued criticism throughout the project. Additionally I would like to give thanks the faculty and staff at the school of architecture, who through their persistent dedication to the school, its values, and its students, create a unique and encouraging learning environment. 


\section{TABLE OF CONTENTS}

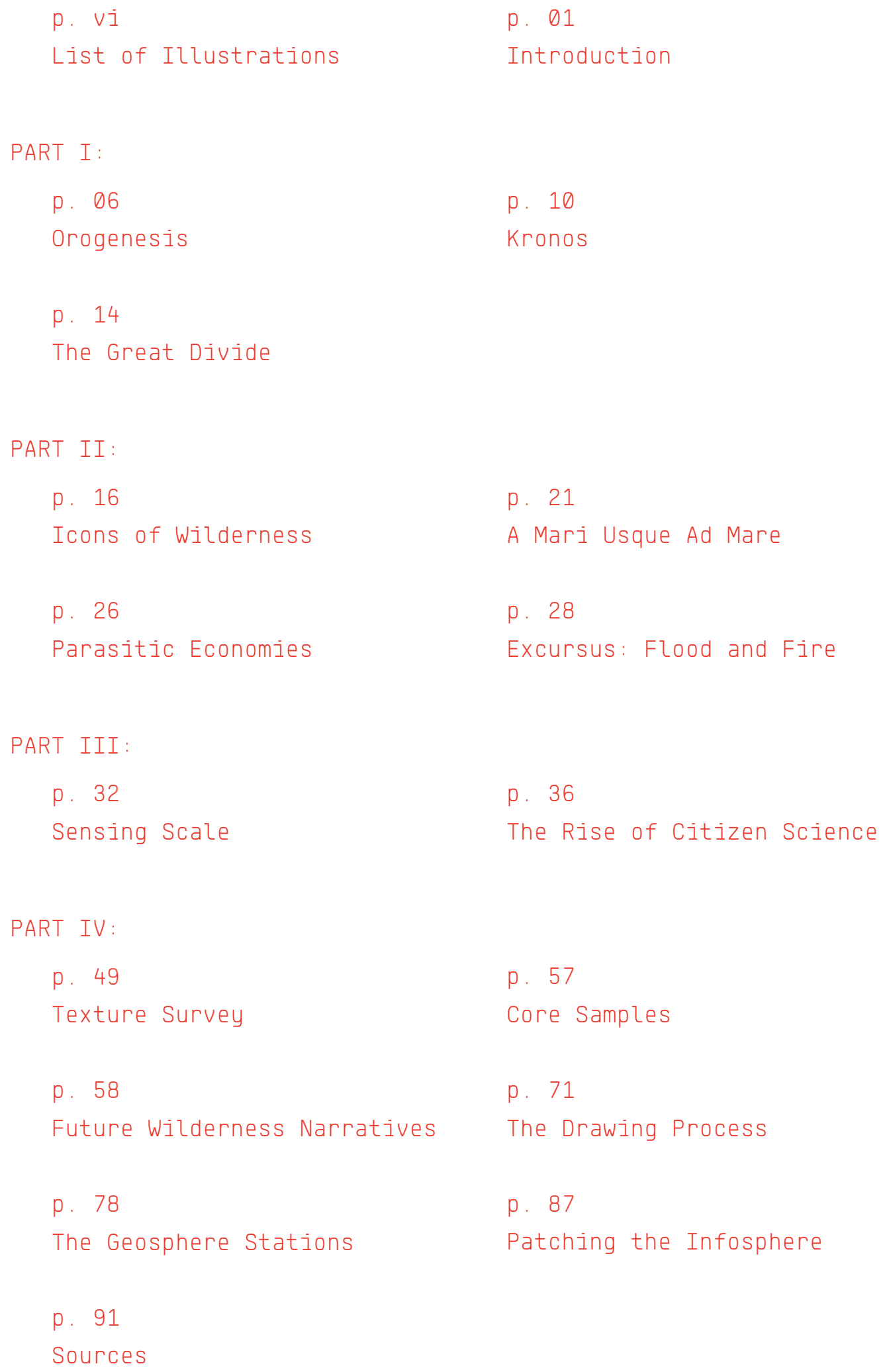

p. 01

Introduction

p. 10

Kronos

p. 21

A Mari Usque Ad Mare

p. 28

Excursus: Flood and Fire

p. 36

The Rise of Citizen Science

p. 57

Core Samples

p. 71

The Drawing Process

p. 87

Patching the Infosphere 
Fig. 01: Present

Fig. 02: Late Cretaceous

Fig. 03: Late Jurrasic

Fig. 04: Late Pennsylvanian

Fig. 05: Early Devonian

Fig. 06: Late Cambrian

Fig. 07: Exerpt from Genesis

Fig. 08: Exerpt from A Theory of the Earth

Fig. 09: CPR Postcard - The Great Divide

Fig. 10: Athabasca Glacier, 1918

Fig. 11: Athabasca Glacier, 1918

Fig. 12: Athabasca Glacier, 2011

Fig. 13: Athabasca Glacier, 2011

Fig. 14: Table of Surveying Equipment

Fig. 15: Columbia Icefield Recession

Fig. 16: Athabasca Glacier Recession

Fig. 17: Dominion Exhibition Poster

Fig. 18: Dominion Exhibition Poster Detail

Fig. 19: Athabasca Oilsands, 1984

Fig. 20: Athabasca Oilsands, 2016

Fig. 21: Cowboy lassoing at Columbia Icefield

Fig. 22: Bow River, 2013

Fig. 23: Bow River, 2016

Fig. 24: Satellite Image of Burn Scar

Fig. 25: Satellite Image of Fire Progress

Fig. 26: Antenna Controller

Fig. 27: Spectrometer

Fig. 28: Triton Buoy

Fig. 29: Radiosonde

Fig. 30: Artist Rendering of Nimbus Satellite

Fig. 31: Nimbus II spacecraft system

Fig. 32: Satellite Image of Weather System

Fig. 33: Satellite Image of Weather System

Fig. 34: Meteorologists
Pg. $\oslash 8$

Pg. $\oslash 8$

Pg. $\oslash 8$

Pg. $\oslash 8$

Pg. 08

Pg. $\oslash 8$

Pg. 12

Pg. 12

Pg. 15

Pg. 18

Pg. 18

Pg. 18

Pg. 18

Pg. 18

Pg. 19

Pg. 20

Pg. 22

Pg. 22

Pg. 27

Pg. 27

Pg. 27

Pg. 28

Pg. 28

Pg. 29

Pg. 29

Pg. 33

Pg. 33

Pg. 33

Pg. 33

Pg. 34

Pg. 34

Pg. 34

Pg. 34

Pg. 34 
Fig. 35: Satellite Image of Weather System

Fig. 36: 3D Visualization of Corings and Subsurface Surveying

Fig. 37: Citizen Scientist 01

Fig. 38: Citizen Scientist 02

Fig. 39: Citizen Scientist 03

Fig. 40: Citizen Scientist 04

Fig. 41: Citizen Scientist 05

Fig. 42: Citizen Scientist 06

Fig. 43: Citizen Scientist 07

Fig. 44: Citizen Scientist 08

Fig. 45: Citizen Scientist 09

Fig. 46: Citizen Scientist 10

Fig. 47: Heightfield Diagram + Maps

Fig. 48: Texture Survey Map 01

Fig. 49: Texture Survey Map 02

Fig. 50: Texture Survey Map 03

Fig. 51: Texture Survey Map 04

Fig. 52: Texture Survey Map 05

Fig. 53: Texture Survey Map 06

Fig. 54: Core Sample Diagram

Fig. 55: Core Samples

Fig. 56: Process Sketch 01

Fig. 57: Process Sketch 01

Fig. 58: Process Sketch 01

Fig. 59: Process Sketch 01

Fig. 60: Silk Screen Preparation + Process

Fig. 61: 110-Thread Mesh Screen

Fig. 62: 200-Thread Mesh Screen

Fig. 63: Screen Print Test

Fig. 64: Atmosphere Station Print Components

Fig. 65: Hydrosphere Station Print Components

Fig. 66: Cryosphere Station Print Components

Fig. 67: Lithosphere Station Print Components
Pg. 34

vii

Pg. 37

Pg. 38

Pg. 39

Pg. 40

Pg. 41

Pg. 42

Pg. 43

Pg. 44

Pg. 45

Pg. 46

Pg. 47

Pg. 50

Pg. 51

Pg. 52

Pg. 53

Pg. 54

Pg. 55

Pg. 56

Pg. 57

Pg. 57

Pg. 61

Pg. 64

Pg. 67

Pg. 70

Pg. 72

Pg. 73

Pg. 73

Pg. 73

Pg. 74

Pg. 75

Pg. 76

Pg. 77 
Fig. 68: Atmosphere Station

Pg. 79

vii

Fig. 69: Atmosphere Station Details

Pg. 80

Fig. 70: Hydrosphere Station

Pg. 81

Fig. 71: Hydrosphere Station Details

Pg. 82

Fig. 72: Cryosphere Station

Pg. 83

Fig. 73: Cryosphere Station Details

Pg. 84

Fig. 74: Lithosphere Station

Pg. 85

Fig. 75: Lithosphere Station Details

Pg. 86

Fig. 76: Infosphere

Pg. 89 
Due to industrial and technological advancement, at times reckless, humanity has, since the Industrial Revolution, begun to act on the planet as a geophysical force. This entirely new age is called the Anthropocene, a concept first introduced by Dutch chemist Paul J. Crutzen in 2002. The Anthropocene marks the convergence of human and geological history. Crutzen suggests that humanity's ceaseless and perhaps irreversible anthropocentric activity has impacted earth's geophysical systems in a matter that is detrimental to its own survival. The theory proposes that humanity's existence will be physically recorded in earth's geological strata. ${ }^{01}$

In this new era, humankind's ability to influence its geophysical surroundings through processes - often times technological and industrial - has brought to the forefront the inextricably intertwined character of the natural environment and human culture. The impact of human activity has historically been thought of as being limited to the biosphere, the realm of all life on earth, evident in phenomena such as species extinction. In the advent of the Anthropocene, this reach has now extended into the geosphere, the physical habitable sphere comprised of air, water (in all its states), and earth. This relationship can be defined as geological agency. ${ }^{02}$

At the heart of a global conflict between industrial capitalism and the environment stands Alberta, Canada. Instrumental in defining the Canadian conception of "untouched" and "pristine" wilderness, the provinces national parks now serve as a measure of physical and conceptual ecological change. The love for and pride in the wilderness, deeply woven into Albertans' cultural identity, is confronted by the relentless exploitation of its resources. The "sunshine province" has been criticized for its controversial agricultural-industrial practices, such as the Alberta beef industry and the Athabasca Oil Sands Project - undertakings crucial to the Canadian economy.

01 Paul Crutzen, “Geology of Mankind," Nature, Vol. 415, (January 2002), 23.

02 Dipesh Chakrabarty, "The Climate of History: Four Theses," Critical Inquiry, Vol. 35 (Winter 2009), 206-207. 
Territories and cartographies drawn through geological surveys in the expansion

of Canada's mineral and agricultural industries in the mid-1800's have framed Albertans', and moreover Canadians, perception of wilderness. This has resulted in an adverse ecological relationship impacting not only Alberta's geophysical landscape but also its population.

Through studies and explorations in techniques of representation and narrative the project explores representing changing environmental conditions and perceptions of wilderness at the Columbia Icefield. The work explores the infrastructural potential of citizen science to illuminate the interconnectivity of humanity and the physical environment. A data acquisition and analysis practice that sources the observational capability of a network of actively engaged citizens. How can this collective power of citizen science prompt a new understanding of the changing Canadian wilderness?

The project embraces deep time, the concept of time as viewed from a geological scale rather than through the lens of human history, as a way to resituate the definitions of nature and culture. Throughout human history, these terms have enjoyed a variety of meanings. Two ambivalent terms, which by way of definition underline the fraught relationship humanity has with nature. The Oxford English Dictionary defines the word nature as: "The phenomena of the physical world collectively ... as opposed to humans and human creations." ${ }^{3}$ In the Anthropocene, and amid climate change, the term nature and how humanity is situated within it is being redefined and unearthed.

The project narrative will unfold at the Columbia Icefields, an immense $325 \mathrm{~km}^{2}$ accumulation of glaciers along the continental divide at the hydrographic apex of three distinct watersheds. The meltwaters of the icefield feed the headwaters of the North Saskatchewan, Columbia, Athabasca and Fraser river systems, which have been fundamental to the settlement and industrial development of the areas surrounding the Rockies. At the precipice of environmental transformation, the

03 "Nature, n.11, a". OED Online. March 2017. Oxford University Press. http://www.oed.com.proxy. library.carleton.ca/view/Entry/125353 (accessed March 27, 2017). 
traditional icon of Canada's pristine wilderness - a National Park - has transformed into an image of rapid climate change. 
$+$

$+$

PART I 


\section{"We understand two seemingly inconsistent verities about things: that there is nature out there that lies beyond our ability to co-create, and that our forms of perception make it resemble what we choose."}


Due to the dominant influence of religious beliefs on scientific thought, the proposition of a geological history that predates what had been known to be the "beginning of time" defied all principles. ${ }^{04}$ Deep time is a concept first mentioned in 1981 by American writer and journalist John McPhee, who used the term to help comprehend the seemingly insurmountable geological time scale. Foundational to his theory is the work of James Hutton, and later John Playfair, who with their research marked the emergence of modern geology in the 1780 s. ${ }^{05}$ Hutton's seminal work during the Enlightenment posited an existence of earth that predated the sacred origins propagated by Judeo-Christian belief (exemplified in Genesis). Hutton's search for a geological history aligned with Enlightenment thinking as it was part of a larger trend to historicize and find the origins of phenomena (i.e. Rousseau and Laugier). His discoveries led to contemporary models of earth's tectonic evolution such as the formation of mountain regions (orogeny), or the concept that the current continents evolved from millennia of continental drift and collisions of supercontinents. Naturally his idea proved to be extremely controversial and was not taken seriously well into the $19^{\text {th }}$ century. ${ }^{06}$ Recently however, in the dawn of the Anthropocene, a paradigm shift has occurred.

In this new age of geological agency, Alberta has transformed into a conflict zone. The vast geological wonder of the Rocky Mountains that has been crucial to institutions of nation-building in the nation building of Canada has fallen subject to heavy industrial exploitation through agriculture, forestation, and mining. This has resulted in changes to the entire landscape. Much like the forces that sculpted the terrain, the harmful effects threatening to destroy many of its wonders will unfold on a timescale that is difficult to imagine. For example, the term orogenesis refers to the collective "violent" geological processes that take place over millions

04 Lewis Mumford, Technics and Civilization (New York: Harcourt, Brace \& World, Inc., 1932; Reprint, New York: Harbinger Books, 1963), 12.

05 Noah Heringman, “Deep time at the Dawn of the Anthropocene," Representations, Vol. 129, No. 1. (Winter 2015), 57.

06 Heringman, “Deep time at the Dawn of the Anthropocene," 80. 
of years resulting in the major structural deformations of the Earth's crust. ${ }^{07}$

Orogeny occurs at the rate of a few centimeters per year or less, and its evolution escapes all but those who seek to concern themselves with the study of the earth. This does not make it any less drastic, even violent. When it comes to environmental degradation, only by being able to understand the effects on a long-term chronological scale - in other words, deep time - can a sense of "violence" be approximated or comprehended. Unlike human history, which only focuses on much shorter spans of time (decades to centuries), deep time is crucial in understanding the effects of, for example, glacial depletion or the accelerated rate of species extinction.

The history of the Anthropocene must therefore be understood at a vastly different scale than the 250 years since the industrial revolution - in other words, at an epochal, millennial scale of deep time. The influence of Judeo-Christianity on Western industrial societies, through beliefs in for example Genesis, has cultivated the idea that nature serves humanity. As a result of the export of these systems through different forces including trade and colonialism, the concept of deep time or deep history still plays a marginal role in the grand historical narrative of humanity. ${ }^{08}$

07 “Orogeny, n.1," OED Online. March 2017. Oxford University Press. http://www.oed.com.proxy. library.carleton.ca/view/Entry/132702?redirectedFrom=orogeny\#eid (accessed March 29, 2017)

08 Daniel Lord Smail, On Deep History and the Brain (Berkley and Los Angeles: The University of California Press, 2008), 2. 

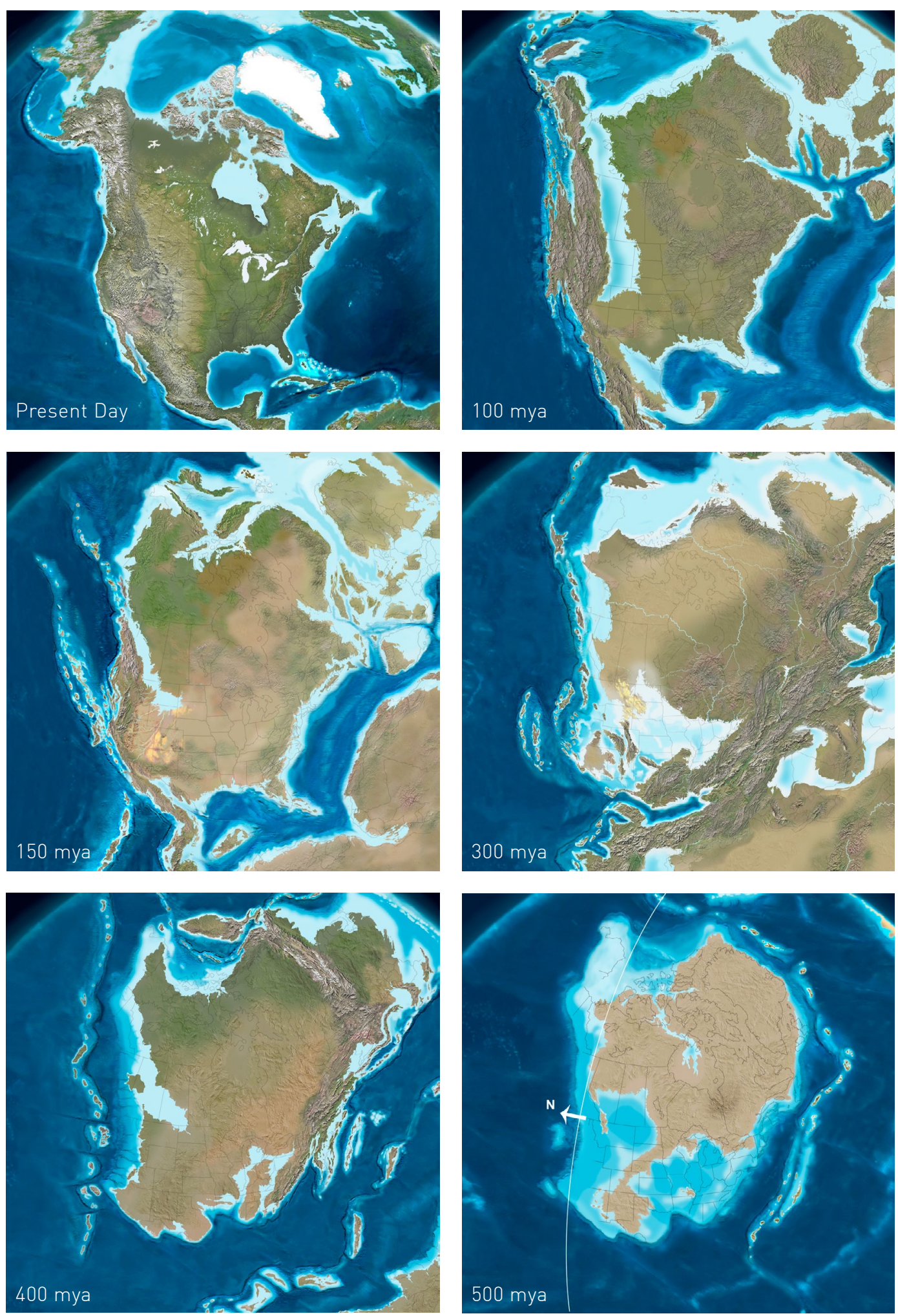

Maps depicting, the tectonic paleology of the North American continent from the present day to 500 million years ago

Fig. 01: Present

Fig. 02: Late Cretaceous

Fig. 03: Late Jurrasic 
"God blessed them and said to them, 'Be fruitful and increase in number; fill the earth and subdue it. Rule over the fish in the sea and the birds in the sky and over every living creature that moves on the ground." 
In the current age, the story of Genesis resonates with particular force. Human history in Western culture has been heavily influenced by the religious concept of Genesis. ${ }^{09}$ Judeo-Christian beliefs have defined how we perceive the natural world and how we situate ourselves in it. While our belief in Genesis may have influenced our accepting the concept of deep time, the concept of time, as a regular measurement for human life has had an equally influential impact. The shift to industrial capitalism in the $19^{\text {th }}$ century demanded a greater synchronization of labour than the irregular mercantilist industry from which it evolved. ${ }^{10}$

It is a commonly held belief that the rapid advances in technology in the $18^{\text {th }}$ century mark the beginning of environmental degradation and human impact on the planet. However human industriousness has developed through a successive series of technological inventions, which in some case predate the industrial revolution. ${ }^{11}$ In Technics and Civilization (1932), Lewis Mumford states: "The clock, not the steam engine, is the key machine of the modern industrial age." 12 Technological development and the invention of the clock allowed for a departure from mercantile industries. The invention of the steam engine and a shift to resource extraction in a culture that now relies heavily on energy quickened the pace of human society. The following paragraph is a synopsis of Mumford's argument.

Mumford credits the regimentation of daily life not to the invention of the clock in the $13^{\text {th }}$ century but to the Benedictines of the $7^{\text {th }}$ century. In his canonical text The Rule of Saint Benedict, Benedict of Nursia proclaimed that the divine office must be performed seven times throughout the day. Regimentation opposed the unorganized fluctuations of worldly life and the orderly rhythm was widely accepted. The Benedictine rule "helped give human enterprise the regular collective beat and rhythm of the machine; for the clock is not merely a means of keeping track of the hours, but of synchronizing the actions of men." ${ }^{13}$ The introduction of the

09 Lord Smail, On Deep History and the Brain, 4.

10 Thompson, E. P. “Time, Work-Discipline, and Industrial Capitalism." Past \& Present, no. 38 (1967): 80. http://www.jstor.org/stable/649749.

11 Mumford, Technics and Civilization, 3.

12 Ibid., 14.

13 Ibid., 13-14. 
regular measurement of time is crucial to the study of nature and quantitative methods of reasoning. Scientific thought and the whole-hearted embrace of regimentation has led to the alienation of humanity from the natural order. ${ }^{14}$ Mumford reiterates the claim that the Benedictines can, perhaps, be considered the original founders of modern capitalism and deduces that the invention of the clock has resulted in dissociating time from organic sequences. ${ }^{15}$

The construct of time and the regimentation of labour is therefore linked to western civilizations' perception of landscape due to its important role in capitalist industry. The resource dependency in capitalism has resulted in heavy exploitation of the landscape and can be assumed to be one of the causes of environmental degradation..$^{16}$

14 Ibid, 15.

15 Ibid, 13.

16 Ibid, 167-172. 

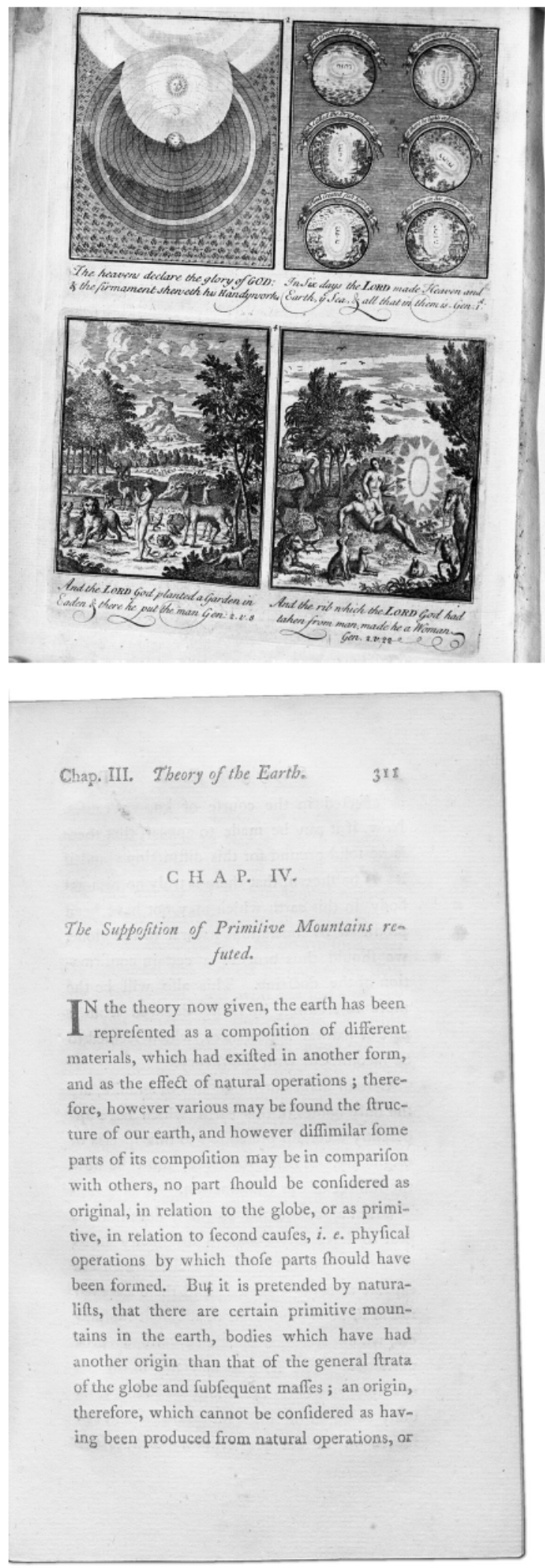

T The Firt Book of Mosss,

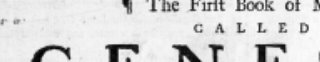
G E N E S I S.

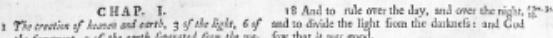

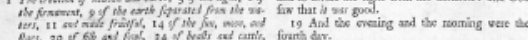

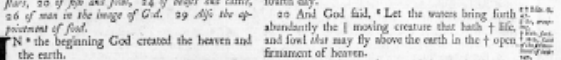

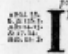

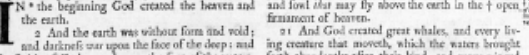

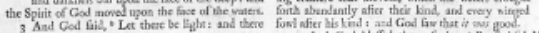

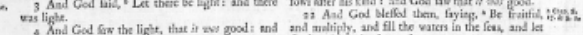

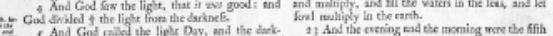

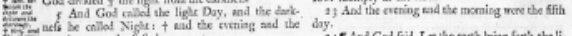

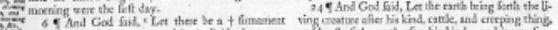

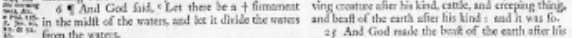

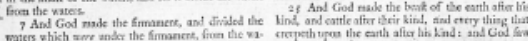

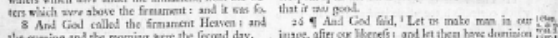

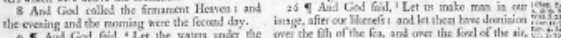

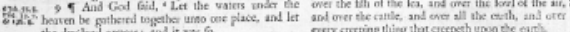

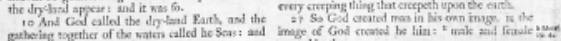

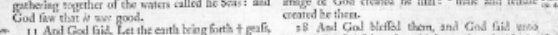

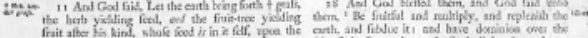
einth: and it mis bi

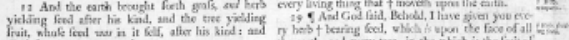

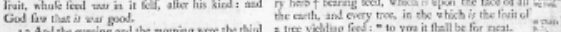

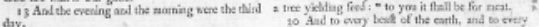

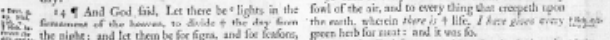

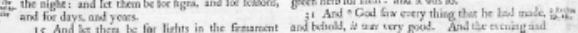

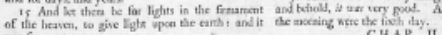

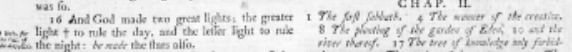

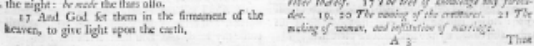

Fig. 07: (Above)

Opening Chapter of Genesis, Exerpt from: Bible Richard Watkins, 1744

Fig. 08: (Left)

Exerpt from: Theory of the Earth, James Hutton, 1795 
$+$

$+$

PART II 
The pervading image of wilderness as an economic resource to industry and tourism to Alberta was defined by the transcontinental railroad project and the ensuing surveying and settling of the land. This is reflected in historical narratives of exploration, conquest, resource extraction, parceling of land, protection of the wilderness, etc. - all deeply "heroic" acts venerated in annals of Canadian history. The current geological epoch proposes to unravel the wilderness ethos that has defined the Canadian understanding of nature.

The dichotomy between man's creations - 'culture' - and natural creations 'nature' - is quintessential to understanding the Anthropocene. ${ }^{17}$ Amid climate change, the term 'nature' is now being redefined. "Any full history of the uses of nature," semiologist Raymond Williams claims, "would be a history of a large part of human thought"18. In Keywords, Williams highlights the problematic meanings of the words nature and culture as they were used during the time of nation building as well as today. He suggests that one of the meanings of nature is "the material world itself, taken as including or not including human beings." 19 This relationship is also evident in the word culture, which, as Williams puts it, has specifically in the Western sense of an enlightened dominant civilization assumed that humanity is superior to nature. ${ }^{20}$ With the evolution of the word culture, in the mechanized industrial sense, one can begin to see how, at least in Western ideology, this relationship becomes apparently problematic. To progress from a natural order to a cultural domain is to enter into the realm of "irreversible" linear human history through the development of time and capitalism. ${ }^{21}$

This disjointed relationship is noticeable in the tension between Alberta's national parks and industry as Canada's National Parks emblematize Williams' definition of nature. While environmental degradation is undeniable, the effects of the ener-

17 Adrian Forty, Words and Buildings (New York: Thames and Hudson, 2000), 220.

18 Raymond Williams, Keywords: A Vocabulary of Culture and Society (USA: Oxford University Press, 1985), 221.

19 Williams, Keywords, 219.

20 Ibid., 89.

21 Christopher Pendergast, ed., Cultural Materialism: On Raymond Williams (Minnesota: Minnesota University Press, 1995), 5. 
gy industry on the environment are often slow and evade our attention. The image

of pristine wilderness institutionalized through advertising and literature in national and provincial emblems is now threatened in the face of change. ${ }^{22}$

22 Benedict Fullalove, "Places, Desire, and Maps: Representing Wilderness at the Columbia Icefield," in Found in Alberta: Environmental Themes for the Anthropocene (Waterloo: Wilfrid Laurier University Press, 2014], 266.

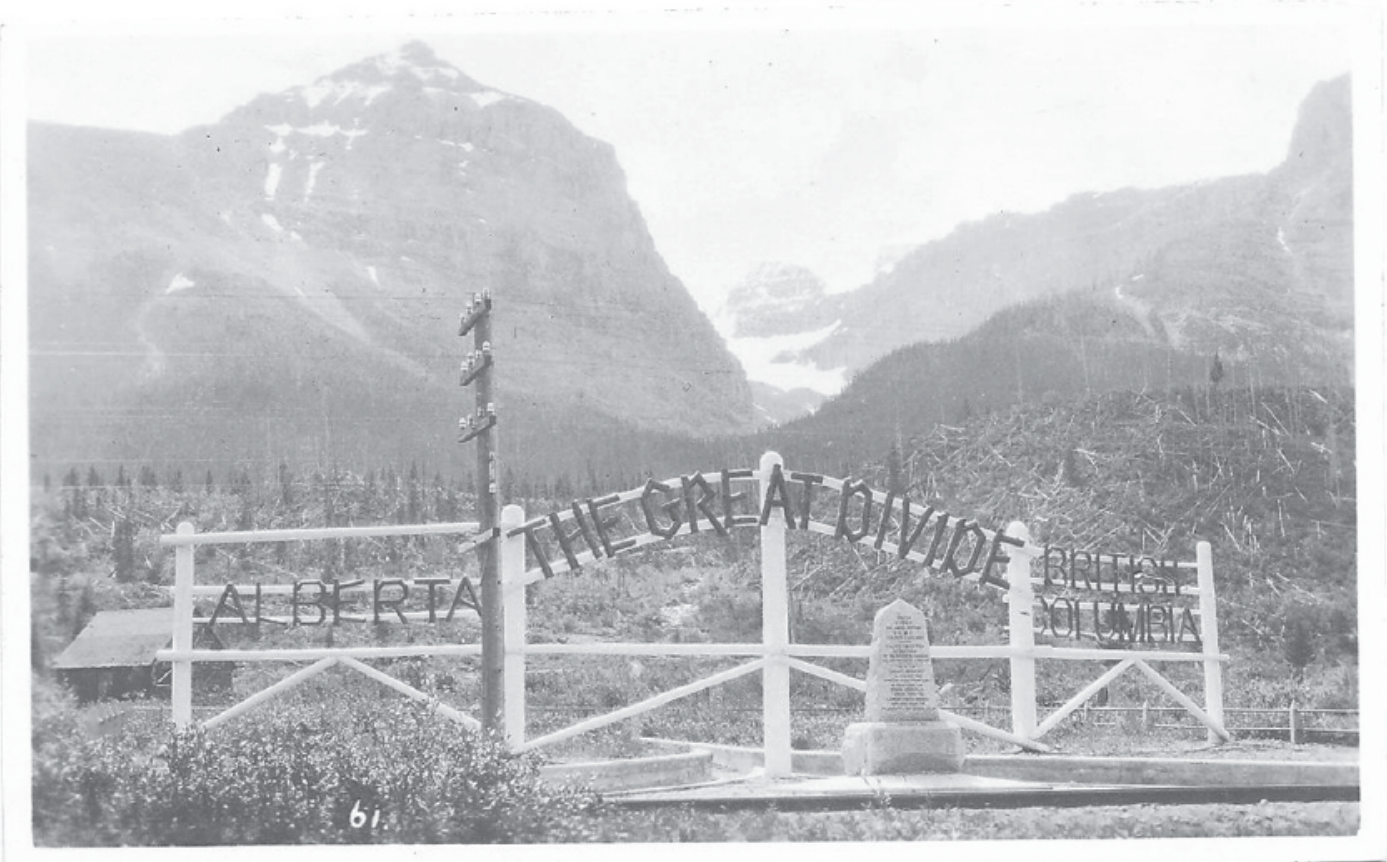

Fig. 09: CPR Postcard - The Great Divide The Great Divide is physically embodied at the continental divide, the hydrographic apex that splits eastern and western Canada. 
Since the time of nation building the Canada's National Parks have been instrumental in defining the wilderness ethos. Former Assistant Chief of the National Parks Service in Canada William F. Lothian defines a national park as an "area set aside as a public heritage or trust, to preserve forever outstanding examples of a nation's scenery, wilderness, geology, natural phenomena or native flora and fauna. ${ }^{23}$ As an icon of nature, their preserved geophysical wonders, still described by Parks Canada as "natural", can now be seen as a reference point for environmental change. ${ }^{24}$

Home to two of Canada's most notable national parks: Banff National Park lformerly known as Rocky Mountains National ParkJ and Jasper National Park, is Alberta. They were established in 1887, following extensive geological surveying of the Rocky Mountains in of the transcontinental railway. Upon completion of the railway explorers and tourists flooded into the newly established national parks to experience their geological wonders of the Rocky Mountains unearthed by scientists and surveyors. ${ }^{25}$

Originally founded on the principles of preservation, public enjoyment, and recreation, Alberta's National Parks are important as they emblematize Canadians' understanding of "pristine" nature. Many of their features, such as the mountains, boreal forests, and ice caps, now suffer from effects of human activity. In an attempt to represent environmental degradation, glacial depletion has become an enduring motif for climate change. However, the image of the wilderness foundational to the identity of Canada, and in this case Alberta, has become a product of how it is represented in Canadian culture. A repeatedly iconized geophysical wonder of the national parks is the Columbia Icefield at the border of Banff and Jasper National Park.

23 William F. Lothian, A Brief History of Canada's National Parks (Ottawa: Environment Canada, Parks, Canada, 1987), 10.

24 "National Parks of Canada, National Parks - Introduction," Parks Canada, last modified March 31, 2015, accessed March 28, 2017, http://www.pc.gc.ca/progs/np-pn/intro_e.asp

25 Lothian, A Brief History of Canada's National Parks, 15. 
The Icefield has been used as an archetypal example of what can be termed

wilderness. ${ }^{26}$ Astride the Continental Divide, the Columbia Icefield lies at the hydrographic apex of North America. Called the "mother of rivers," its meltwaters nourish the North Saskatchewan, Columbia, Athabasca and Fraser river systems. Studies show that the Columbia Icefield in the Rocky Mountains has seen a steady decline in ice mass over the past 100 years. ${ }^{27}$ As much of the regions' river basins derive their primary source from the meltwaters of the vast conglomeration of glaciers, most of the cities and industry in the areas will be affected by the dwindling water supply. ${ }^{28}$

26 Fullalove, “Places, Desire, and Maps: Representing Wilderness at the Columbia Icefield," 266.

27 Christina Tennant and Brian Menounos. "Glacier Change at the Columbia Icefield, Canadian Rocky Mountains, 1919-2009," Journal Of Glaciology, Vol. 59, No. 216, (2013). 677

28 Eric Bailey. Columbia Icefield: Ice Apex of the Canadian Rockies (Jasper: Parks Canada, 1987), 43-44. 

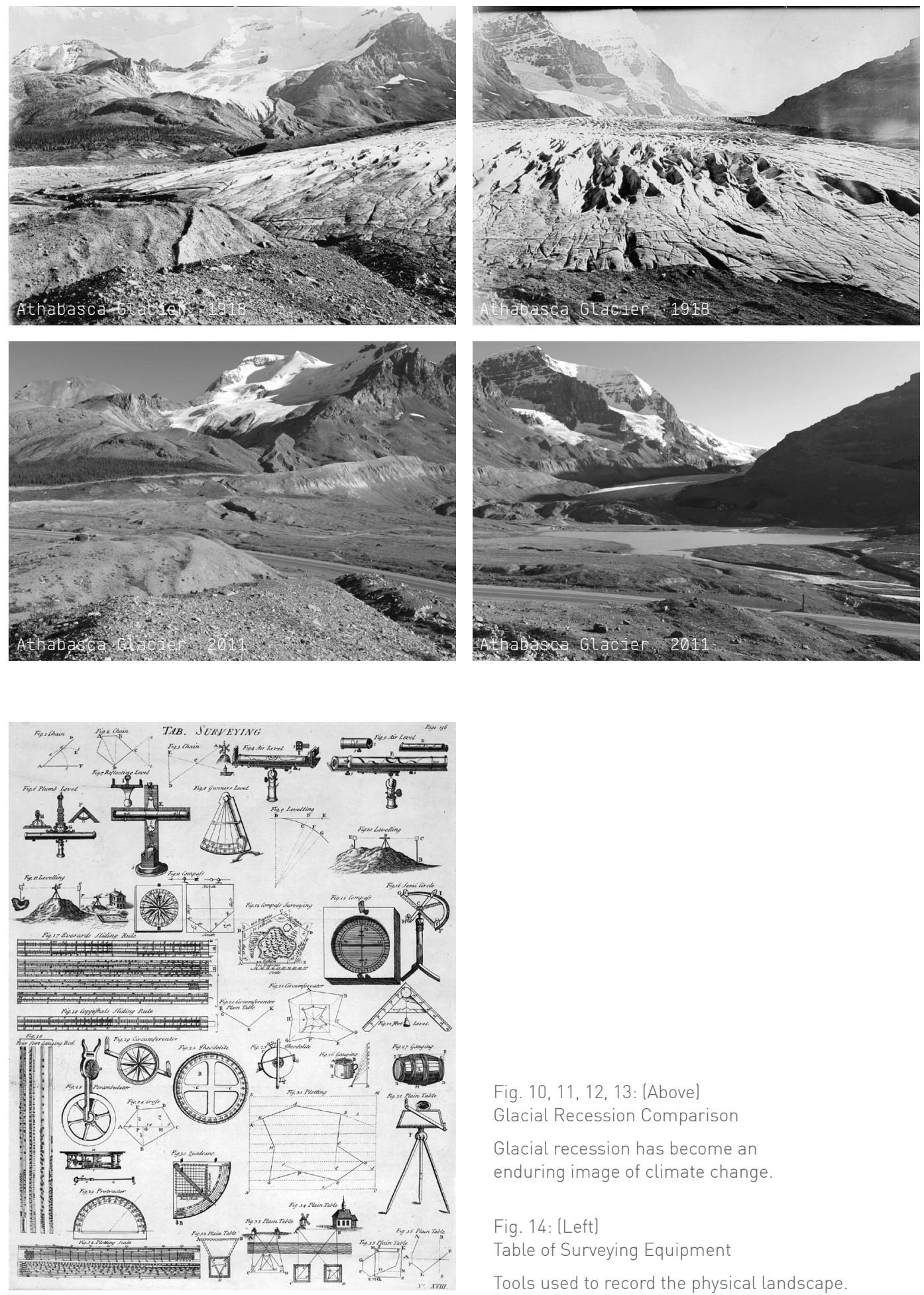

Fig. 10, 11, 12, 13: (Above)

Glacial Recession Comparison

Glacial recession has become an

enduring image of climate change.

Fig. 14: (Left)

Table of Surveying Equipment

Tools used to record the physical landscape. 

Fig. 16: Athabasca Glacier Recession

This map depicts the rate of glacial

depletion determined by a 1971 study.

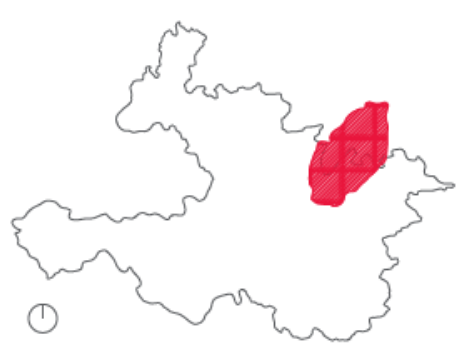

\section{LEGEND \\ $10 \mathrm{~m}$ Contour Lines $50 \mathrm{~m}$ Contour Lines Meltline \\ Snowpack/Glacier Coverage} Water
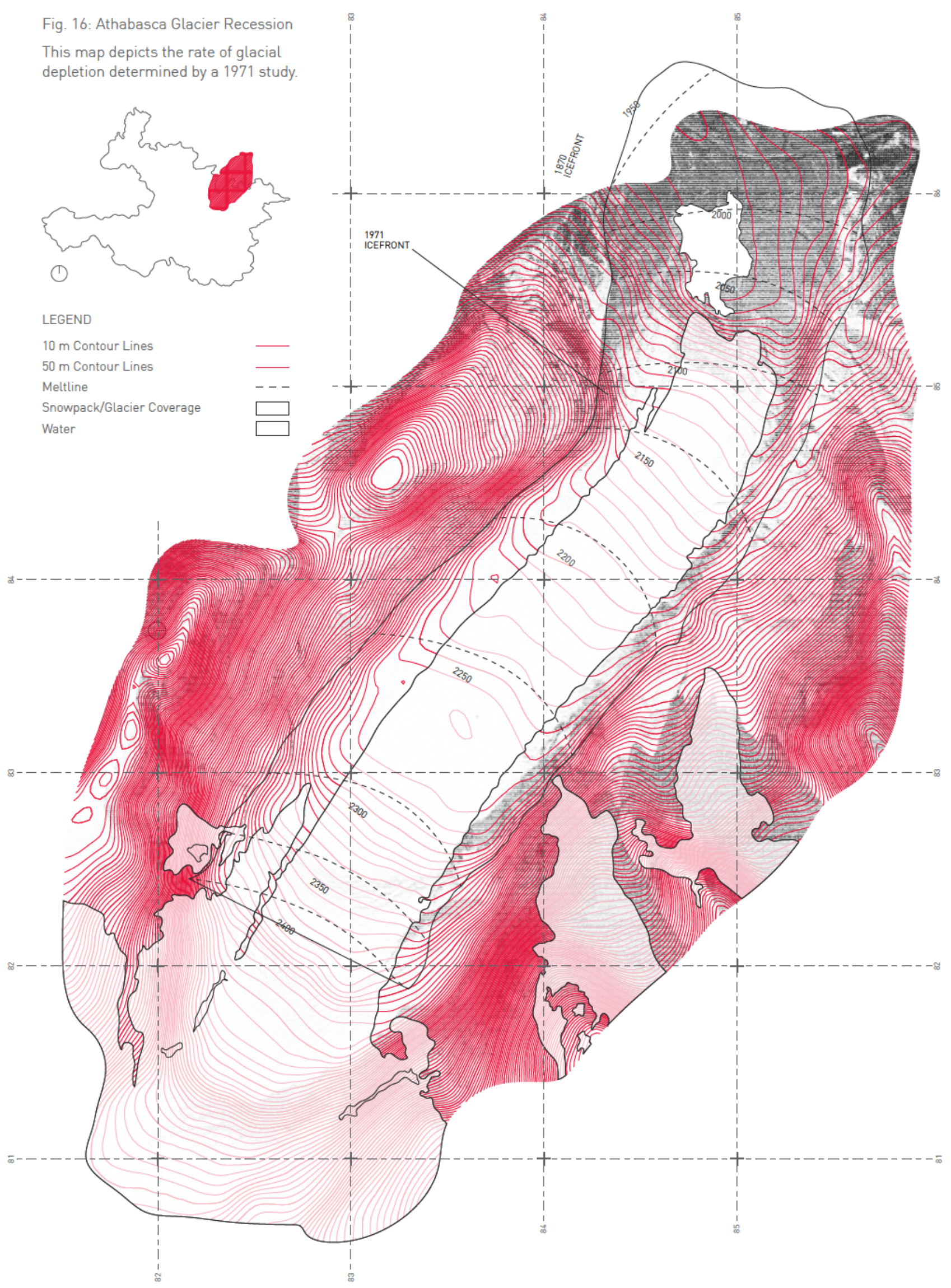
The introduction of the Northwest Territories to the Dominion of Canada in 1870 can be seen as the beginning of Alberta's abusive relationship with the environment. Lacking a firm presence in the newly acquired land was met with unease by the government: fearing American expansion, it pushed the development of the Canadian Pacific transcontinental railway. ${ }^{29}$ Under the Prime Minister John A. Macdonald, the Northwest Territories became the promised land of adventurous and entrepreneurial settlers as well as many agricultural and industrial works. The unique climatic and geophysical conditions of southern Alberta that made it so appealing to settlers are a culmination of geological and glacial evolution as well as geographic location. Yet the region's conditions have historically been a double-edged sword.

With the settlement of the land came official designations leading to resource extraction and vast agricultural development. This resulted in unprecedented systematic exploitation of the landscape and its indigenous population creating tension between the settlers and the native tribes. The plight began prior to 1870 when traders from below the $49^{\text {th }}$ parallel sensed opportunity on the open range and began exploiting the region's wildlife, agricultural, and mineral resources. Of primary interest were the buffalo of the southern plains. The encroachment on indigenous and settler land was met with resistance by the Hudson's Bay Company, which had occupied vast stretches of land since 1670.30 The traders' ill intentions became even more apparent as news of violent conflicts with the indigenous population spread across the country, leading to the eventual development and mobilization of the North-West Mounted Police. The introduction of "law and order" and the security it provided for the settlers marked the beginnings of large-scale settlement of southern Alberta. ${ }^{31}$

29 Brian Ballantyne, ed., Survey, Parcels, and Tenure on Canada Lands (Edmonton: Natural Resources Canada, 2010), 17.

30 Arthur J. Ray, "The Hudson's Bay Company," The Encyclopedia of Canada, last modified June 22, 2015, accessed March 28, 2017, http://www.thecanadianencyclopedia.ca/en/article/hudsonsbay-company/

31 Edward Brado, Cattle Kingdom: Early Ranching in Alberta (Victoria: Heritage House Publishing Co. Ltd., 2004), 32-33. 

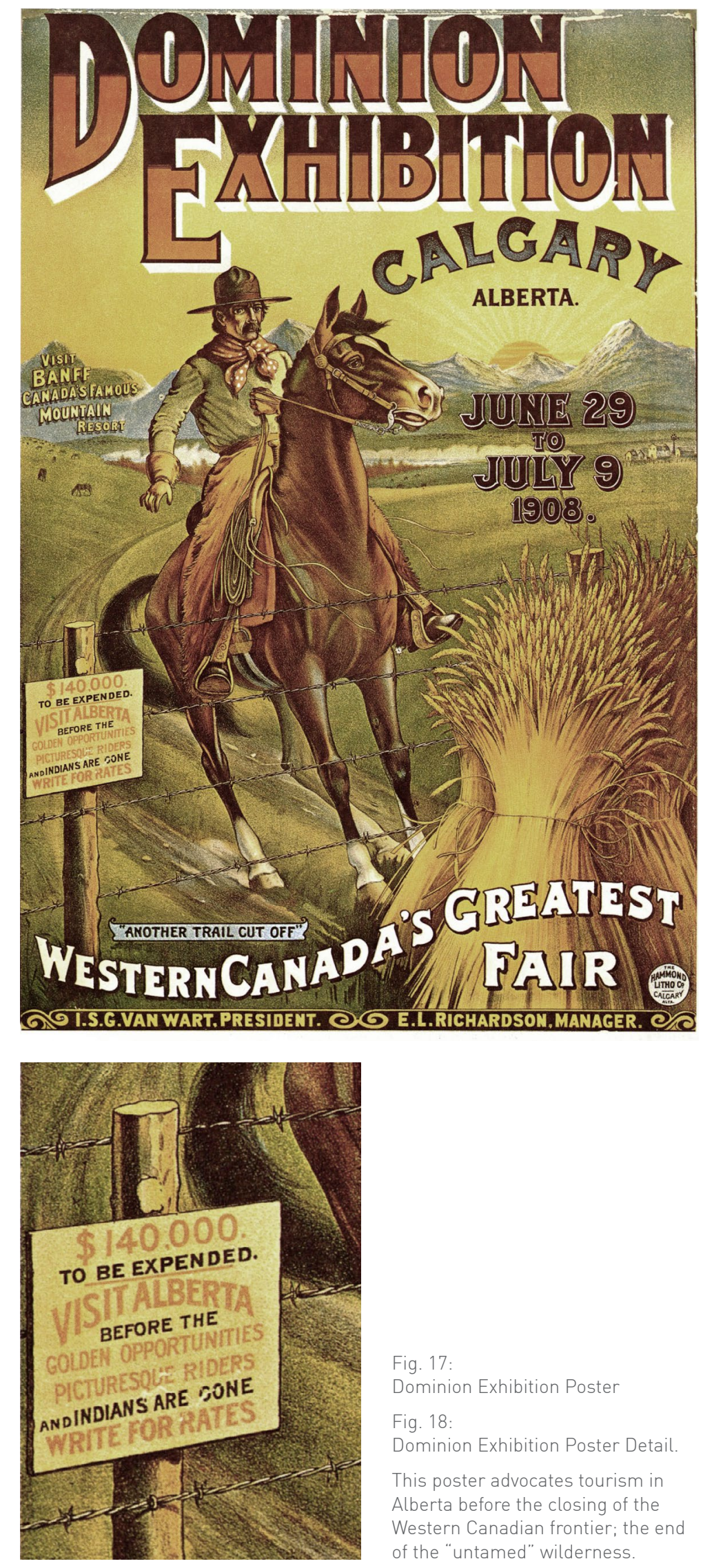

Fig. 17:

Dominion Exhibition Poster

Fig. 18:

Dominion Exhibition Poster Detail.

This poster advocates tourism in Alberta before the closing of the Western Canadian frontier; the end of the "untamed" wilderness. 
The railway project brought surveyors sent by the government to scout and map the newly acquired regions. In the ensuing official land designations implemented by the Canadian Government, indigenous landscapes were discounted and treated, as Rob Nixon observes, as "uninhabited by the living, the unborn, and the animate deceased."32 Extensive land surveys during the completion of the transcontinental railway led to the introduction of the Canadian national park through the Rocky Mountains Park Act in 1887.33 Established by the Parliament of Canada as a public park for preservation and recreation, the Canadian national park quickly became institutional in framing the concept of wilderness. As a result of the discovery of valuable mineral resources through these surveys, land began to hold monetary value. This constructed idea of wilderness and the preceding Dominion Lands Act of 1872 wreaked havoc on the indigenous populations of the mountain, foothill, and prairie regions of Alberta. An amendment to the Act in 1881 made large swaths of land available for lease to non-residents. This created a boom of agricultural enterprises securing safe economic investments for the government. It also marked the real end of the open range in the Canadian west. ${ }^{34}$

The newly imposed property ownership created an invisible and incomprehensible boundary between the native culture and the environment severing spiritual ties to the land. ${ }^{35}$ The influx of settlers into the prairie lands shortly after resulted in the extinction of the already heavily exploited buffalo, spiritually and physically affecting the indigenous people for which these animals were a vital source of life. The colonial actions of the settlers and the Canadian government fall under the category of what sociologist Johan Galtung calls "structural violence". Structural violence challenges how we understand violence because it remains innately invisible. Rather than physical actions, structural violence is a series of socio-political constructions, which Rob Nixon describes as "vast structures that can give rise to

32 Rob Nixon, Slow violence and the Environmentalism of the Poor (Cambridge, US: Harvard University Press, 2011), 17.

33 Lothian, A Brief History of Canada's National Parks, 22.

34 Brado, Cattle Kingdom: Early Ranching in Alberta, 41.

35 Ibid., 36-37. 
acts of personal violence and constitute forms of violence in and of themselves."

This network hides agency subduing causal affect and responsibility creating public amnesia of the violent affairs. ${ }^{36}$ The systematic expansion of the Dominion resulted in devastating long term effects that created the foundation for the development of industry and still prove detrimental to the survival of indigenous culture in the present day.

36 Nixon, Slow violence and the Environmentalism of the Poor, 10. 


\section{"It's a pride that's been passed down to me, Deep as coal mines, wide as farmer's fields, Yeah, I've got independence in my veins."}

Paul Brandt, Alberta Bound, 2004 (Song)

\section{"Wait till you try our brand of sunshine."}

Sam Peckinpah, Junior Bonner, 1972 (Film) 


\section{PARASITIC ECONOMIES}

Due to the economic prosperity and cultural practices with origins in the settlement of Alberta, the province has often ignored environmental degradation. Much like the geological development that resulted in the formation of the Rocky Mountains, which produced unique environmental and geological resources, climate change and long-term industrialization have also developed over extended periods of time making the growth nearly imperceptible. Since its settlement the identity of Alberta has been tied to economic prosperity. Agro-industrial projects have developed into immense international enterprises spoiling the image of pristine wilderness foundational to the cultural identity of Canada. Animal agriculture and energy projects in Alberta are large contributors to greenhouse gas (GHG) emissions in Canada. ${ }^{37}$ The problem is that these industries represent Alberta's most sizeable economic resource. As author Roy Scranton concludes: "any politician who honestly and frankly worked to detach [his or her] nation's economy from oil and coal would not survive in any kind of democratic or oligarchic government..." ${ }^{38}$ It seems fitting here to introduce the concept of slow violence. The term is used to describe a sort of violence that, in Rob Nixon's words, "occurs gradually and out of sight, a violence of delayed destruction that is dispersed across time and space, an attritional violence that is typically not viewed as violence at all." ${ }^{39}$ Nixon argues that our "turbo-capitalist" culture venerates the spectacular feeding our need of instant gratification blinding us to the effects of the industries it relies on to sustain itself..$^{40}$ The situation appears to be hopelessly self-destructive.

In context, Alberta's agricultural and industrial heritage has generated societal conditions that celebrate certain opinions of its landscape (i.e. as a resource). This, for example, is evident in Rodeo, a public exhibition born out of the ranching industry that showcases traditional cowboy skills as a series of competitive events

37 "Climate Change and Agriculture," Alberta Agriculture and Forestry, last modified December 23, 2016, accessed January 14, 2017, http://www1.agric.gov.ab.ca/\$department/deptdocs.nsf/all/ c19706

38 Roy Scranton, Learning to Die in the Anthropocene: Reflections of the End of a Civilization ISan Francisco: City Light Books, 2015), 53.

39 Nixon, Slow violence and the Environmentalism of the Poor, 2.

40 Ibid., 3. 
such as bull riding, calf roping, and steer wrestling. This iconic event glorifies

ranching practices and ideals, focusing on the human subjugation of nature in the form of the animal. Rooted in the colonization of the prairies and the conquest of wilderness the beef industry has long been a source of pride for Albertans. However, due to the harmful effects of animal agriculture on the environment the industry could be seen as committing an act of slow violence.
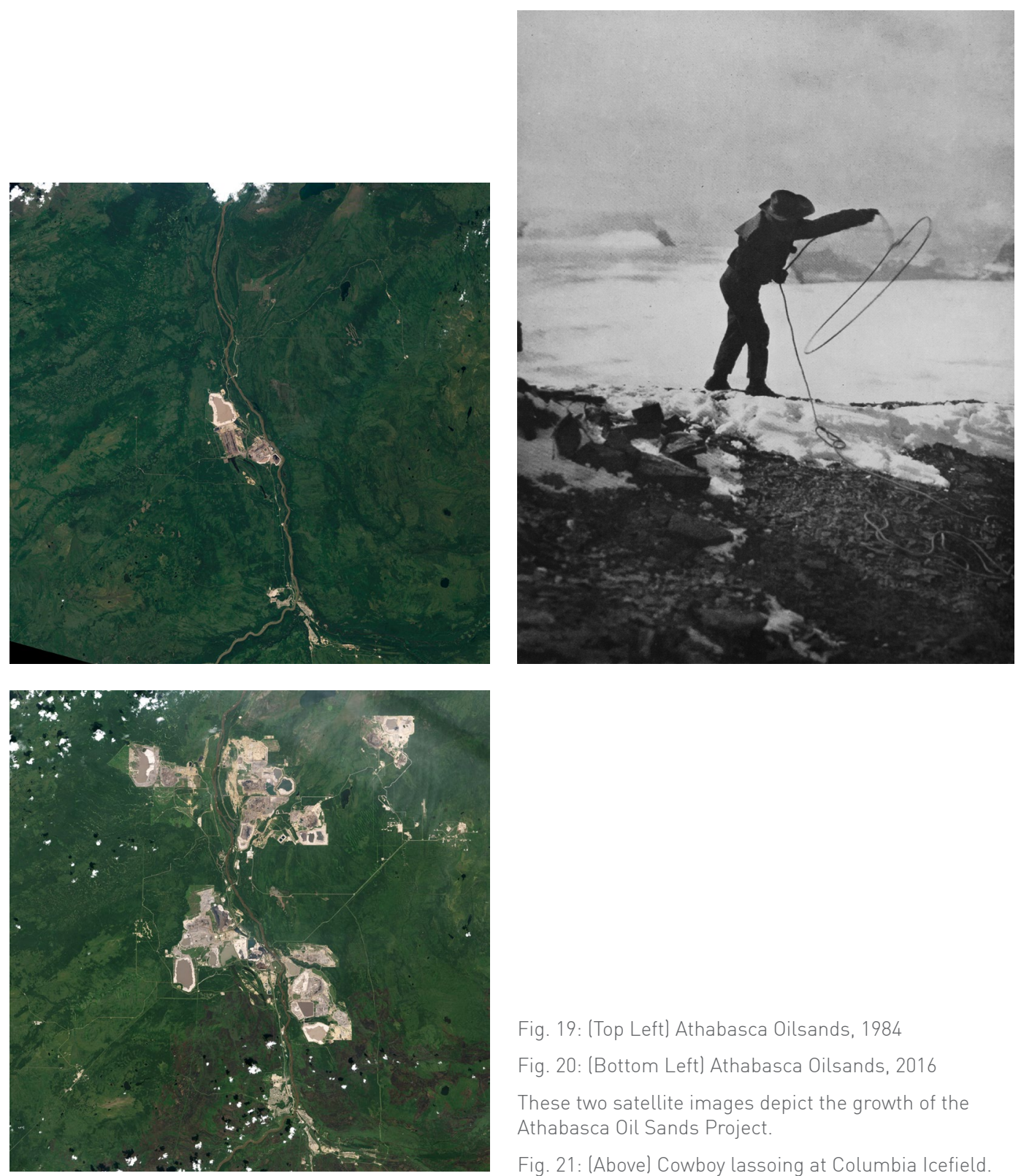

Fig. 19: (Top Left) Athabasca Oilsands, 1984

Fig. 20: (Bottom Left) Athabasca Oilsands, 2016

These two satellite images depict the growth of the Athabasca Oil Sands Project.

Fig. 21: (Above) Cowboy lassoing at Columbia Icefield. 
Of importance in the discussion about the connection of human activity and the geophysical environment are two recent climate related events: the Alberta Floods and the Fort McMurray Wildfire. These disasters are contextual examples of the dependency and relationship between the Albertan economy and the natural environment.

A late spring followed by unusually high amounts of rainfall, with the highest being $345 \mathrm{~mm}$ during the flooding period, in a semi-arid region not known to large amount of precipitation resulted in the flooding of large portions of southern Alberta. ${ }^{41}$ The volume and force of the raging waters carved new channels for rivers dramatically altering the landscape. The 2013 Alberta floods had, up until the 2016 Fort McMurray wildfire, been the costliest natural disaster in the history of Canada resulting in damage losses and recovery costs in excess of $\$ 6$ billion. ${ }^{42}$

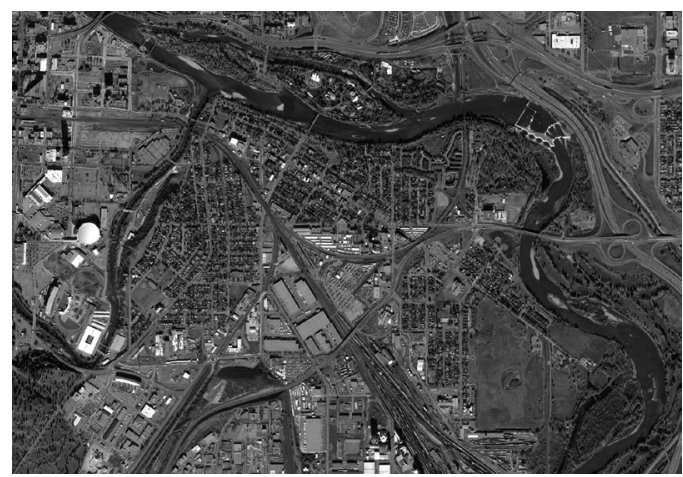

The Alberta Flood not only caused extensive amounts of damage but also dramatically altered the landscape in specific regions.

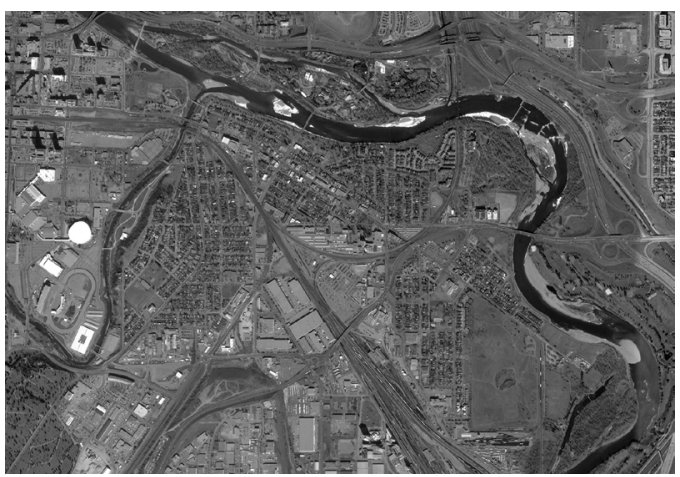

Fig. 22: Bow River, Calgary, Alberta, 2013

Fig. 23: Bow River, Calgary, Alberta, 2016

41 "Alberta's Flood of Floods," Canada's Top Ten Weather Stories for 2013, Environment and Climate Change Canada, last modified May 17, 2014, accessed January 14, 2017, https://www. ec.gc.ca/meteo-weather/default.asp?lang=En\&n=5BA5EAFC-1 \&offset=2\&toc=show 42 Environment and Climate Change Canada, "Alberta's Flood of Floods." 
An early spring due to the unusually strong El Nino in the winter combined with high temperatures and low relative air humidity created ideal conditions for wildfires in Alberta. ${ }^{43}$ On May 1 ${ }^{\text {st }}, 2016$ a wildfire sparked near the Athabasca Oil Sands in Fort McMurray, Alberta. The blaze outpaced firefighters and resulted in the displacement of 80,000 people, charring more than 1.43 million acres of land and destroying a tenth of the city's buildings and infrastructure. ${ }^{44}$ It is considered to be the largest wildfire recorded in North America and the largest and costliest natural disaster is Canada's history succeeding only the flood of southern Alberta three years prior. ${ }^{45}$
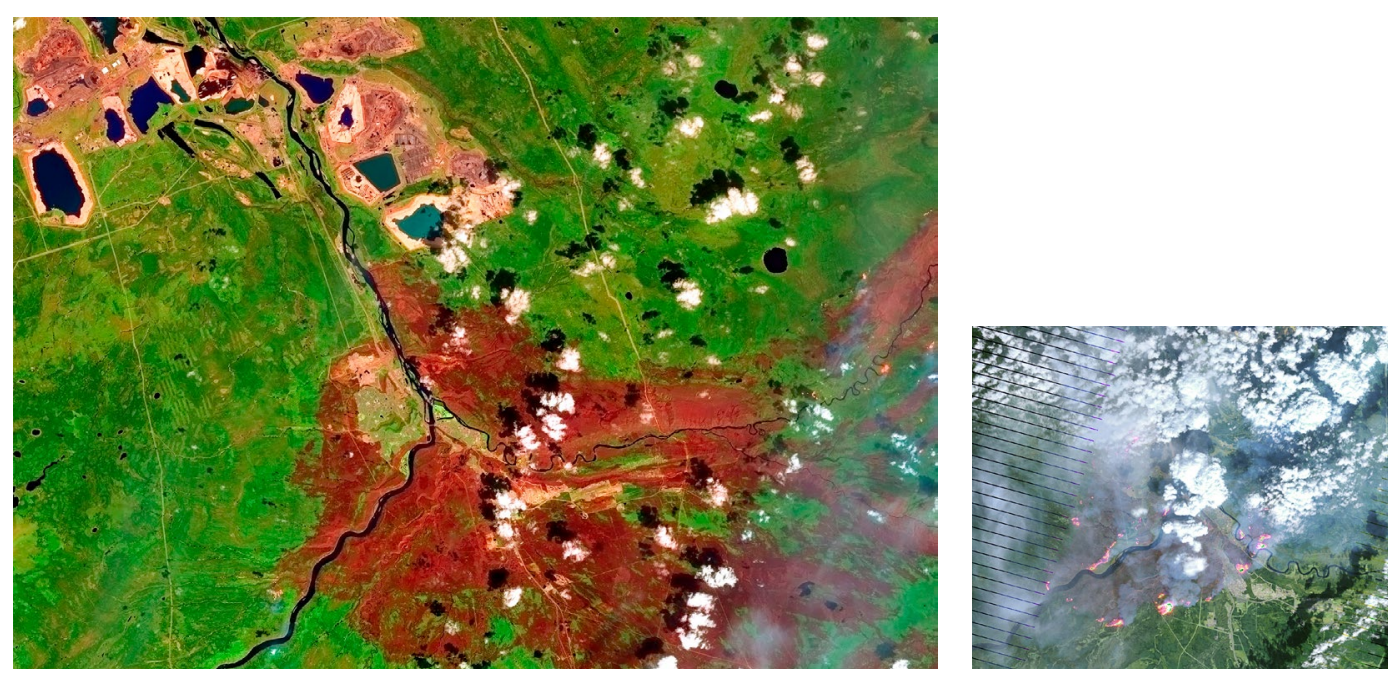

Fig. 24: (Left) Satellite Image of Burn Scar, Fort McMurray, Alberta

Fig. 25: (Right) Satellite Image of Fire Progress, Fort McMurray, Alberta.

43 Nicole Mortillaro, "Fort McMurray Wildfire: Why the Fire Engulfed the City Within Hours."

Global News, May 4, 2016, accessed January 14, 2017, http://globalnews.ca/news/2679397/fortmcmurray-wildfire-why-the-fire-engulfed-the-city-within-hours/

44 Caroline McDonald, "The Insurance impact of the Fort McMurray fire." Risk Management, September 2016, accessed January 14, 2017, proxy.library. carleton.ca/login?url=http://go.galegroup.com/ps/i.do?p=AONE\&sw=w\&u=ocul_ carleton\&v=2.1\&id=GALE\%7CA463401075\&it=r\&asid=64277e4922d93d50774caa32e8af9211.

45 McDonald, "The Insurance impact of the Fort McMurray fire." 
These tragically ironic calamities were followed by heavy scrutiny of Alberta's contribution to environmental degradation. The importance of this debate is expressed by architect and urbanist Paolo Tavares. He suggests that: "extreme climate events are never simply natural phenomena; they are immediately embedded within a historical-political terrain formed both by environmental forces and by social cleavages, local ecologies and global vectors of power and capital, and, crucially, by the frictions and relations established between them." 46

46 Paolo Tavares, "Stratoshield," in Textures of the Anthropocene: Grain, Vapor, Ray, Vol. 2 (Cambridge and London: The MIT Press, 2015), 67. 
$+$

$+$

PART III 
At a global scale, the problem that humanity faces in understanding the temporal and spatial scales of climate change in the Anthropocene is that it prompts new methods of narrative and visual representation..$^{47}$ How do you represent, for example, the "pervasive but elusive" effect of environmental degradation at the Columbia Icefield in a way that is not muted by our cultural need for instantaneous gratification? The answers could be found in the scientific instrumentation used to record environmental systems. Modern remote sensing instruments, as well as those used to survey the Rocky Mountains, allow us to see slow "violent" processes that would be otherwise undetectable to the human eye. In the face of environmental degradation and climate change a paradigmatic shift is occurring. Our perception is now mediated by technological devices that record change in real time. As technology evolves it has the potential to transform our conception of nature.

Air, water, and land collectively comprise the environmental conditions of the geosphere, the earth's physical realm with which organisms are in constant interaction. These distinct physical properties are separated into intricate interconnected systems: the atmosphere, hydrosphere, and lithosphere. The atmosphere is the gaseous layer surrounding the planet while the hydrosphere and lithosphere respectively make up all forms of water and the superficial mantle of the earth's continental crust. ${ }^{48}$ These systems function at different spatial and temporal resolutions. While changes in atmospheric conditions might occur in a matter of seconds, lithospheric change may occur over millions of years.

As a way of recording the behavior of these systems instruments have been developed that measure physical and chemical properties..$^{49}$ These instruments allow scientists to record and interpret the dynamics and complexities of constantly changing environmental systems helping them predict and model future scenarios. The equipment must therefore react and adapt to the scales of time and space

47 Nixon, Slow violence and the Environmentalism of the Poor, 3.

48 J.Y.Wang and Catherine M. M. Felton, Instruments for Physical Environment Measurements, Vol. 1 (Dubuque, lowa: Kendall/Hunt Publishing Company, 1983), 1

49 Wang and Felton, Instruments for Physical Environment Measurements, 1. 
that the environmental systems operate in. On the Columbia Icefield, a seemingly

desolate landscape void of human impact, these environmental conditions act as natural infrastructure, providing a reference point for architectural design.

Fig. 26: (Top Left) Antenna Controller

Fig. 27: (Top Right) Spectrometer

Fig. 28: (Bottom Left) Triton Buoy

Fig. 29: (Bottom Right) Radiosonde
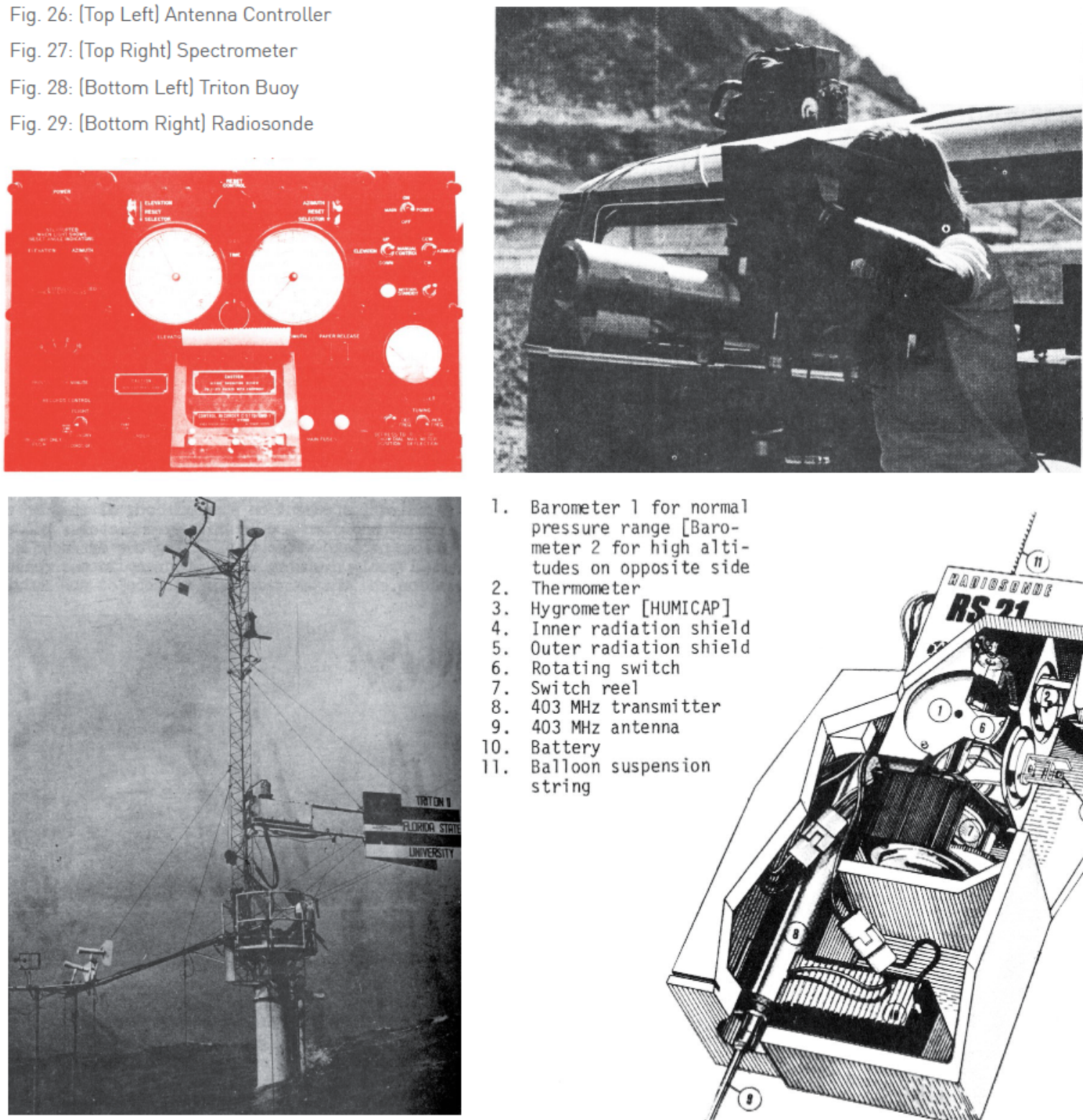

1. Barometer 1 for normal pressure range [Barometer 2 for high altitudes on opposite side

2. The rmometer

3. Hygrometer [HUMICAP]

4. Inner radiation shield

5. Outer radiation shield

6. Rotating switch

7. Switch reel

8. $403 \mathrm{MHz}$ transmitter

9. $403 \mathrm{MHz}$ antenna

10. Battery

11. Balloon suspension string

Various instruments used to survey the physical characteristics of the environment.

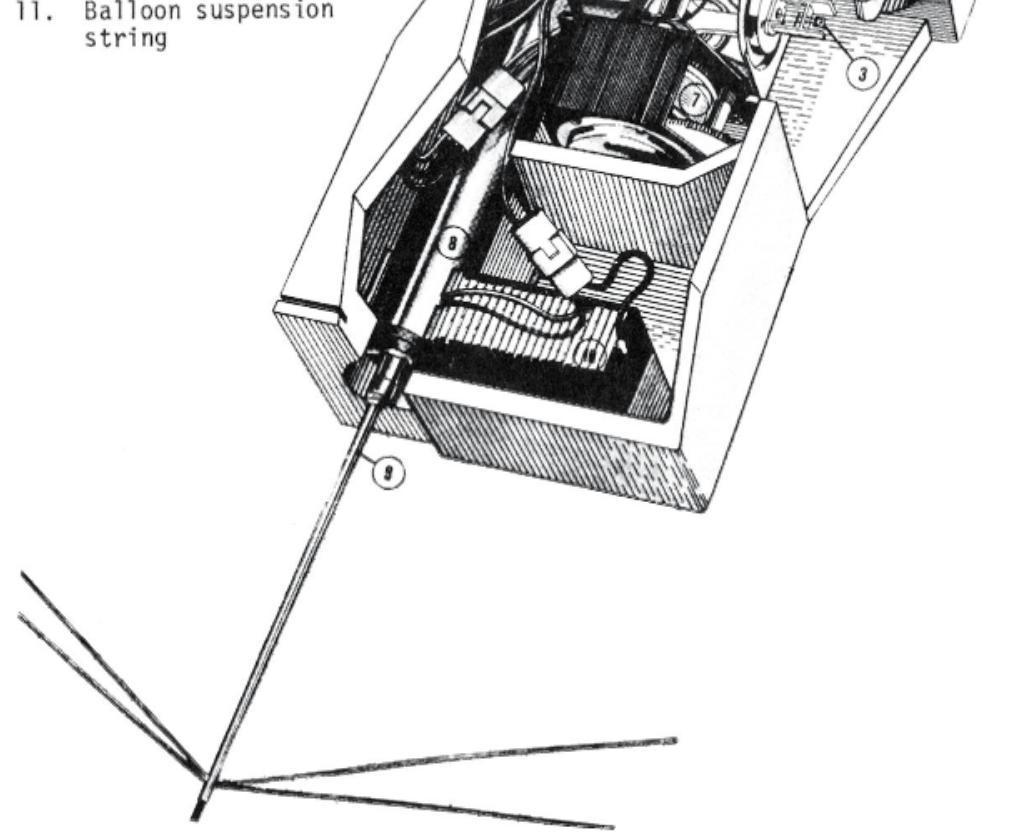



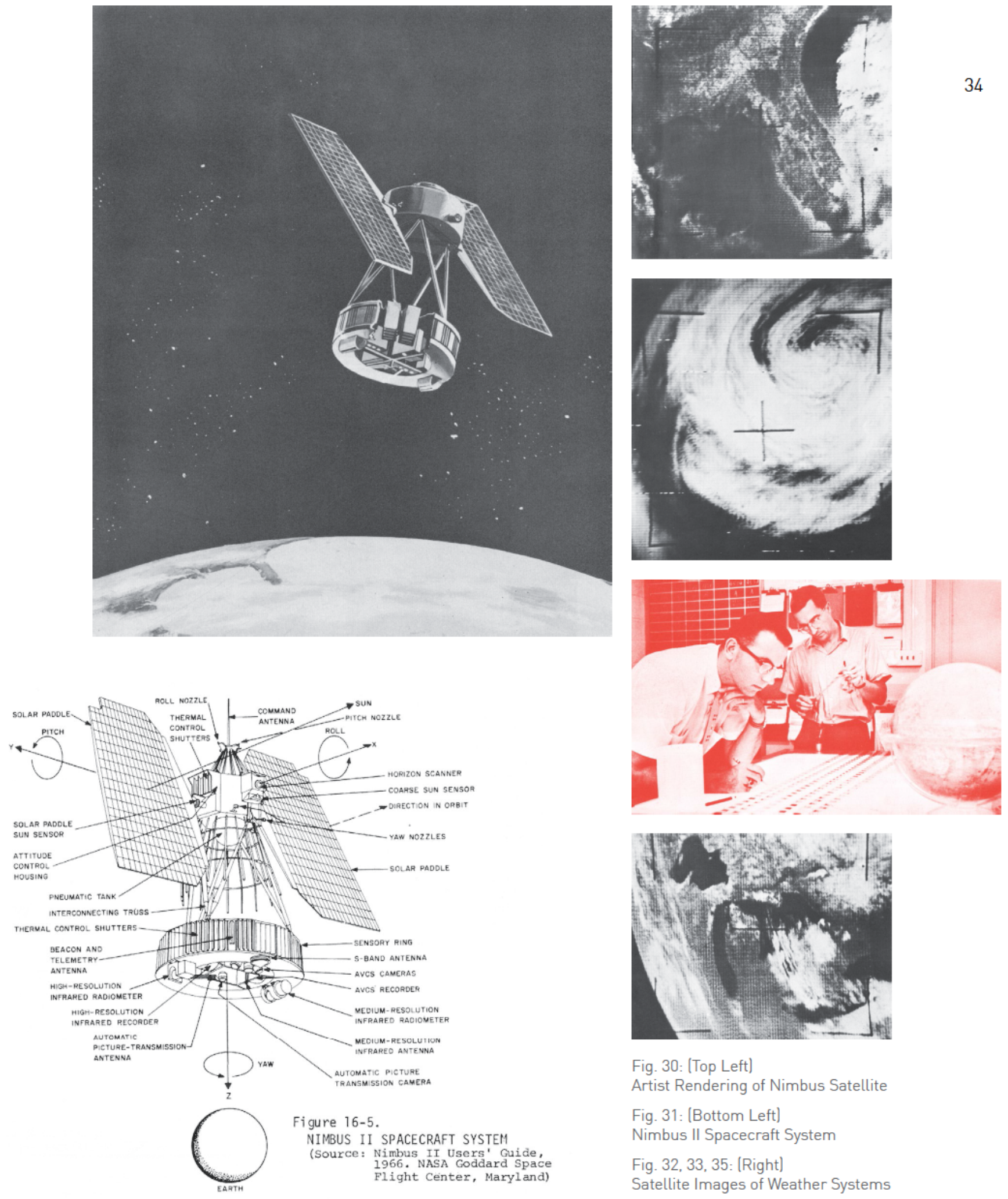

Fig. 30: (Top Left)

Artist Rendering of Nimbus Satellite

Fig. 31: (Bottom Left)

Nimbus II Spacecraft System

Fig. 32, 33, 35: (Right)

Satellite Images of Weather Systems

Fig. 34: (Right)

Meteorologists 
The instruments for measuring the physical environment act as a tool for humanity to sense and predict environmental degradation at a deep spatial and temporal scale. The issue, however, lies in the relationship humanity facilitates with the environment in the current geological epoch. Due to the interconnectivity of human activity with climatic and geological events, traditional methods for predicting future environmental conditions through historical data analysis have become out of date. A 2017 CBC article quotes scientist John Pomeroy, who advances this argument. He states that "climate change is causing extreme weather to occur more frequently, so existing systems and models [of future environmental scenarios] aren't up to date." 50 Interconnected ecological systems prompt new methods of data analysis that are able to adapt in real time to changing conditions. Such networks have already begun to develop in the National Parks. Scientists are proposing a network of cameras in the backcountry of the parks to monitor wildlife. Biologist Jesse Whittington states that "pooling data across large areas, ... gives [the researcher] much more power to see how wildlife populations are changing, how their distributions are shifting and a better understanding of why they're changing." ${ }^{51}$ A revolutionary method in the field of biology that would resemble the already in place global system of weather reporting stations.

Recently, the field of citizen science has emerged as a strategy to collect and analyze large swaths of data for scientific research. The system utilizes the collective computational power of the general public to aid scientists in generating models for environmental trends (i.e. species migration, and water contamination). The adaptive resource of citizen science combined with the temporal and spatial sensing capabilities of environmental surveying equipment has the potential to address the notion of slow environmental change. A phenomenon that has until now escaped our limited perception.

50 Briar Stewart, "How 3D Maps of an Alberta Mountain Could Help Predict the Next Flood or Drought." CBC News, March 2017, accessed March 26, 2017, http://www.cbc.ca/news/canada/ edmonton/3d-mapping-fortress-ridge-1.4029656

51 Bob Weber, “Scientists Propose Vast Network of Wildlife Cameras," Calgary Herald, February 8 , 2017, A8. 
National Parks has projected an increase in tourism following the sesquicentennial anniversary of Canada. ${ }^{52}$ With a growth in the tourism sector new infrastructures and recreational activities will develop generating new ideas of wilderness. Ecological awareness has spawned new methods of engaging citizens with the changing natural environment. The growing movement of citizen science has combined the observational power of the general public to monitor vast amounts of data collected from the natural environment. ${ }^{53}$ In fact, this type of scientific research through public engagement is already existent in Canada's national parks, specifically at the Columbia Icefield. Studies undertaken to measure the volumetric change of the Icefield have utilized citizen science as a way to monitor snow depth. ${ }^{54}$ Increased tourism will allow the movement to gain a stronger foothold in the national parks generating a unique opportunity for involving the individual in the observing, recording, and adapting to the slowly changing landscape of the national parks.

In her doctoral dissertation, Elsa Lam, current editor of Canadian Architect, discusses the variable architectural episodes of the wilderness ideal throughout the nation-building history of Canada. Lam suggests that the infrastructure in place during this time period promoted a distinct perception of wilderness spawning specific architecture. As infrastructure shifted from railway to parkway, so did the tourists interaction with the natural environment and as a result the architecture of the national parks. ${ }^{55}$ Through scientific and recreational exploration networks of backcountry infrastructure have already been put in place. The Alpine Club of Canada has built and maintains a system of huts and lodges for explorers and

52 Colette Derworiz, "Canada's Mountain Parks Record Increase in Visitors During Early Summer." Calgary Herald, September 2016, accessed March 3, 2017, http://calgaryherald.com/news/localnews/canadas-mountain-parks-see-another-spike-in-tourism-numbers

53 Dan Drollete, “Citizen Science Enters a New Era.” BBC News, March 2012, accessed March 5, 2017, http://www.bbc.com/future/story/20120329-citizen-science-enters-a-newera?selectorSection=technology

54 Lynn Martell, “Finding Answers in the Ice.” Calgary Herald, July 3, 2011.

55 Elsa Lam, “Wilderness Nation: Building Canada’s Railway Landscapes 1885-1929” (PhD diss., Columbia University, 2011), 1-41. 
mountaineers ${ }^{56}$ As technology continues to evolve new infrastructures will mediate our interaction with nature and change our perception of wilderness. Growing popularity in wearable technology, activity trackers, responsive clothing creates a possibility of bridging the remote sensing equipment used to capture slow change and recreational activities. The influx of actively participating tourists would create an ensemble of remote-sensing instruments that act as a network device measuring the slow change of the environmental conditions; an immaterial inward earth observatory. The choreography of measurements and interactions evolves as more tourists engage with the environment through the use of their equipment. The devices involved with these proposed recreational tourist activities acts as an architectural medium between the body of the tourist and the natural environment. This creates the possibility of creating responsive architectures through the recreational involvement of tourists in the scientific monitoring of the environment.

Fig. 36:

3D Visualization of Corings and Subsurface Surveying.

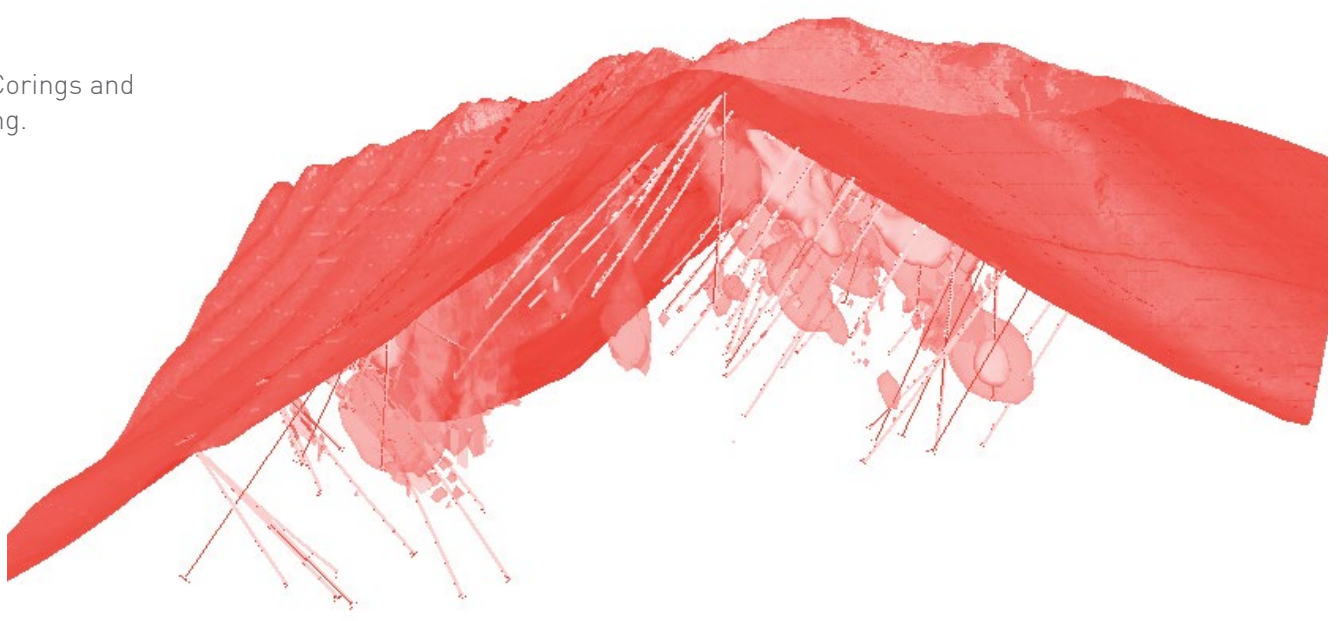

The following exercise collages technical drawings of remote sensing technology with images of traditional tourist activities and sketch explorations to help understand new possible conditions of the citizen scientist in the national parks.

56 "Huts," The Alpine Club of Canada, accessed March 28, 2017, http://www.alpineclubofcanada. ca/facility/ 


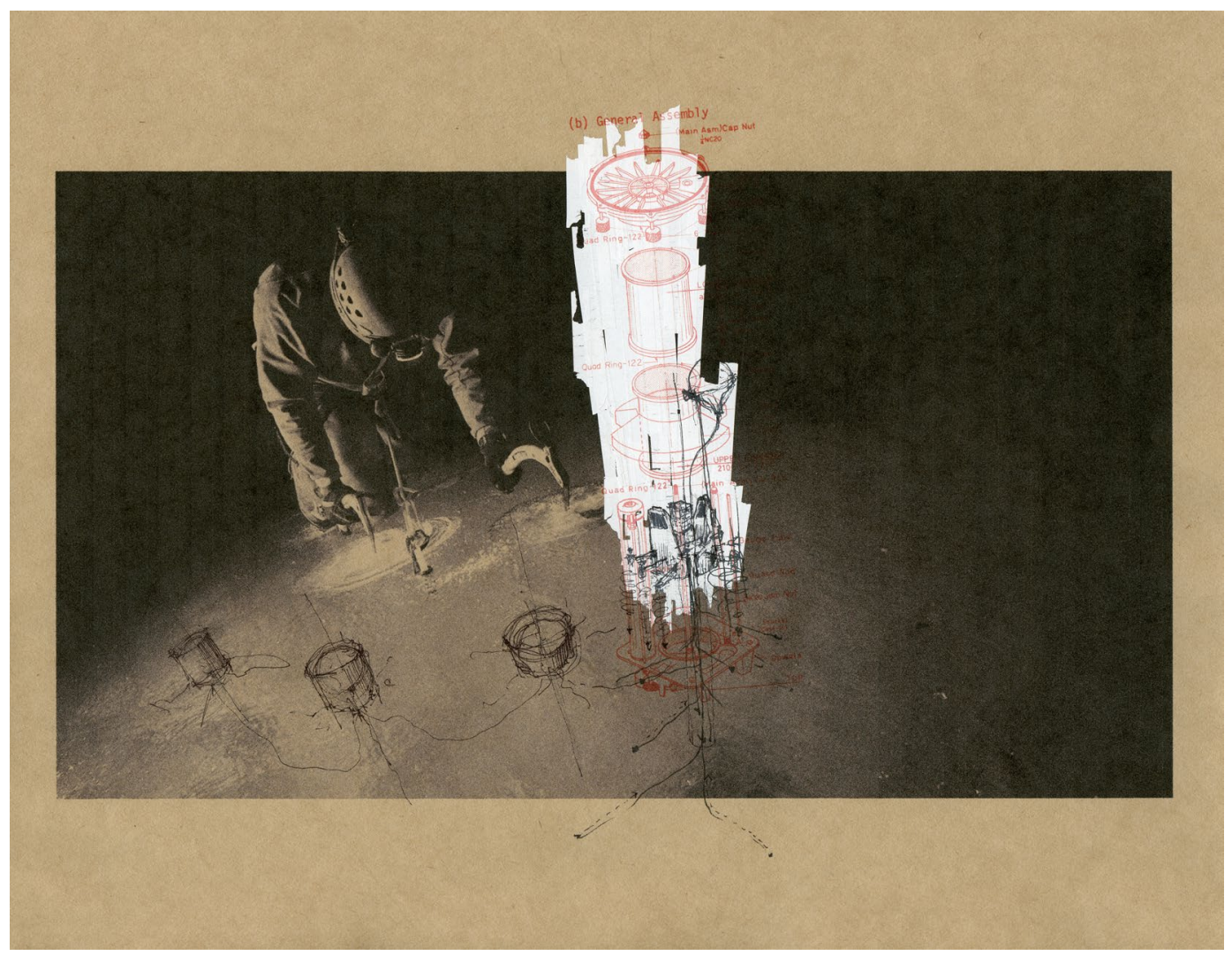

Fig. 37: Citizen Scientist 01 


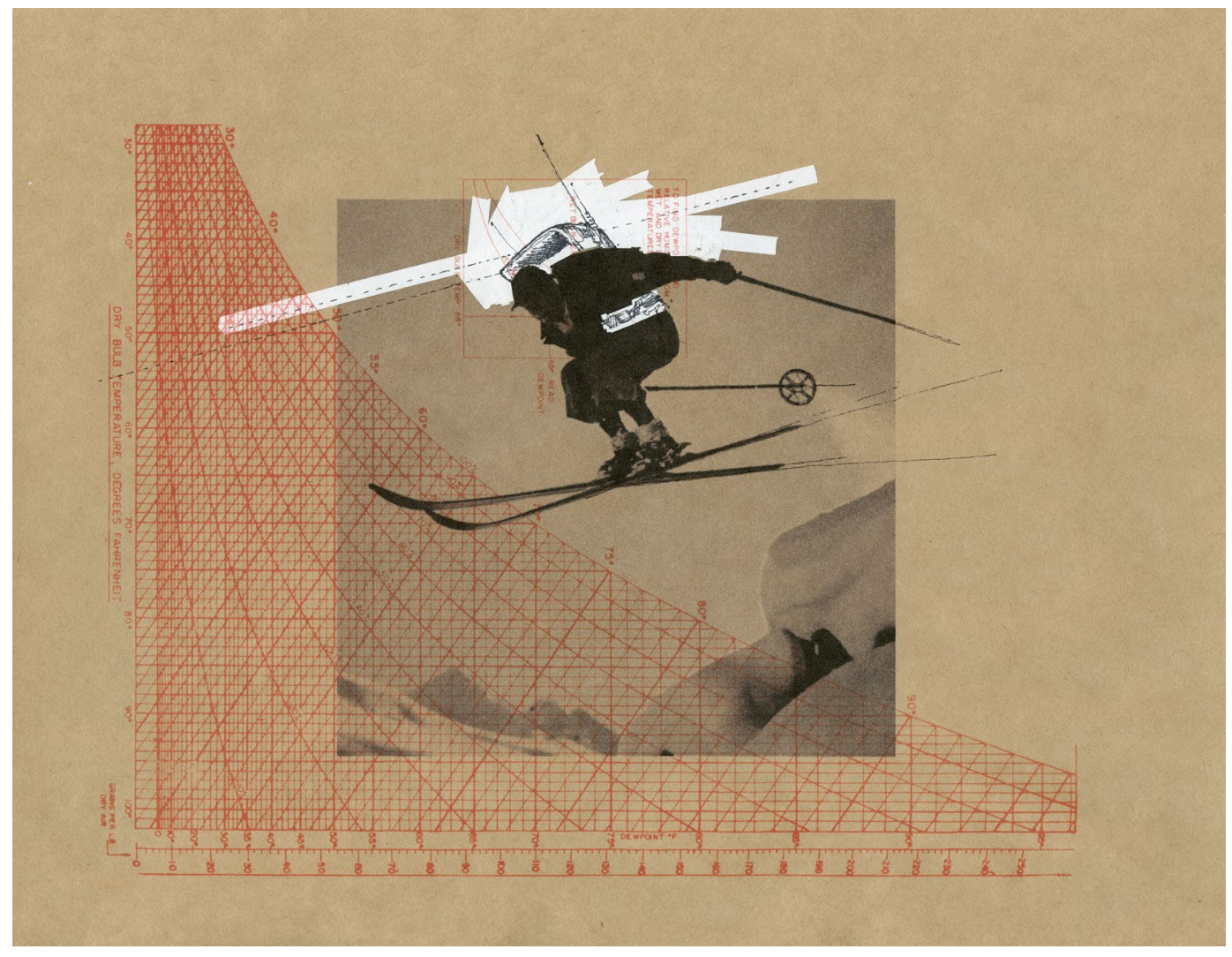

Fig. 38: Citizen Scientist 02 


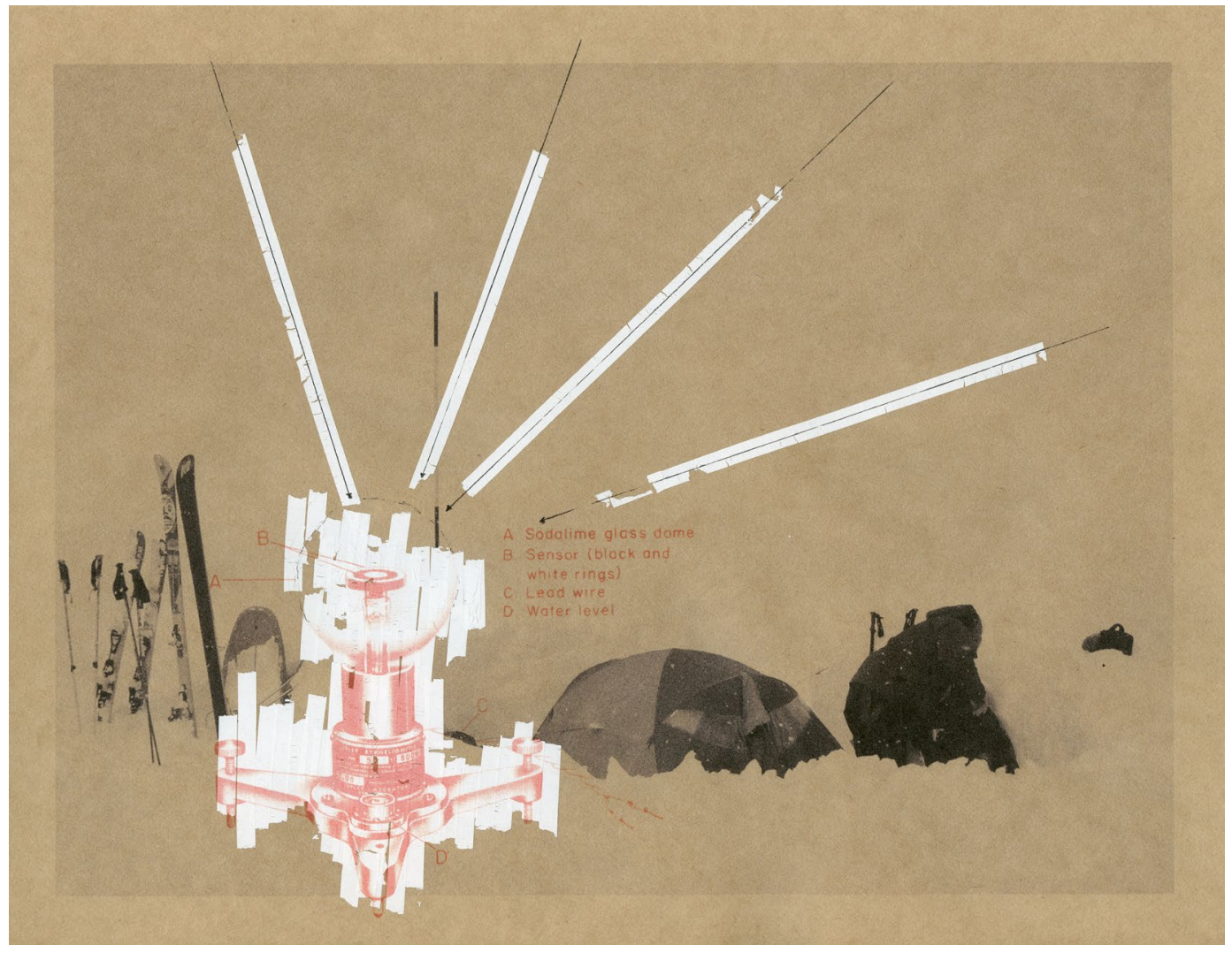

40

Fig. 39: Citizen Scientist 03 


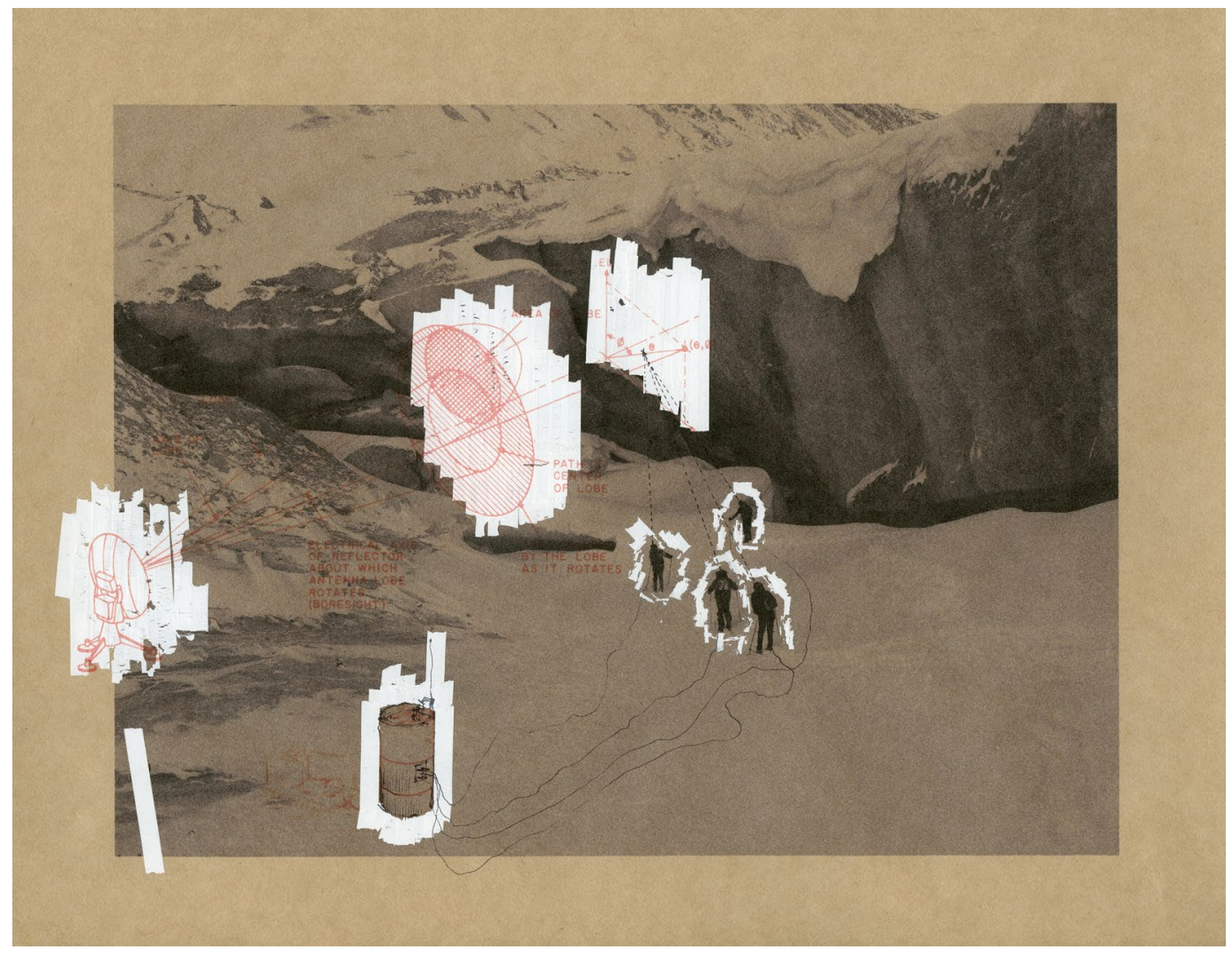

Fig. 40: Citizen Scientist 04 


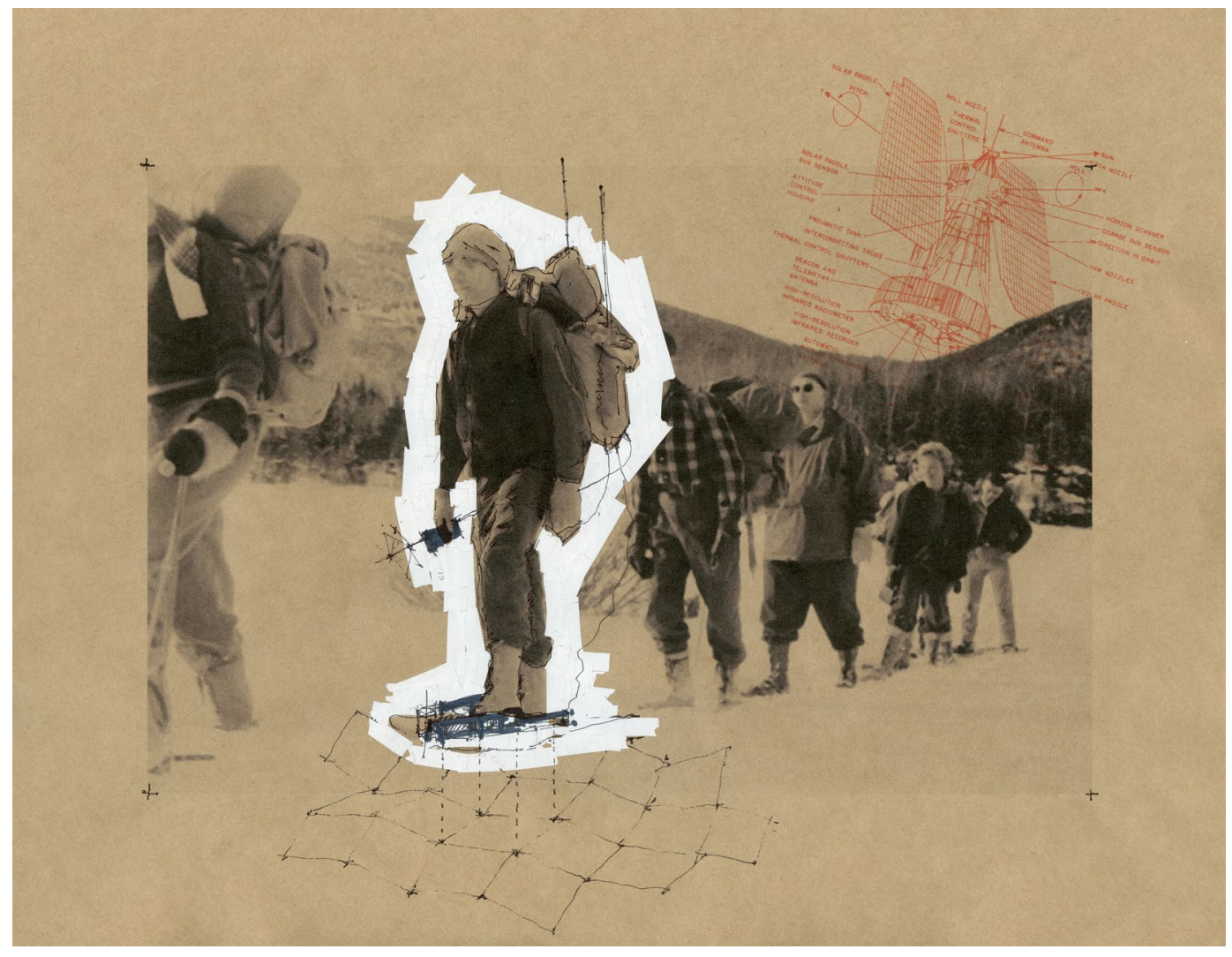

Fig. 41: Citizen Scientist 05 


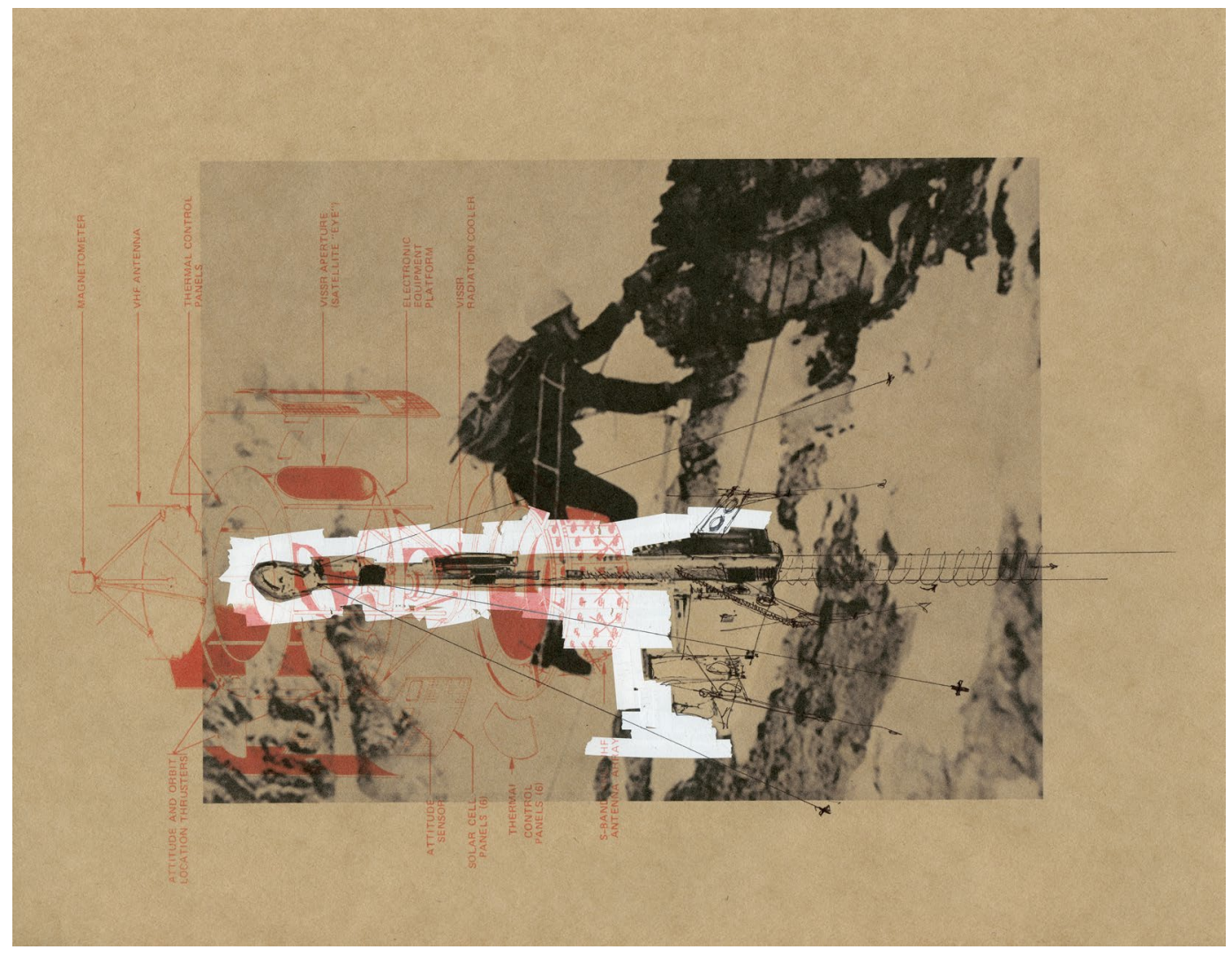

Fig. 42: Citizen Scientist 06 


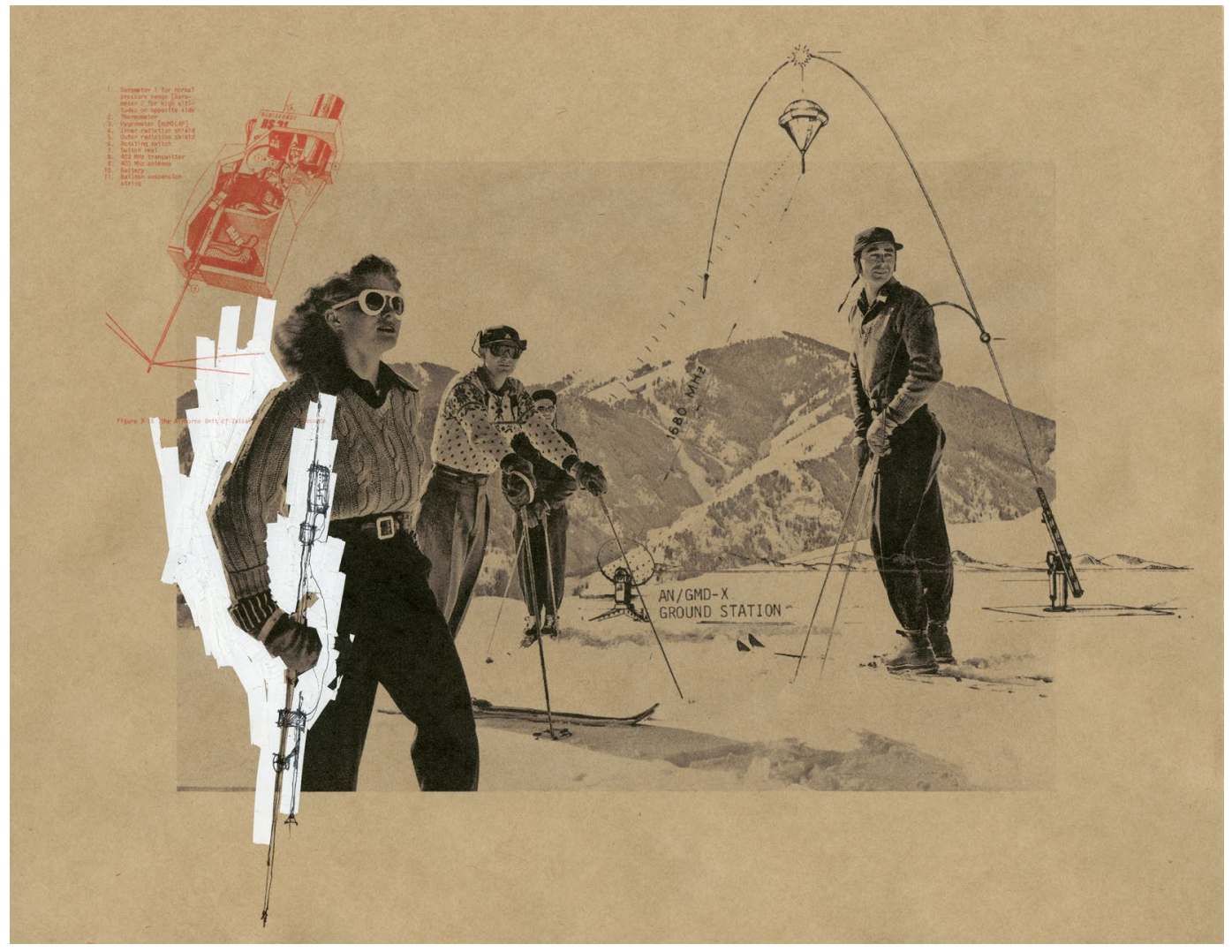

Fig. 43: Citizen Scientist 07 


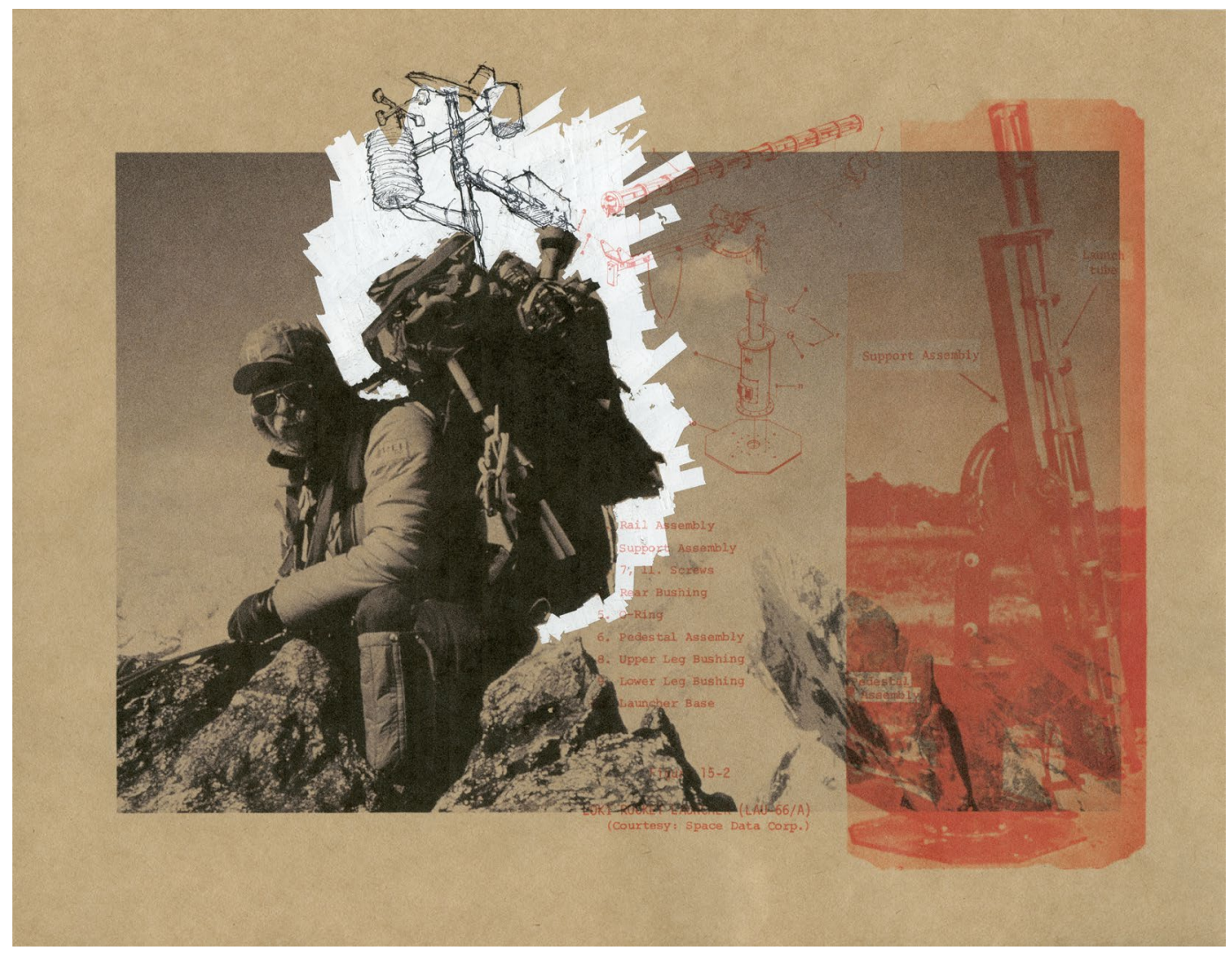

Fig. 44: Citizen Scientist 08 


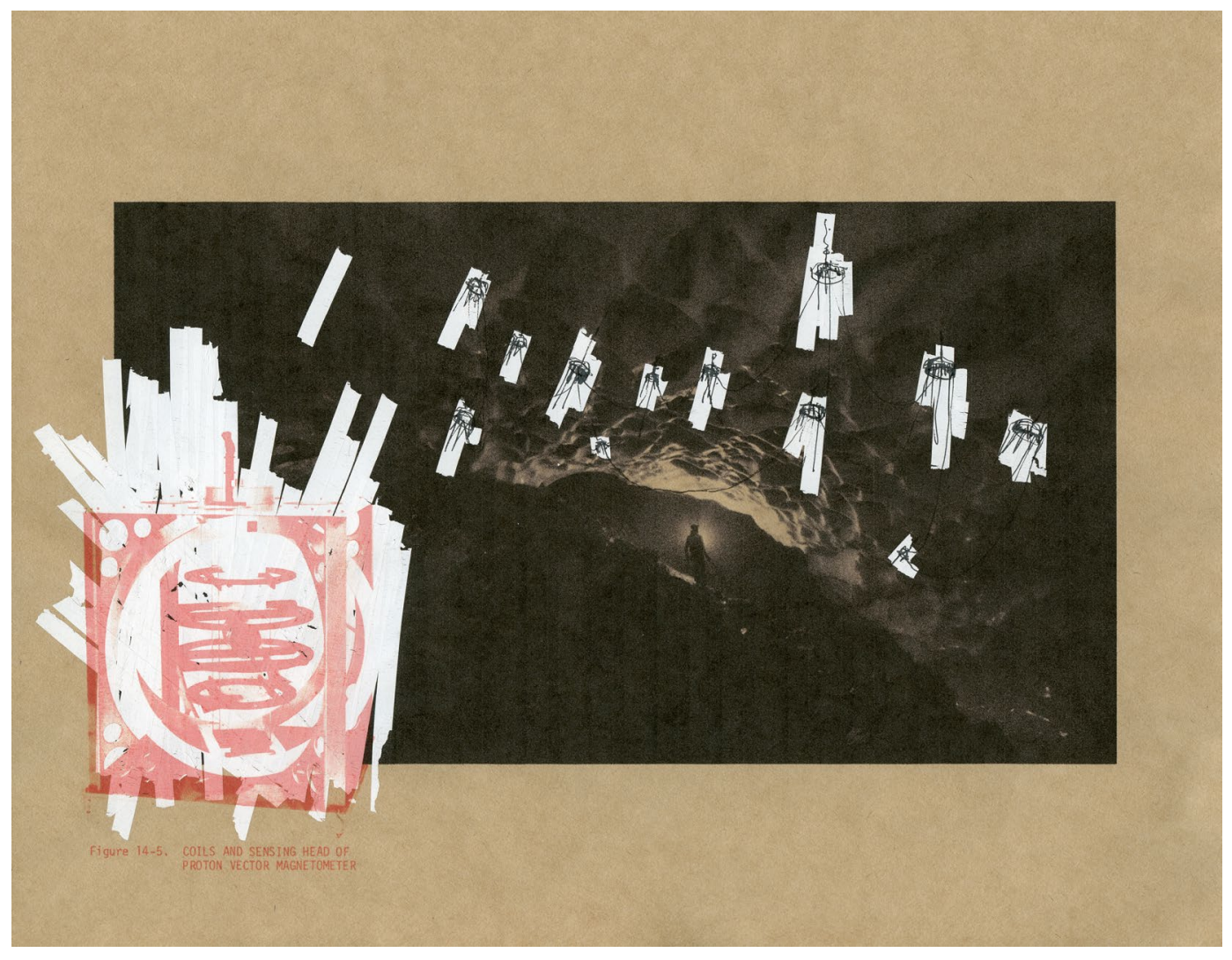

Fig. 45: Citizen Scientist 09 


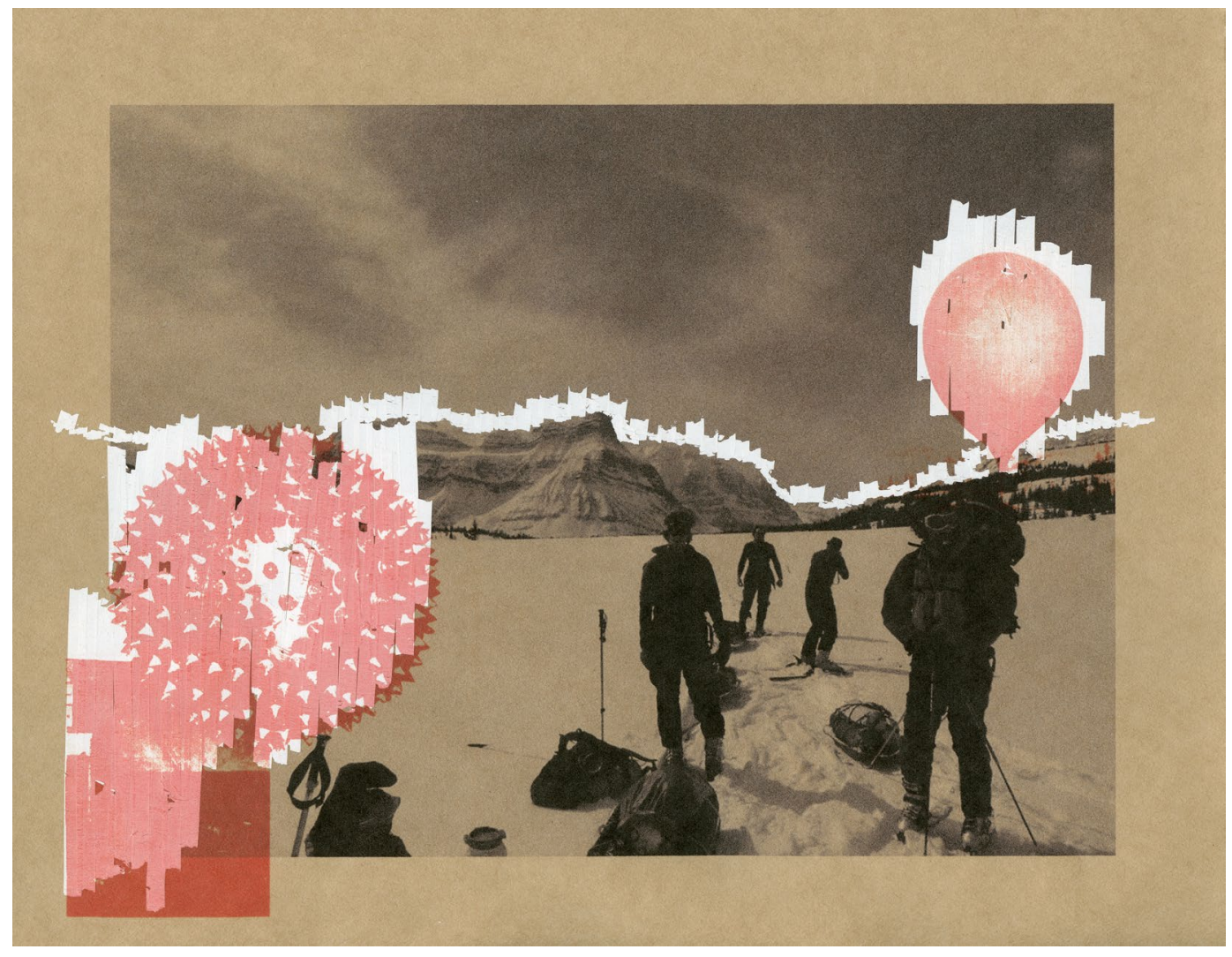

47

Fig. 46: Citizen Scientist 10 
PART IV 
This exploration explores the idea that the technology civilizations have utilized in the conquest of nature and progression of society have in turn created their own landscapes and environments entirely constructed through the hand of humanity. As suggested by Lewis Mumford in Technics and Civilization the evolution of technology has evolved through three distinct yet interwoven phases. Each era has thus shaped new landscapes with respect to its stage of technological advancement. From aerating crops by turning the earth to harvesting natural resources and direct or indirect pollution, first forestation and then mining, each era has fostered its own reality and human-nature relationship. Throughout history traces of these technological realities remain as geological deposits or archaeological evidence and can be studied as the great acceleration in technology and industry is creating new unimaginable landscapes unconducive to suitable habitation. Thus the survey proposes to investigate the new landscapes of our daunting and inevitable future through modes of anachronistic technological abstraction; strange landscapes where the geographical relationship to humanity and architecture remain to be discovered. Through the manipulation of scale the mappings become a visual manifestation of the relationship between human influence and the physical environment. 

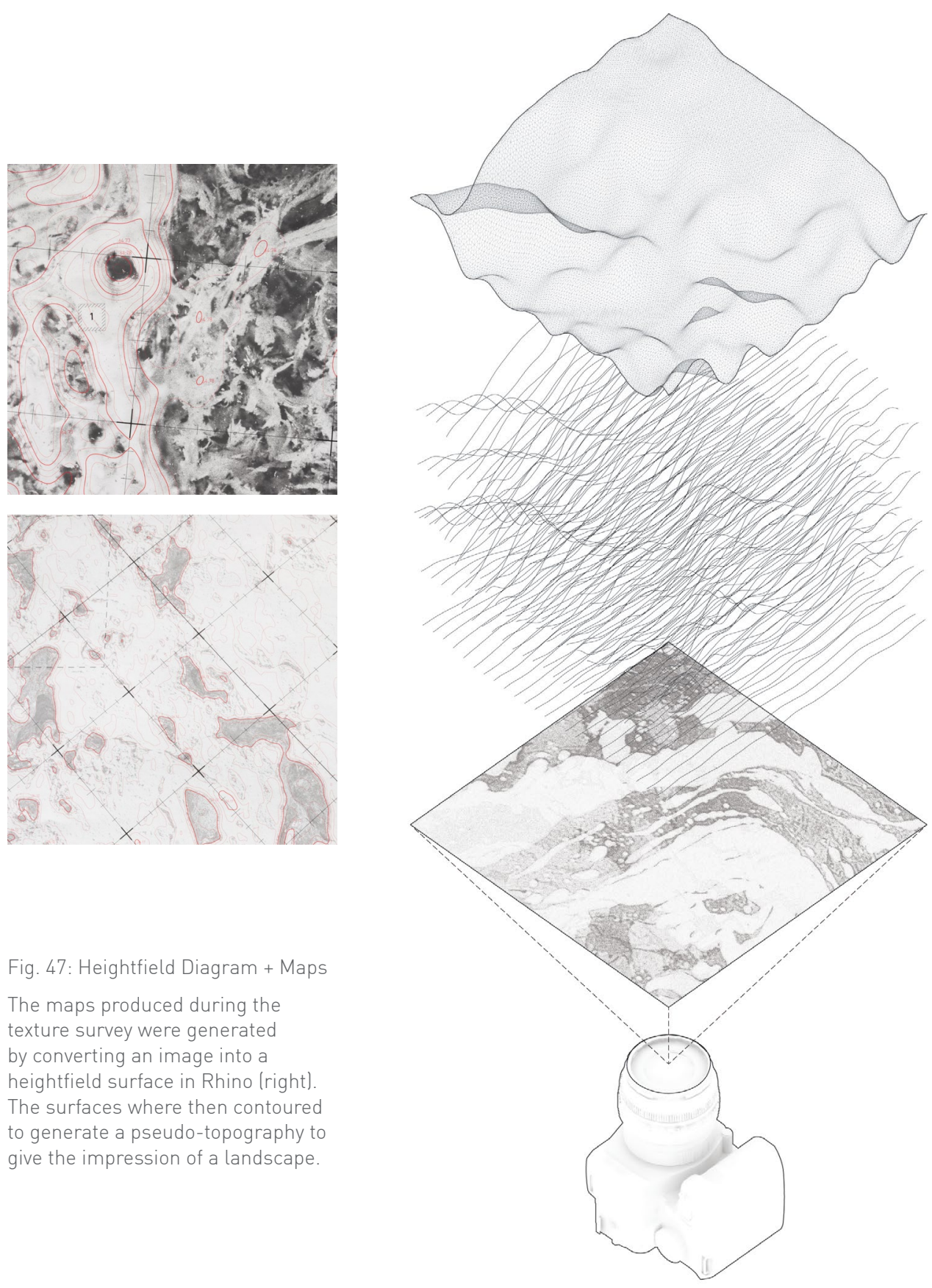

Fig. 47: Heightfield Diagram + Maps

The maps produced during the texture survey were generated by converting an image into a heightfield surface in Rhino (right). The surfaces where then contoured to generate a pseudo-topography to give the impression of a landscape. 


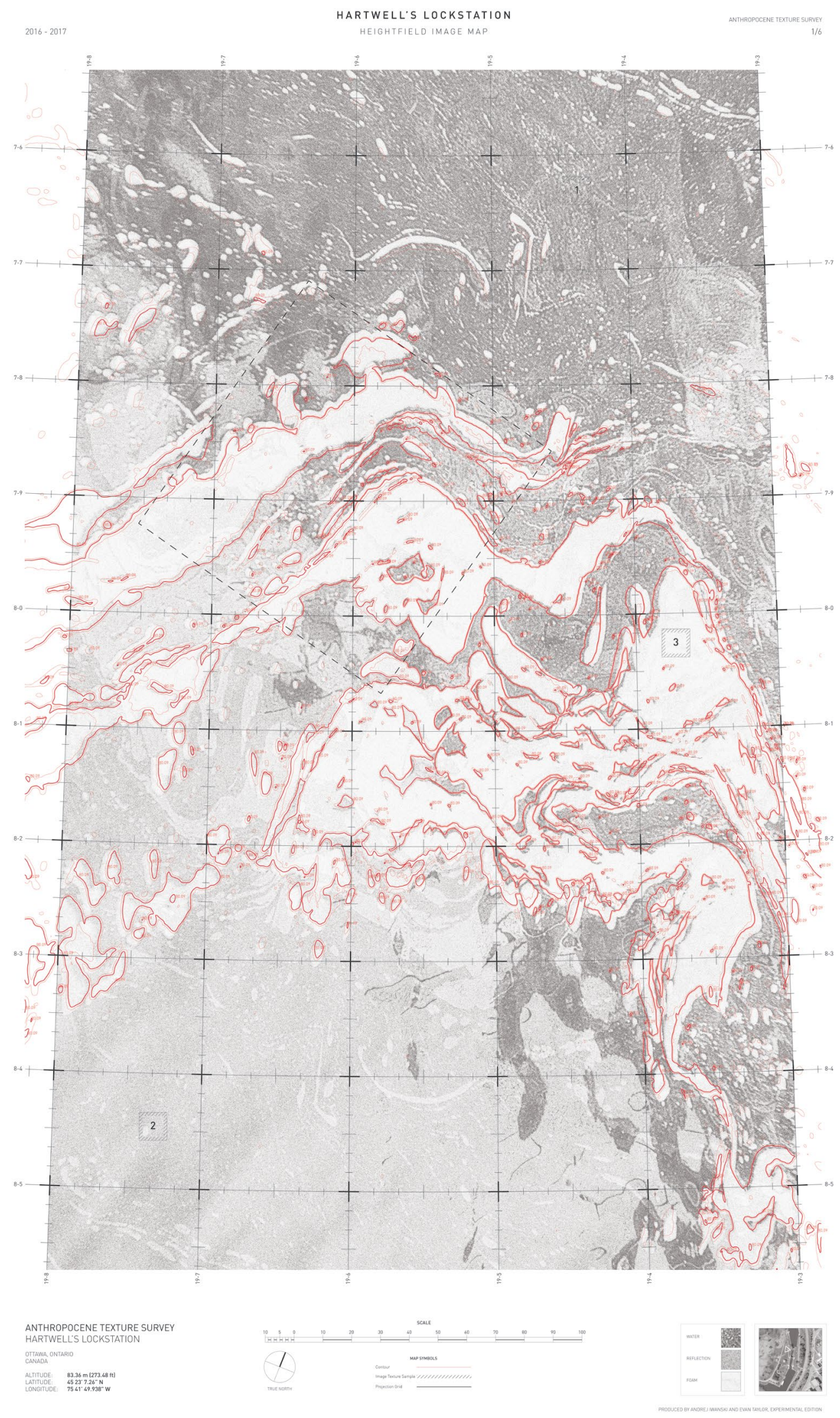

Fig. 48: Texture Survey Map 01 


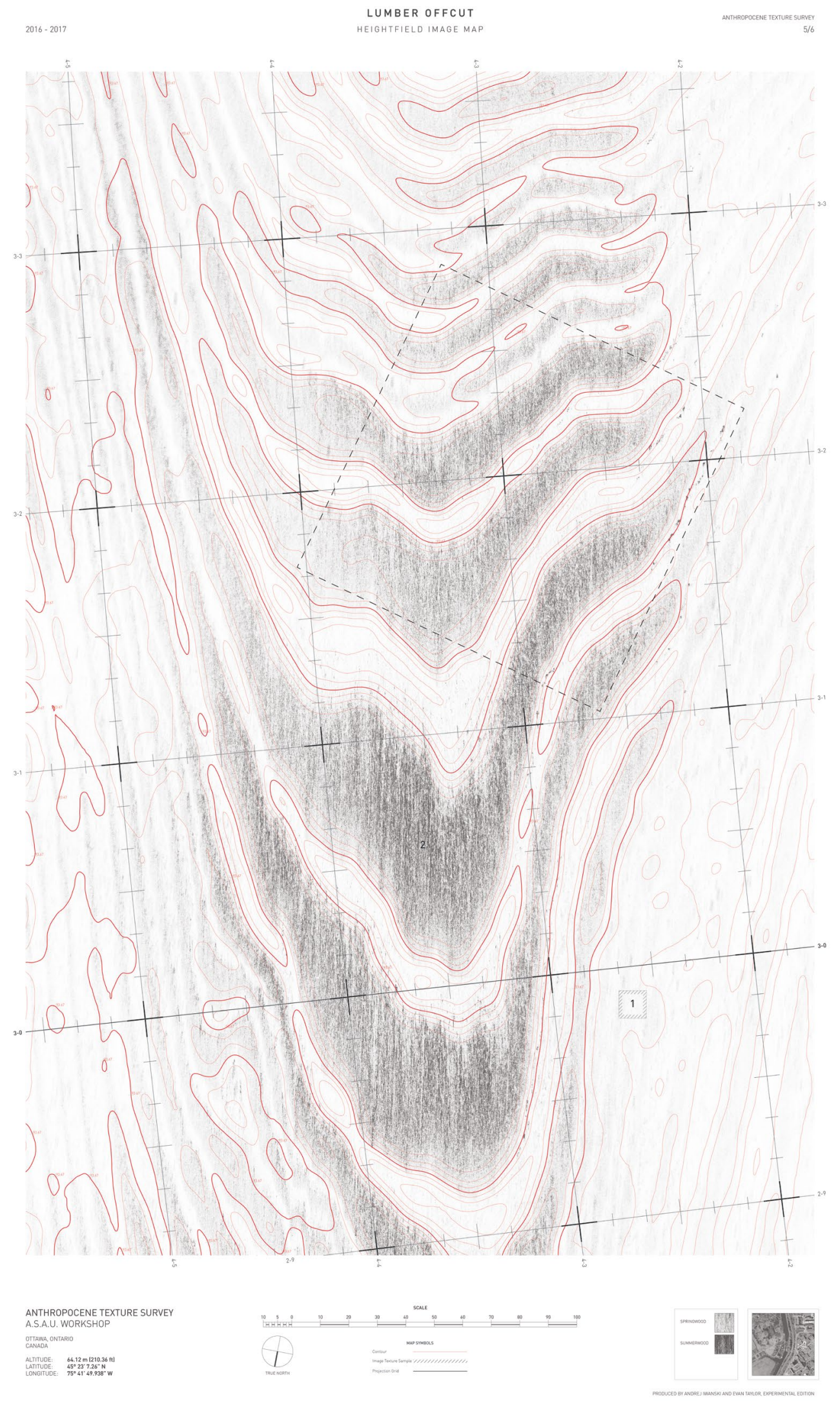

Fig. 49: Texture Survey Map 02 


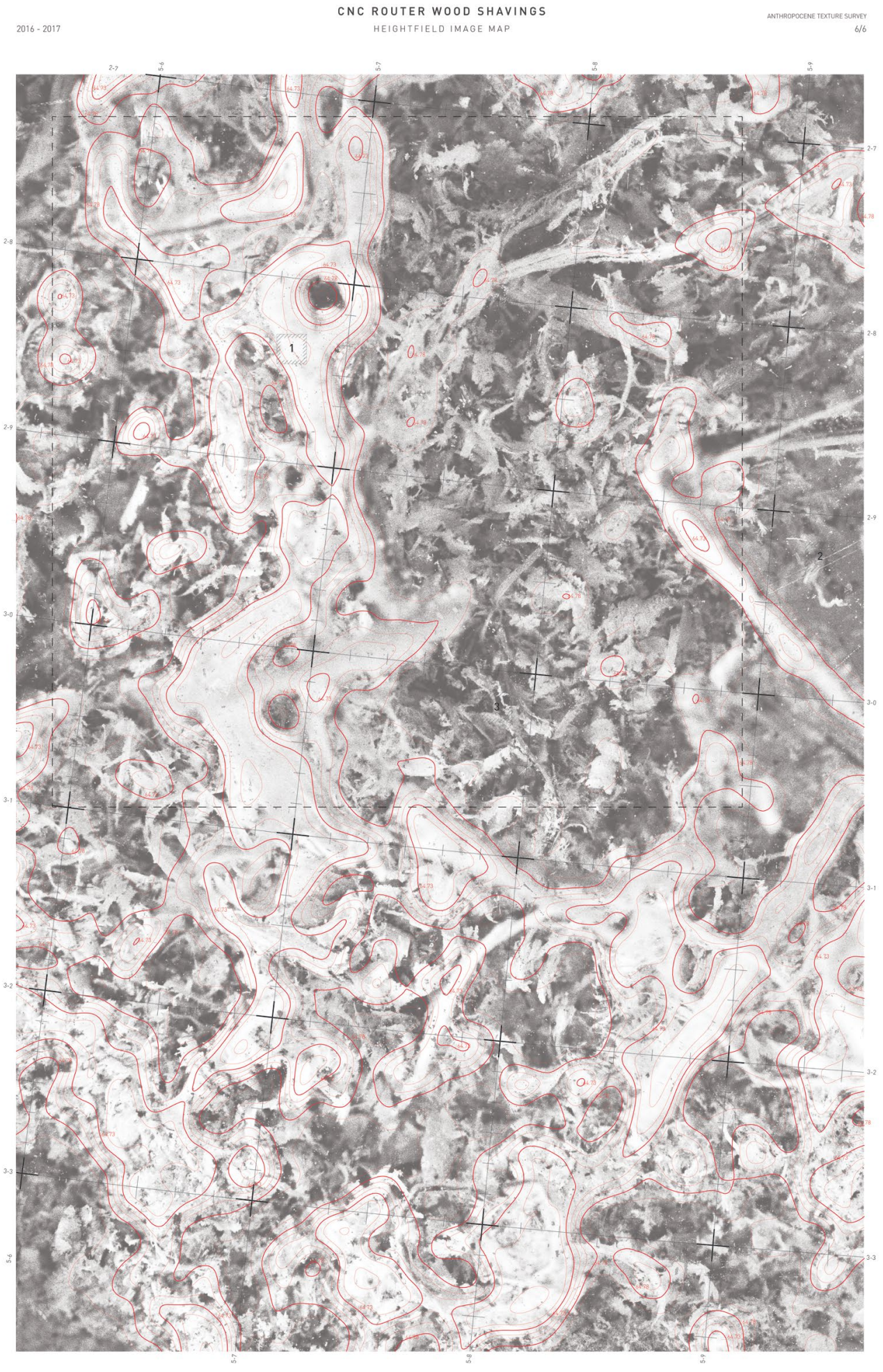

ANTHROPOCENE TEXTURE SURVEY
A.S.A.U. WORKSHOP

OTAAMA ONTRRAL

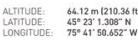
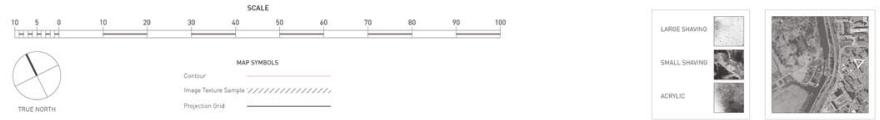

Fig. 50: Texture Survey Map 03 


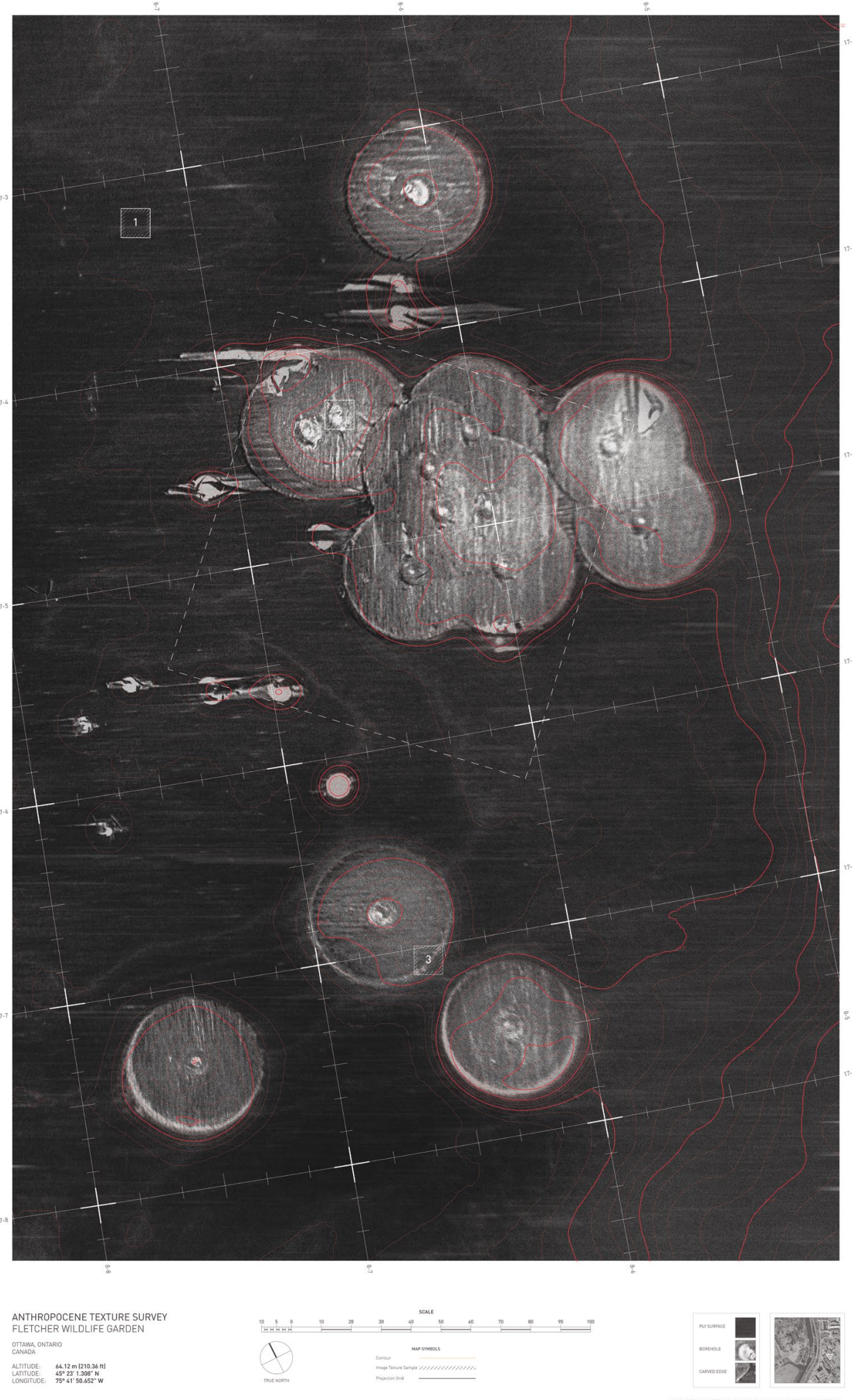

Fig. 51: Texture Survey Map 04 


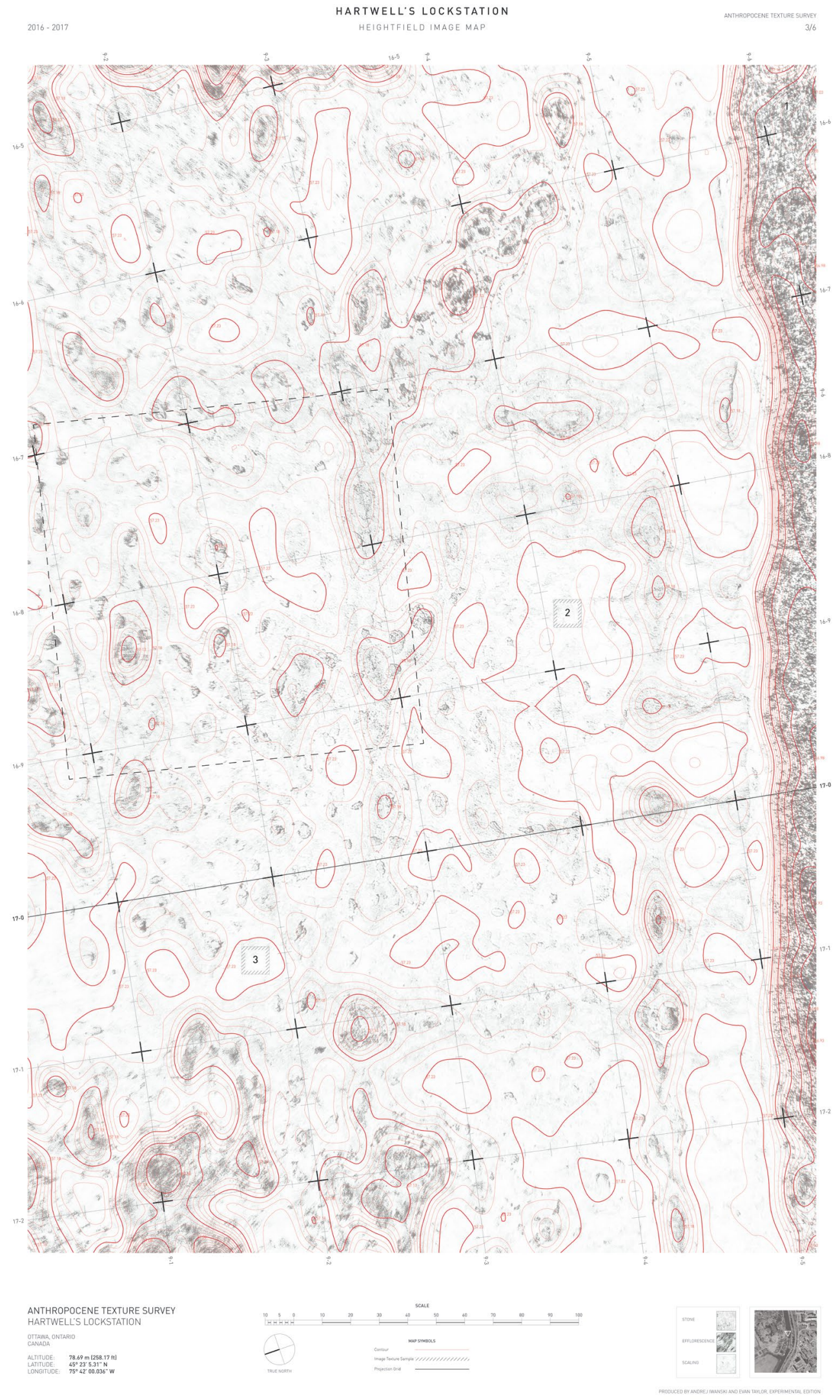

Fig. 52: Texture Survey Map 05 


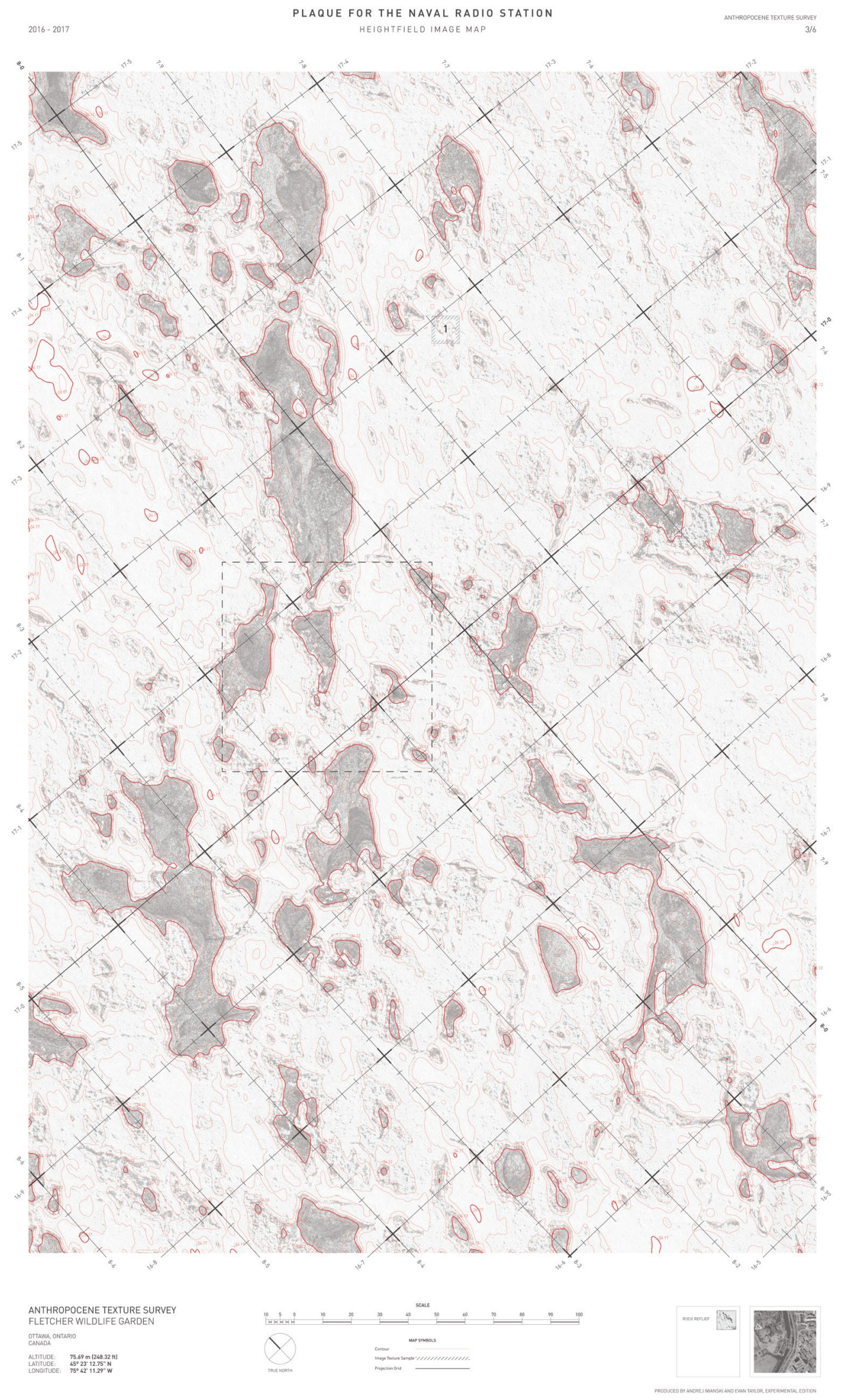

Fig. 53: Texture Survey Map 06 
Building on the manipulation of scale as a visual and narrative tool these core samples propose a new approach to understanding the geological strata of our planet. Where the previous exploration primarily concerned itself with hypothetical landscapes born out of human made textures, these samples explore the cultural and technological implications on the layers of the earth. Tracing human history through geological abstractions posits a new way of understanding the relationship humanity has with the physical realm of the earth. Each core sample presents four distinct abstract image collages each relating to a specific perspective themed through art, fiction, landscape, and technology. Additionally each side is inscribed with $\mathrm{CNC}$ etchings, carving into the cultural representation displayed on its surface.

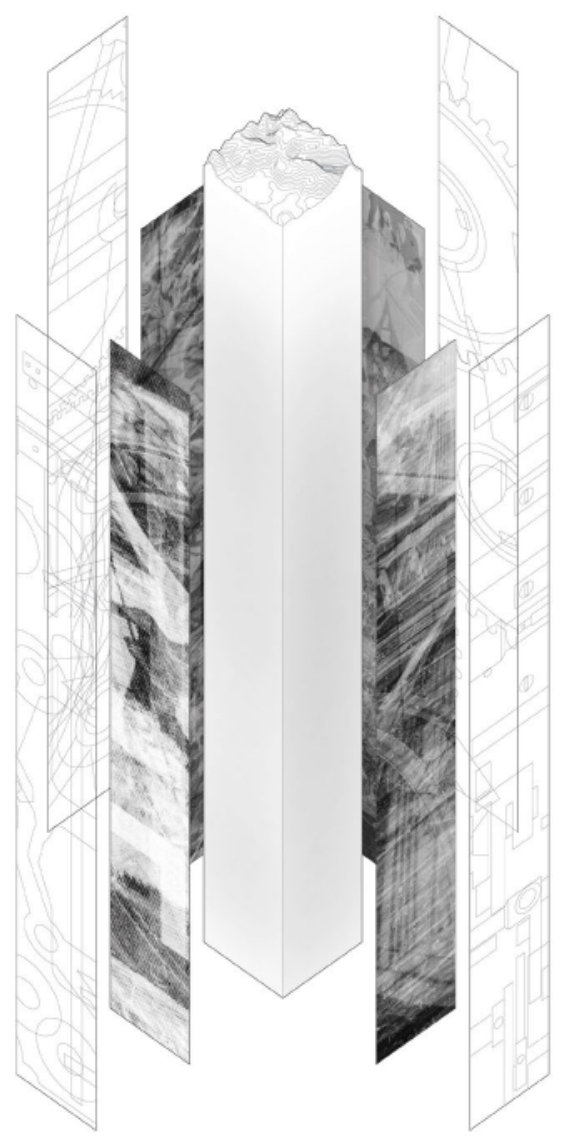

Fig. 54: Core Sample Diagram

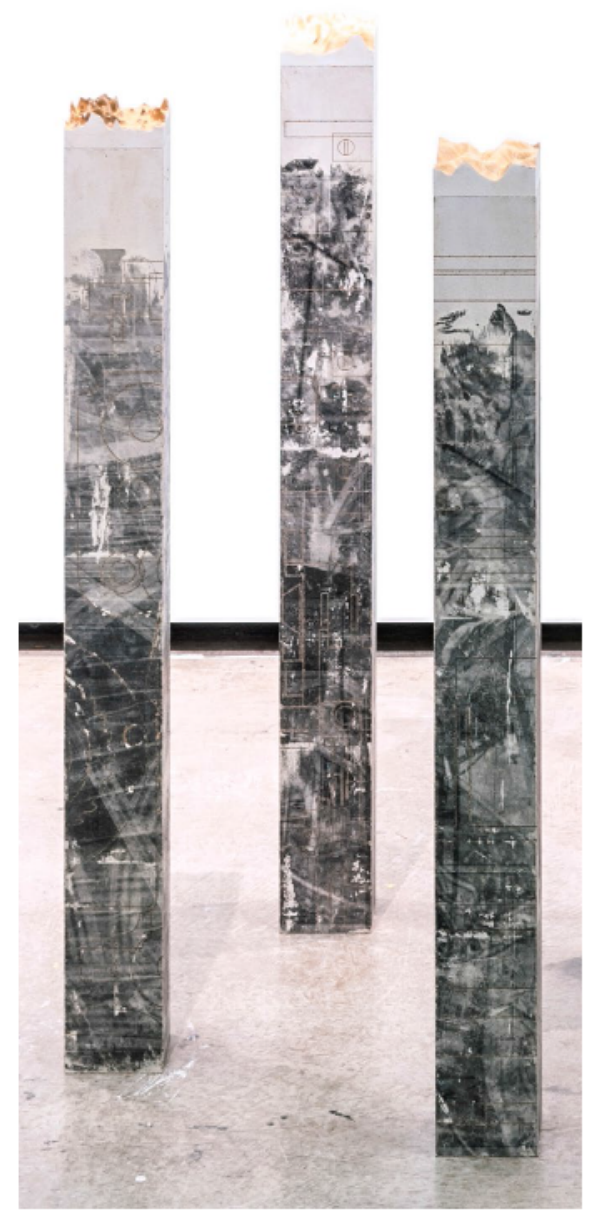

Fig. 55: Core Samples 


\section{FUTURE WILDERNESS NARRATIVES}

In this exploration, narrative was used as means to inspire the drawings of the future conditions of citizen scientists. This was achieved by collaging historical accounts of expeditions across the icefield with new projected futures containing themes derived from previous research. The exercise allows for a critical exploration of time as the perception of the environment of multiple people is collaged together to construct a new reality. New combinations of words and experiences in these imaginative and ephemeral narratives generate new possibilities for architectural design in a future scenario. Acting as devices that can measure the progression of slow environmental change, the architectures that evolve from this exploration attempt to address the issues of geological agency in the context of deep time. 
ATMOSPHERE

The disparate structure stood out like a beacon in the otherwise sublime backdrop. Probing instruments hung from the station, silently gathering information. Its massive sails moved mesmerizingly in the air currents reacting to the slightest change in conditions. It seemed almost lifelike, transforming into new constellations of apparatuses and structural elements. "The day was even more nearly perfect for surveying work than that on which we had ascended Castleguard Mountain. There was a clear vault of indigo sky overhead, with the west banked full of rolling cumulus clouds which gave all the effect of an approaching storm." 57

We began our ascent after lunch and at about 12:15 our surveying equipment alerted us that we had entered the data-sphere.

The layer of humanity's collective digital information suspended in the geosphere, endlessly encircling the planet. Submersed in currents of data our gear made visible the information that passed through us. Strings of data collided with sensors in our jackets cause luminescent reactions. The lights made it easy to spot the team members in the cloudy conditions. Of all the stations in the national park this one was easily the most scenic, its elevation provided breathtaking views of the Rocky Mountains and Columbias. "The rims of the hanging glaciers high up on the mountains to the left and right were scintillant with reflected sunlight while on all sides of us the broken surface of the icefield threw tremulous shadows like those of the waves of a rough choppy sea." 58 The peaks pointed like vectors into the sky projecting tectonic force lines into the atmosphere.

57 Lewis Ransome Freeman. On the Roof of the Rockies: the Great Columbia Icefield of the Canadian Rockies (New York: Dodd, Mead. 1925), 158.

58 Freeman, On the Roof of the Rockies, 158 
When we reached the platform we loaded the cartridges into the probing launchers fixed to the scaffolding and activated the equipment. As the storm neared we sought shelter in one of the suspended pods. We unpacked our gear and set up for the night. Gusts of wind beat against the enclosure. "All night long a thunderstorm kept growling, and the lightning played over the summits of the mountains to the north. The flying rack scudded across the face of the moon, as we lay awake listening to the stones trickling down the dirty ice-cliff below us, the loud murmur of the torrents, now rising in volume, now falling, with the varying gusts of wind, and the occasional roar of an avalanche tumbling down the sides of Athabasca Peak. "59 The tumultuous conditions of the storm prompted the launchers to fire the probes we had installed earlier into the night sky for frequent measurements. Their echoes drowned in the darkness.

59 Hugh Edward Millington Stutfield. Climbs and Explorations in the Canadian Rockies / by Hugh E.M. Stutfield and J. Norman Collie. (London: Longmans, Green. 1903), 117. 


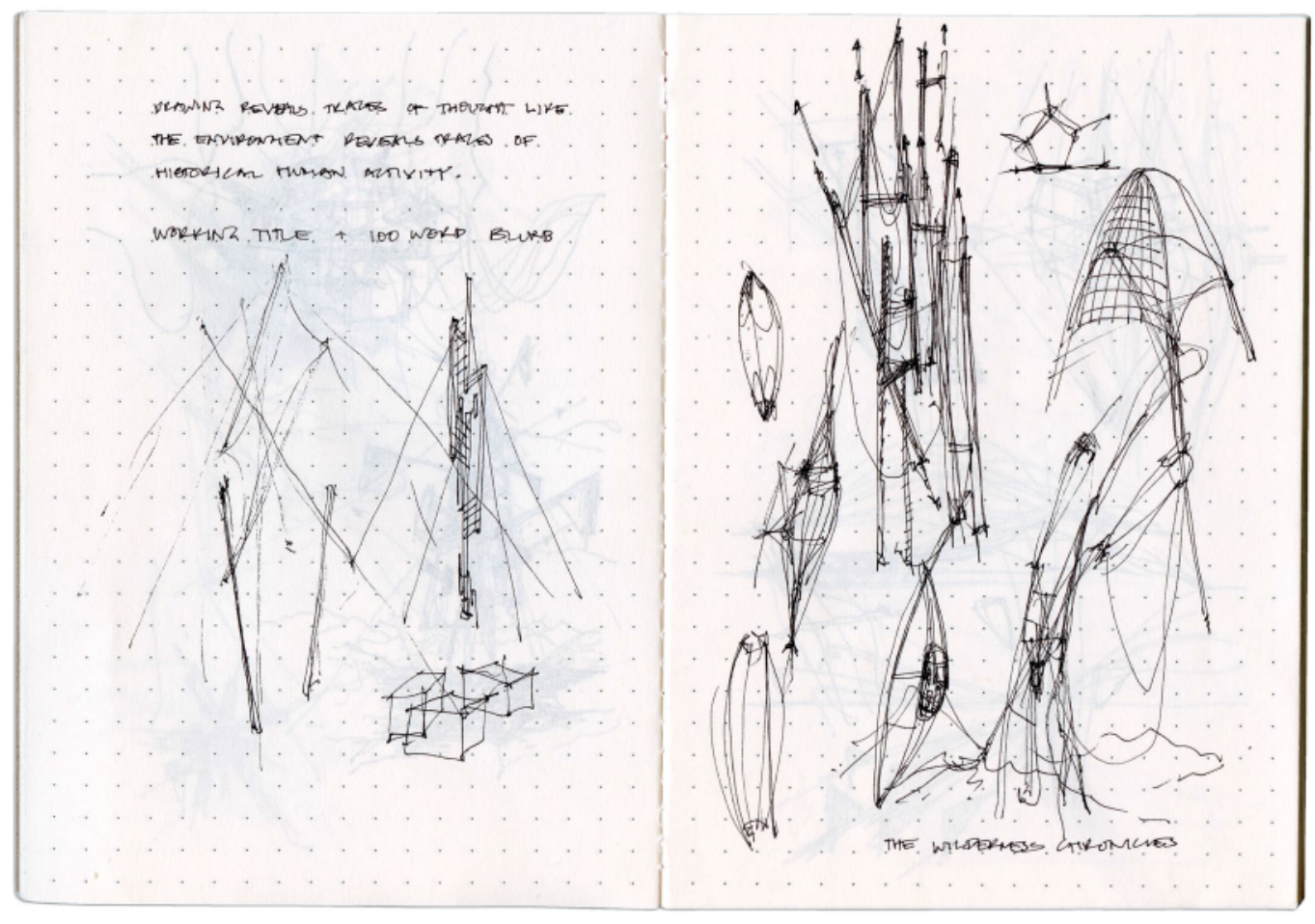

61

Figure 56: Process Sketch 01 
HYDROSPHERE

"A quarter-mile farther through dense second growth brought

us to the trampled mud banks of a sink a couple hundred yards in diameter. In the spring and early summer there must have been a lake here, fed by the stream draining the valley of the meltage from the snows. "60 We hiked up the valley left by the retreating glacier until we reached its face. It was late in the afternoon as we eclipsed the edge of the mountain bowl and "a new world was spread at our feet; westward stretched a vast icefield never before interpreted into data by the physical environment surveying devices carried by the tourists. "From its vast expanse of snow the Saskatchewan Glacier takes its rise," supplying "the head waters of the Athabasca River eventually terminating in the Atlantic Ocean; "while far away to the west, bending over in those unknown valleys glowing with the evening light, the level snows stretched to finally melt and flow down more than one channel into the Columbia River, and thence to the Pacific Ocean. "61 We were standing at the hydrographic apex of the Rocky Mountains, the meeting point of three watersheds - the mother of rivers, supplying the foothills of the surrounding region with life for thousands of years. Its frailty became apparent, what would happen if it disappeared? Rapid global temperature change has resulted in drastic fluctuations in meltwater shed from the glacier. Predictions of glacial depletion loom as an inescapable tragedy over humanity. Surveying stations were deployed at the toes of the retreating glaciers to help calculate when the specific hydrographic region would be void of its primary source of life. Our destination was the surveying station at the toe of the Athabasca glacier. Half submerged in the water the walls of the station

60 Freeman, On the Roof of the Rockies, 167.

61 Ibid., 147 
broke the currents erupting from the glacial precipice channeling water into an array of openings for further testing, measuring its chemical structure and flow rate. The life of the landscape filtering through the body of the structure in a maze of tubes that twisted around each other, cold water rushing through them like veins. At the tail end of the structure the tubes disappeared under the choppy water surface pumping its contents into the stream eventually joining the currents of the ocean. It almost resembled a heart pumping water into the biosphere, the realm of all life on the planet. 


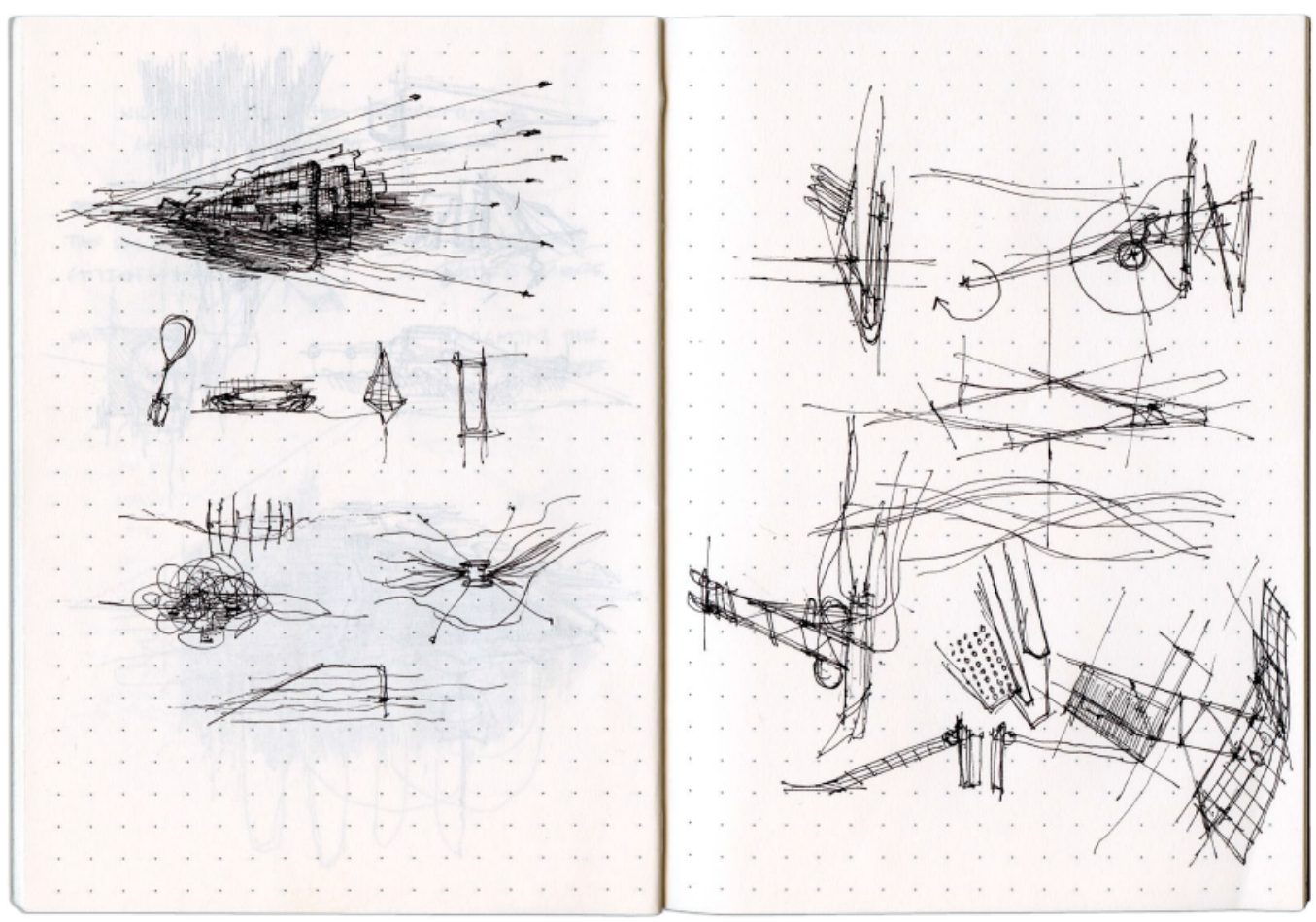

64

Figure 57: Process Sketch 02 


\section{CRYOSPHERE}

"We had been going for nearly five hours when we emerged on to the upper glacier, and the remnants of the wonders of that vast region of snow and ice were unfolded to our view. "62 "What once was a vast sheet of ice had become a maze of isolated formations. Like beached icebergs, colossal islands of ice rose up hundreds of meters, carved by the wind that was now channeled by its walls. It took us several hours to climb up the fragile ice face. "The abysmal groans of cracking ice" on the glacial plateau "were a bit nerve-racking at first, but one steadied to them in time when they failed to make good their threats of opening up the glacier under his very feet. ${ }^{63}$ Through this upper ice-plateau we slowly made our way" to our surveying location, "zigzagging between the séracs, or ice-pinnacles, and innumerable crevasses. The latter were unsurpassably fine. "64 Using our navigation system we located the crevasse which was selected for documentation and drilled an anchor at the mouth of the ice pit. The station was located at the bottom of the gigantic fault. It proved its existence only through vine like data cables that grew out of the icy abyss of the crevasse, remnants of previous expeditions.

The "huge chasm of immense depth yawned beneath us, branching out below into mysterious caverns and long winding grottoes, their sides tinged with that strangely beautiful glacial blue, and festooned with enormous icicles. "65

As we descended into the crevasse light flickered through the ice, dispersed by the undulating glacial surface. Occasionally

62 Stutfield, Climbs and Explorations in the Canadian Rockies, 118.

63 Freeman, On the Roof of the Rockies, 159.

64 Stutfield, Climbs and Explorations in the Canadian Rockies, 118.

65 Ibid., 118. 
filaments would appear, seeming to originate from the heart

of the glacier then disappearing into the darkness beneath

us. Gradually, as the maze of cables began to thicken the station came into view. It had grown firmly into the base of the mountain of ice. A pseudo-neural network of cables spread through the glacial ice, harvesting past histories of information; calculating new potential environmental futures. Physical data stored in the ice over thousands of years have created a databank of the biosphere. All traces of animate activity on our planet stored in the solid form of the substance that gives us life. These historic landscapes and conditions now revealed to us through the technological advancement of surveying equipment. After inserting the new network cables we brought with us we climbed to the center of the apparatus where holographic images projected past and future landscapes, morphing in and out of reality. From what era were these environments? 


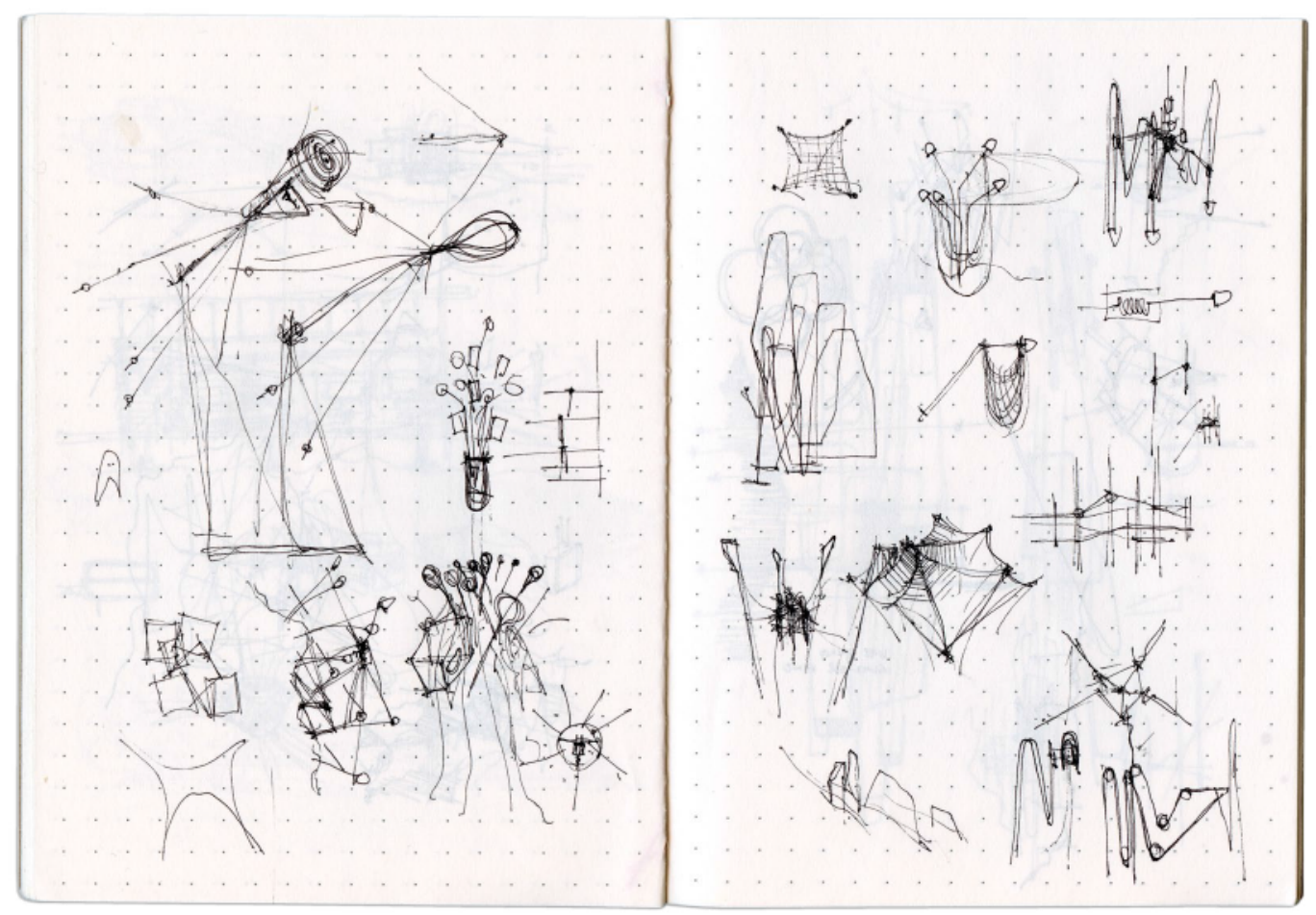

67

Figure 58: Process Sketch 03 


\section{LITHOSPHERE}

"Finally we won through to solid footing again." An expression

of particular irony in the current geological age. The rock beneath us provided our feet with a false impression of stasis, yet to the equipment that we were asked to carry it was fluid, translated into binary particles in constant flux. Our perception of time has made us blind to the deep processes of environmental systems. We have become reliant on scientific instrumentation to see for us. Our party had reached the surveying destination. "This was a sloping cliff of torn and riven bedrock left exposed by the melting glacier;"66 an impression of the once great Columbia Icefield. Sculpted over millennia this brute escarpment is only the most recent manifestation of its substance. The striations read like data. Natural information.

We unpacked and set up base at the foot of the cliff. Part of the ever moving continental crust of the earth, the arête rose sharply into the air like a tectonic skyscraper; the pinnacle of geological ingenuity; a silent placid wave. As we scaled the enormous structure we drilled holes into the rock and inserted small remote-surveying beacons. Immersed in an ocean of sediment these indestructible instruments would process the lithospheric movement throughout the earth's lifespan.

"Meanwhile the thunderclouds gathered, the haze grew denser, and the peaks loomed dim and ghostly through the pervading murkiness. Our view was largely spoiled, but, as compensation, the sense of vastness and mystery was enhanced - and in travelling through a new mountain country the sense of mystery is everything. The spell that once was upon the Alps has been broken" by the sphere of digital information that had been ac- 
cumulated by eager citizen scientists. As a result of the extensive surveying their future reality had become transparent. Predictions of how the Alps would evolve have eroded their historical sublimity. Tourists now scale digital landscapes. "The illusion and the mystery that formerly enshrouded them have departed, never to return; and with the illusion has gone much of the awe and reverence they used to inspire. "67

67 Stutfield, Climbs and Explorations in the Canadian Rockies, 120. 


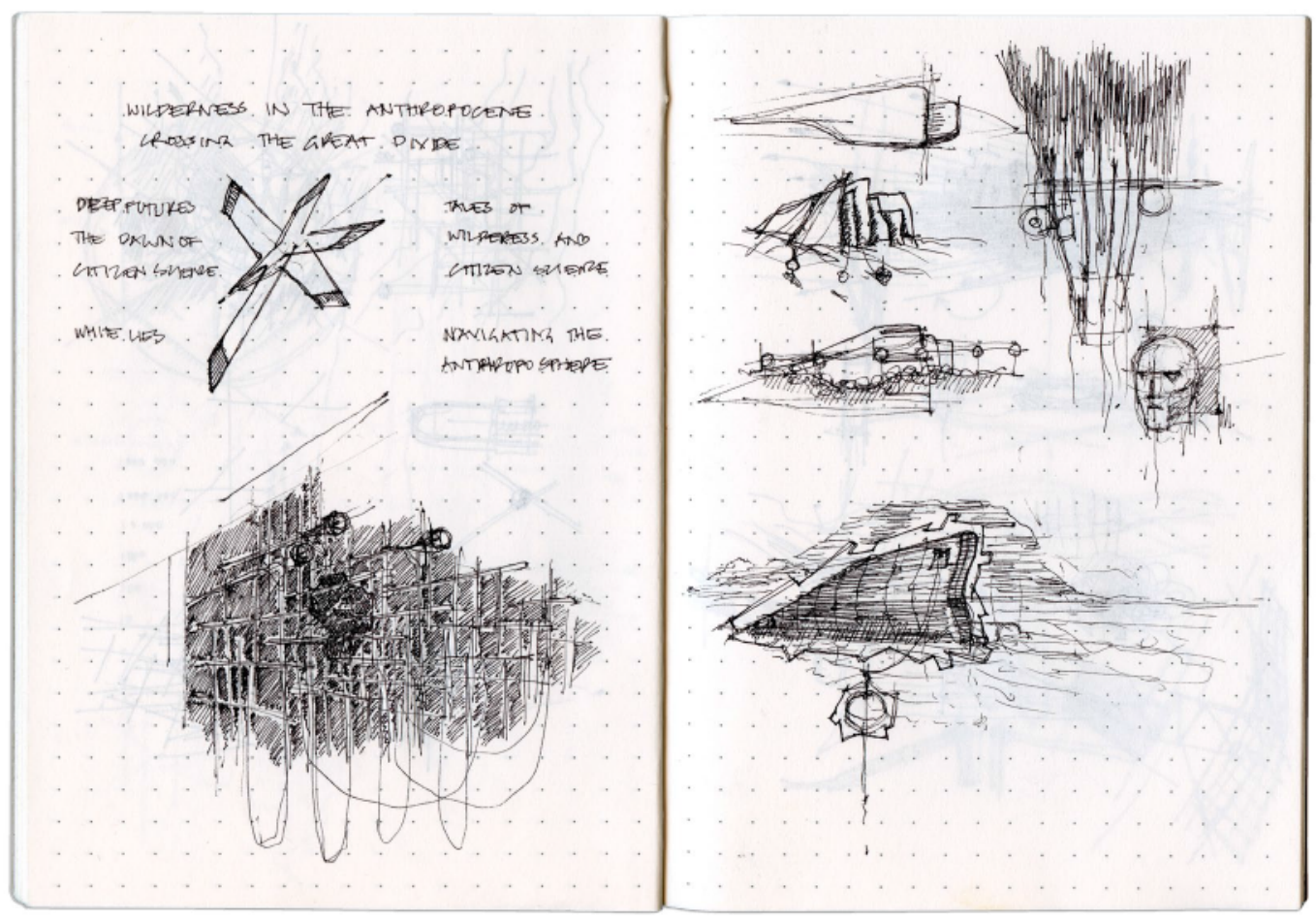

Figure 59: Process Sketch 04 


\section{THE DRAWING PROCESS}

The choice of representation became critical in an attempt to visually address the convergence geological and human historical time. Much like the narrative explorations, the drawing process intends to reflect the idea of layering. Each of the final drawings is composed of five layers: a printed hybrid drawing of sketch and plan view of the stations form and location, a black screen printed image of perspective context, and a white layer of the same but digitally mediated image. The final two layers are a white-out layer that masks out the previous layers and acts as a primer for the final drawing layer through which the station is represented.

By collaging images, which are themselves constructions of particular instances of time mediated by the current state of technology, the drawings become hybridized future speculations. Screen printing lent itself to addressing this challenge due to its innate layering process. Similar to the white-out process used in the sketches of the citizen scientists, there is a logistical procedure of layering to produce the intended effect. The following images show the different screens used to create the prints. 

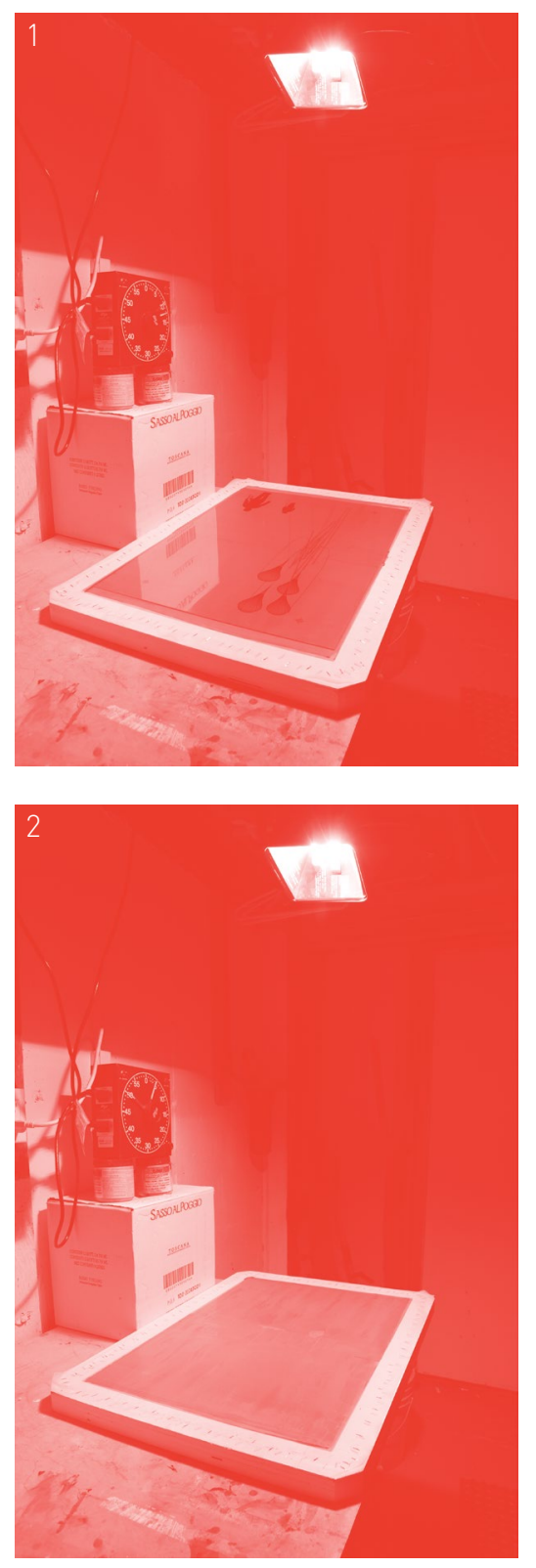

Fig. 60: Silk Screen Preparation + Process

Once the drawing has been completed and the screens have been stretched the layers are printed on clear plastic film. These are used to expose the photo emulsion on the screens (1). After washing the emulsion is re-exposed to fix the drawing (2).Ink can then pass through where the emulsion was left unexposed. The screen is aligned on a chosen medium using reg-istration marks and then ink is pushed through using a squeegee $(3,4,5)$. White-Out tape is then used as a mask for the final drawing layer (6)
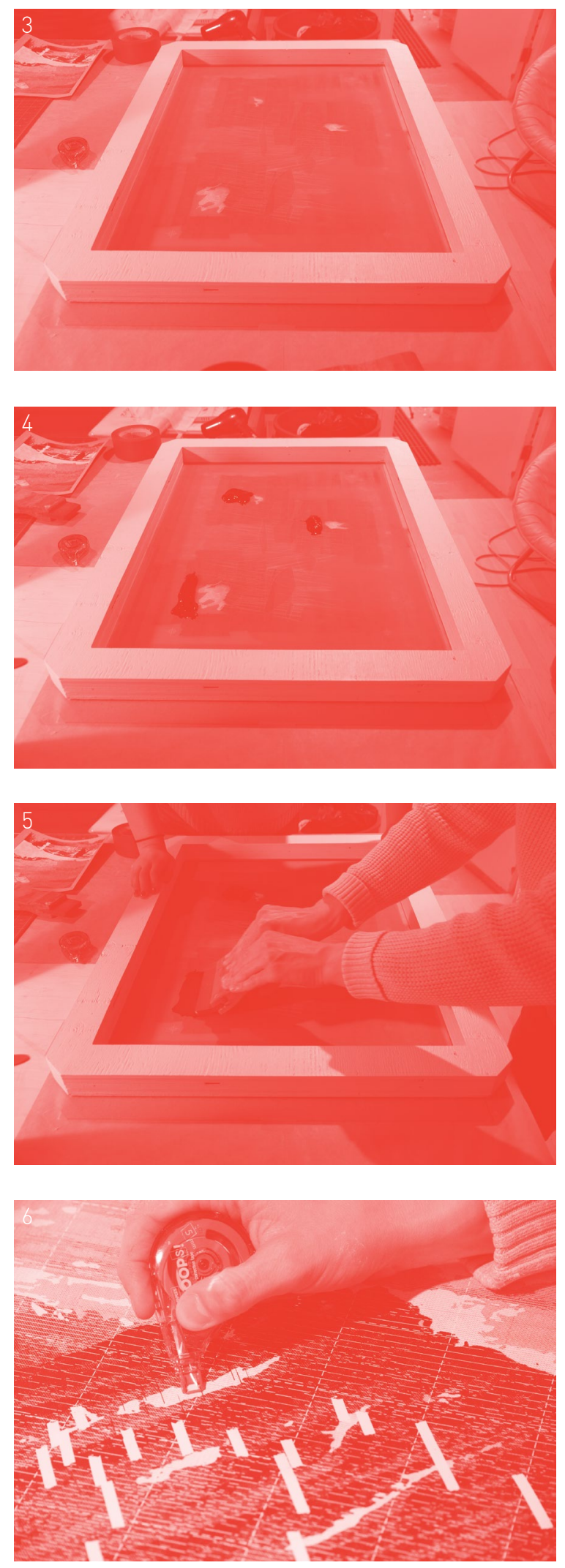

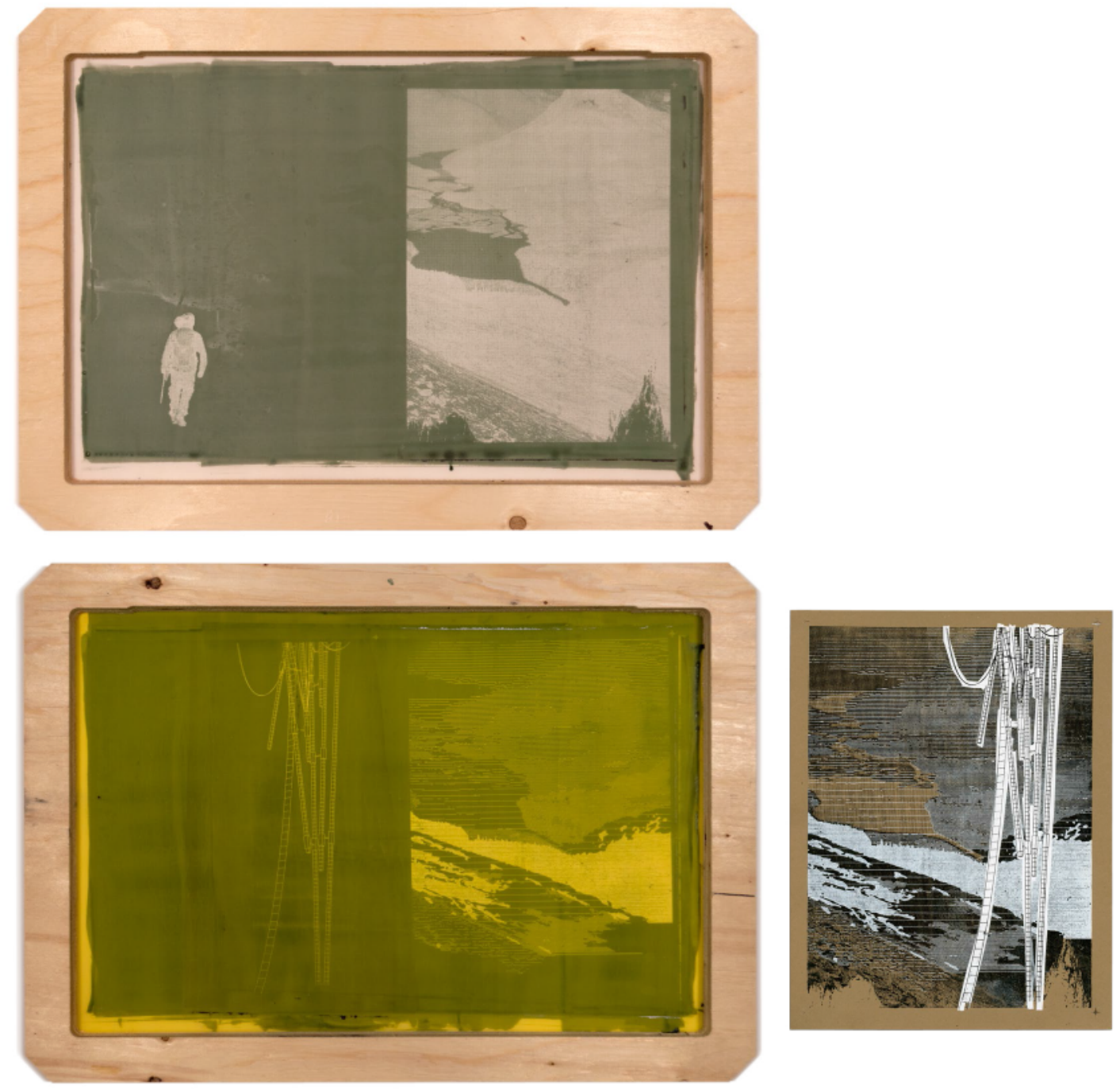

Fig. 61: 140-Thread Mesh Screen in Frame

Fig. 62: 220-Thread Mesh Screen in Frame

Fig. 63: 8.5"x11" Screen Print Test 

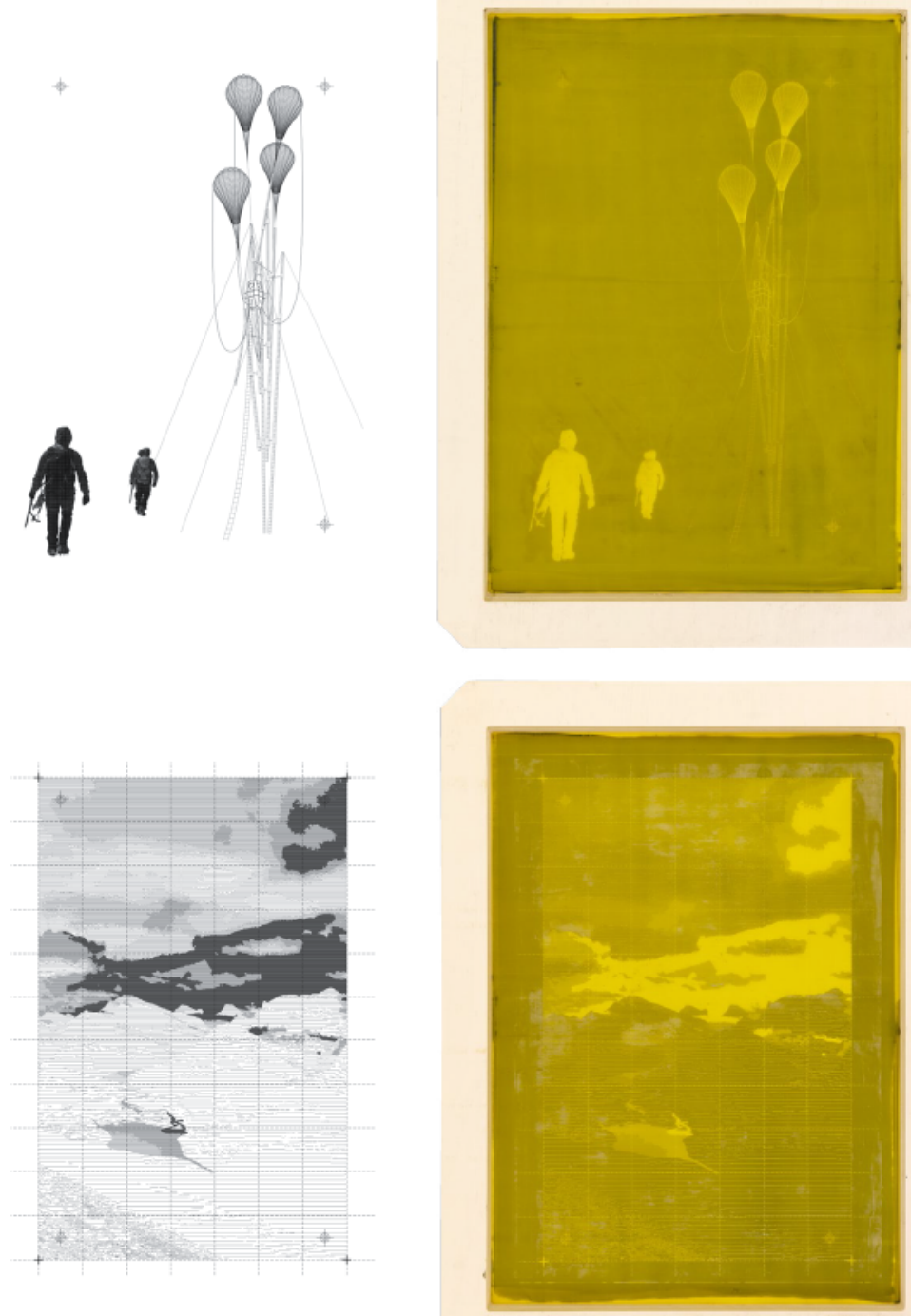

Fig. 64:

Original Drawings

and Screens Used for

Atmosphere Station Print
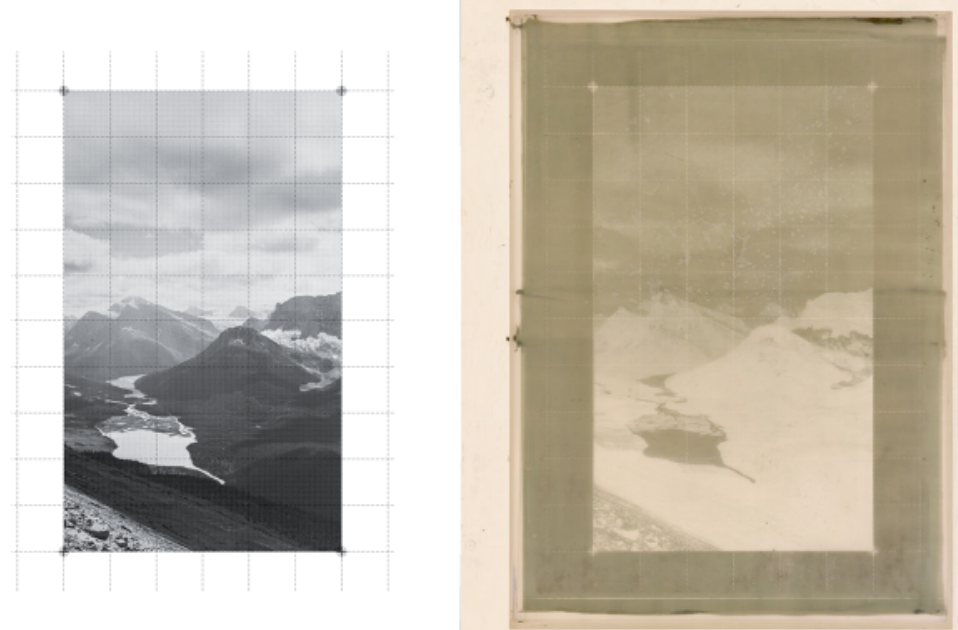

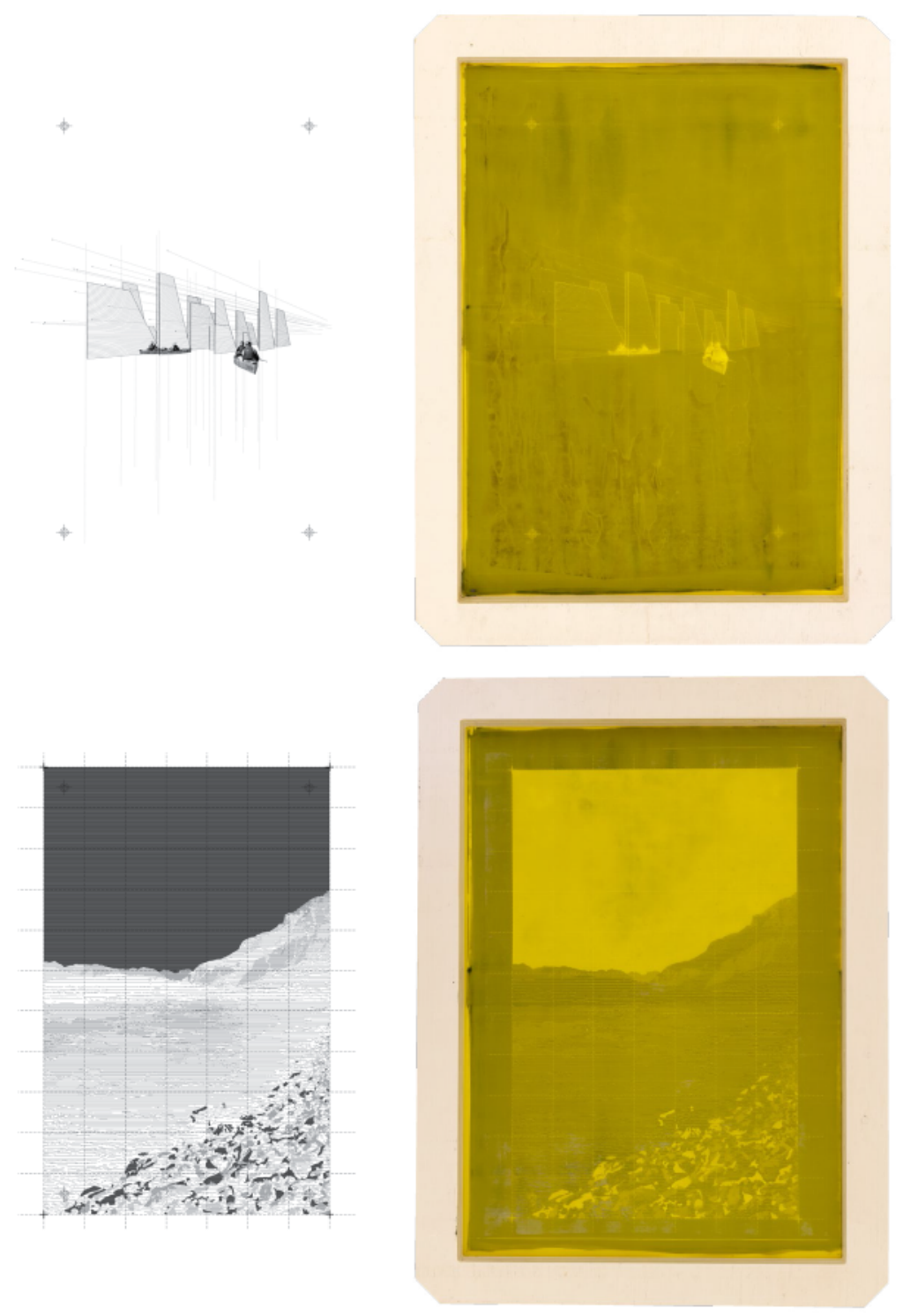

Fig. 65

Original Drawings

and Screens Used for

Hydrosphere Station Print
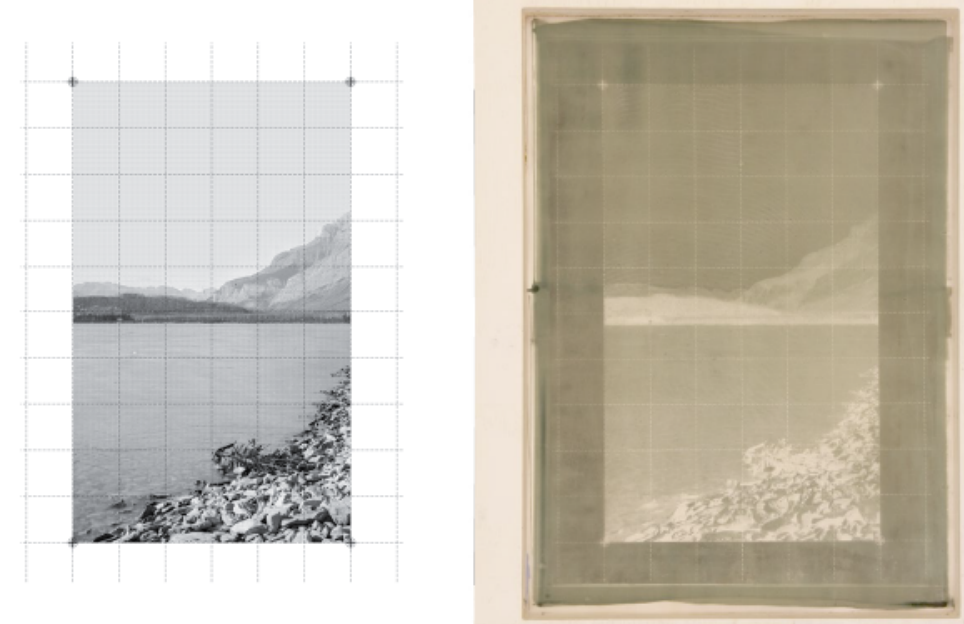

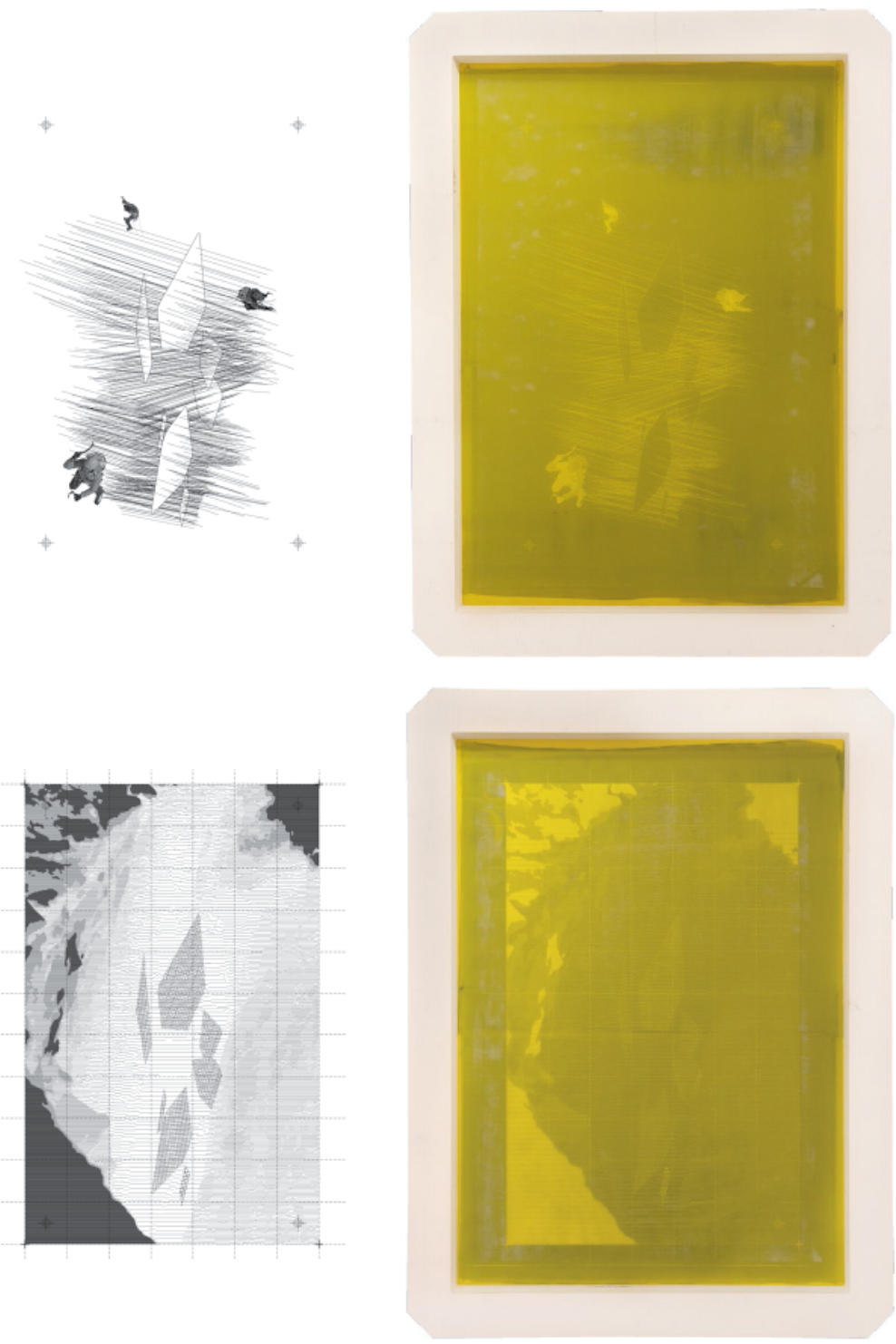

Fig. 66

Original Drawings

and Screens Used for

Crysophere Station Print
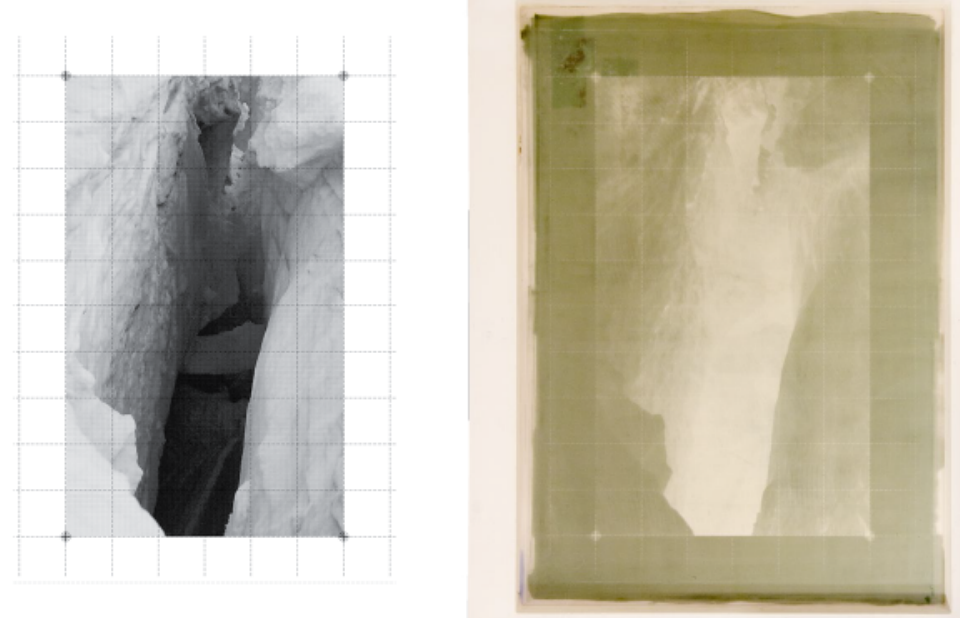

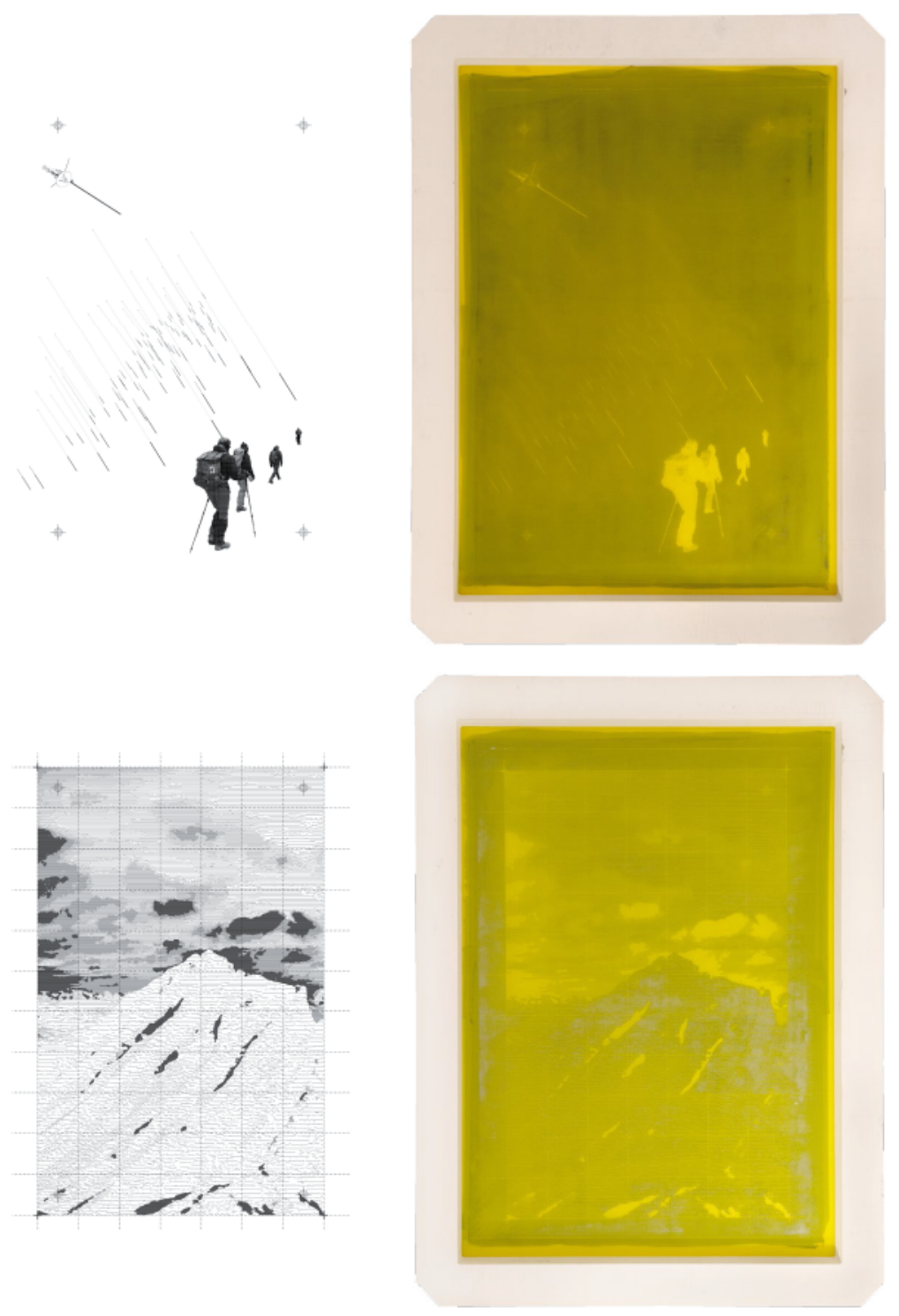

Fig. 67:

Original Drawings

and Screens Used for

Lithosphere Station Print
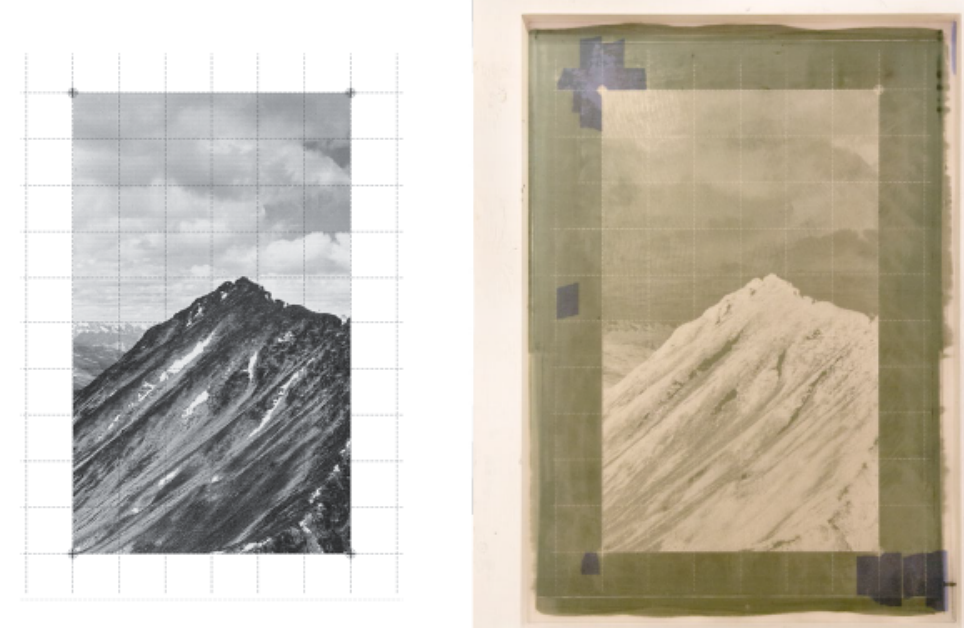


\section{THE GEOSPHERE STATIONS}

Utilizing the future wilderness narratives as a point of departure for the design process, the research and explorations culminate in the form of four surveying stations. These are located in accordance with the environmental systems present at the Columbia Icefield: the atmosphere, hydrosphere, cryosphere, and lithosphere. These conceptual architectural constructions react and respond to shifting landscapes, acting as surveying stations that illuminate characteristics and qualities of the site, while additionally serving as a destination and place of refuge for the future citizen scientist. Through addressing not only climatic events but also fluctuations and changes in deeper and slower systems, such as the cryosphere and lithosphere, the stations pose to facilitate the citizen scientist with the speculative rediscovery of the Columbia Icefield in the Anthropocene. 


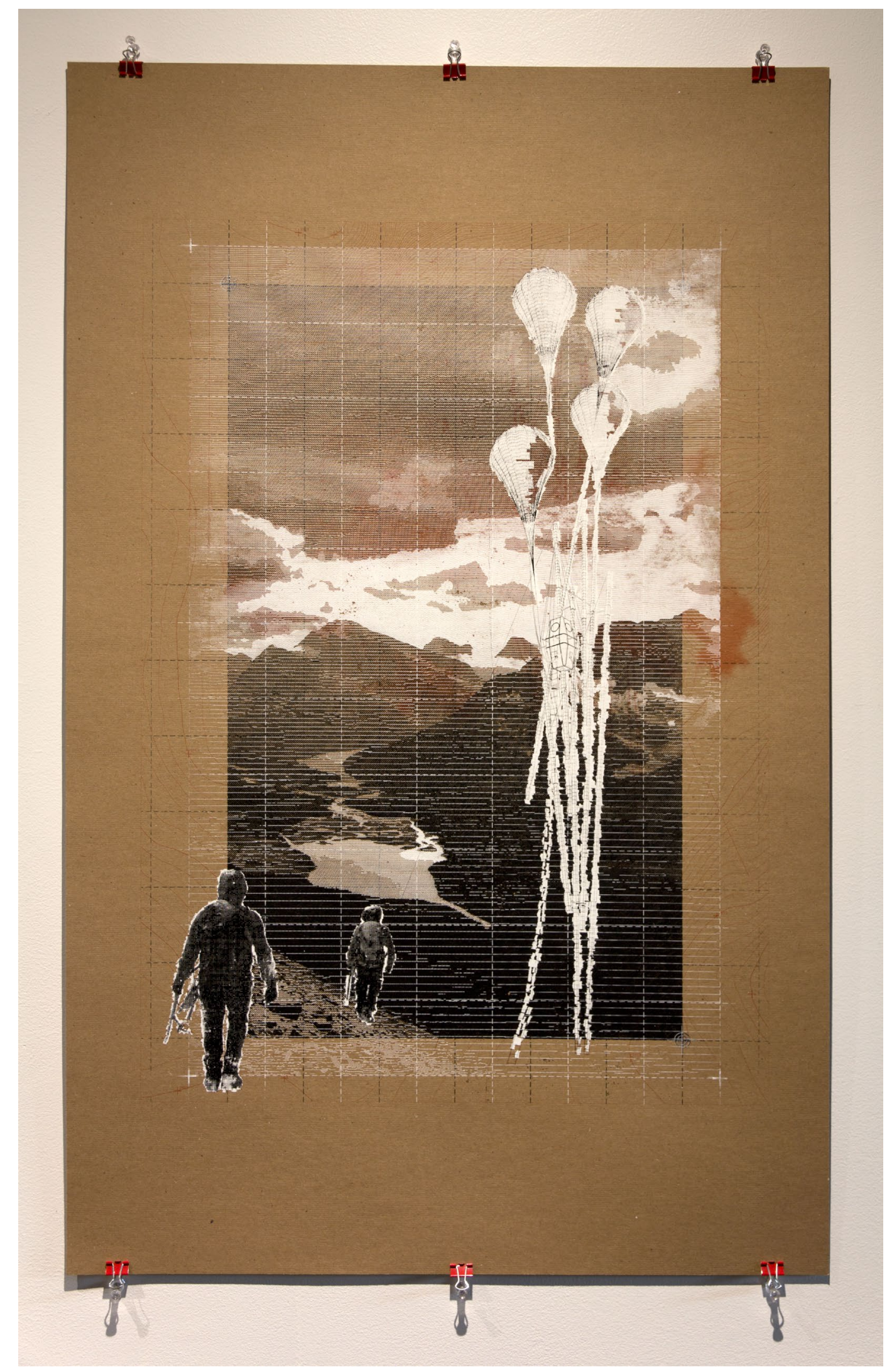

Fig. 68: Atmosphere Station 
Fig. 69:

Details of Atmopshere

Station Print
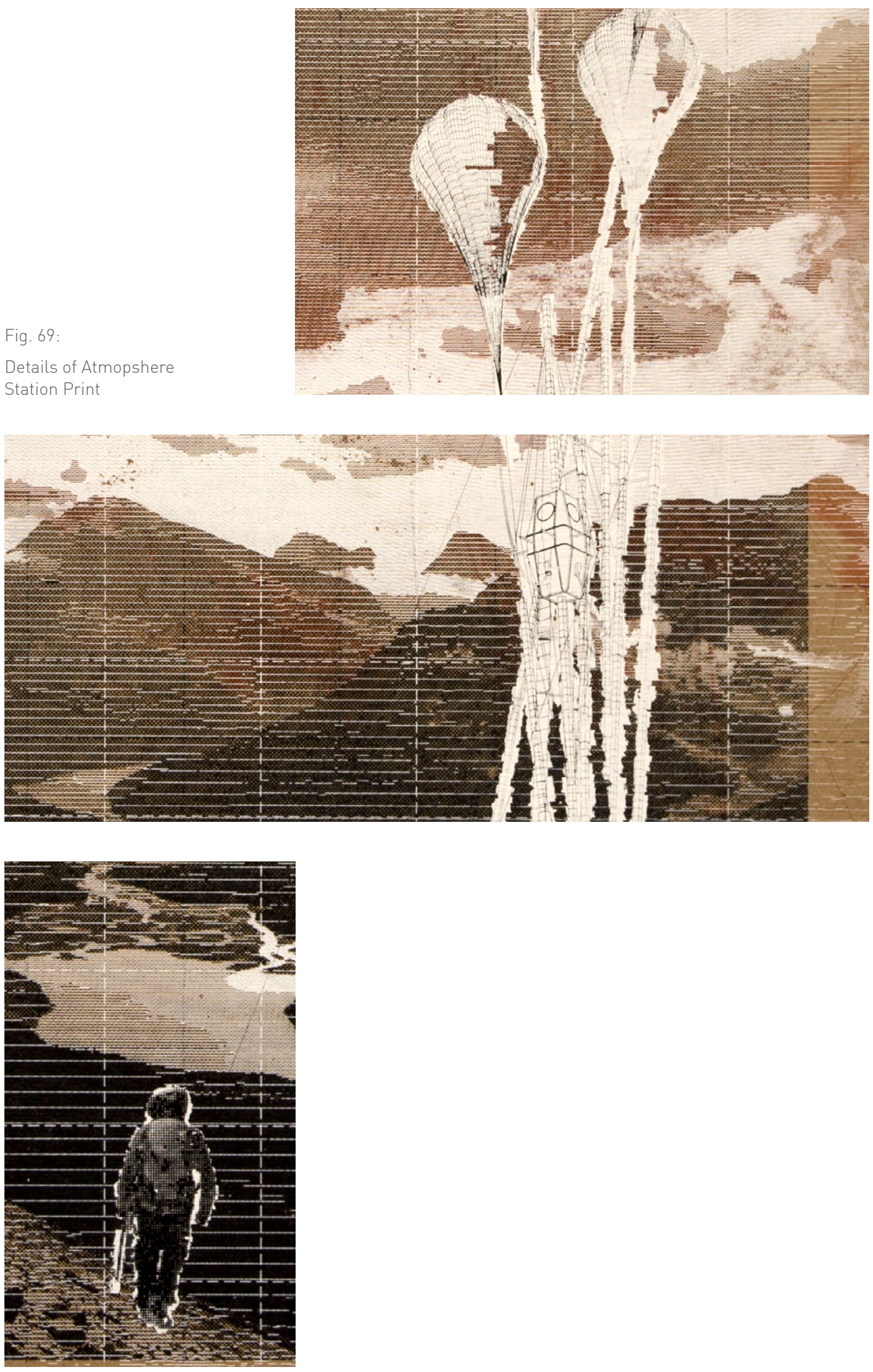


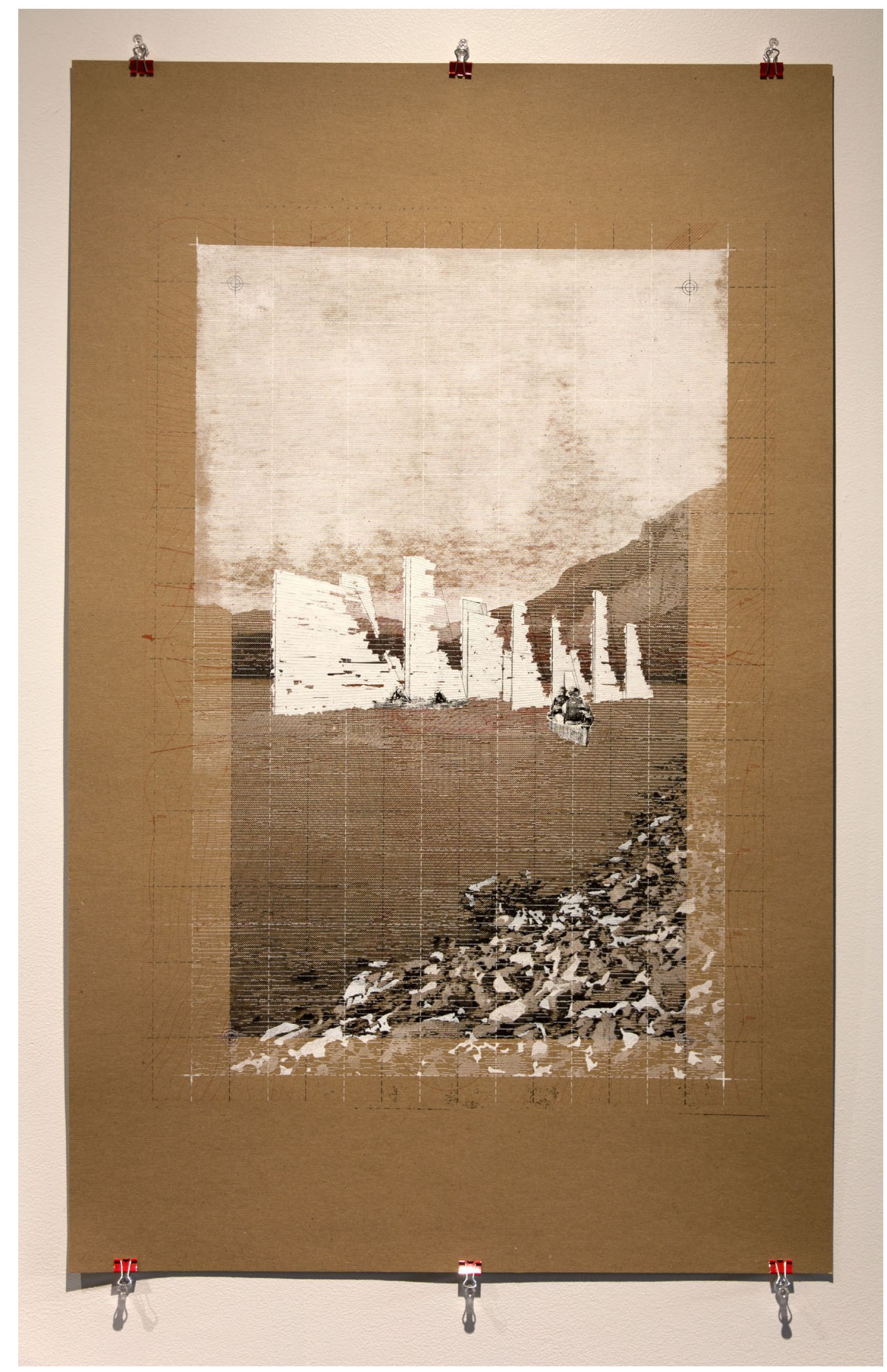

Fig. 70: Atmosphere Station 


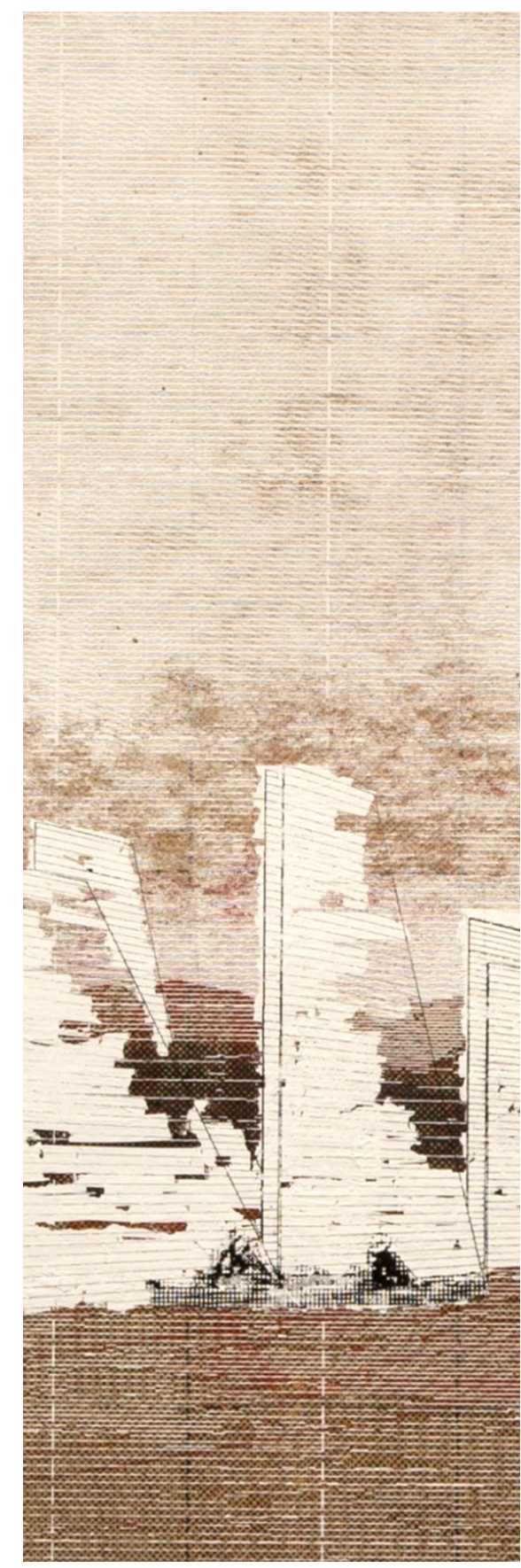

Fig. 71:

Details of Hydrosphere

Station Print

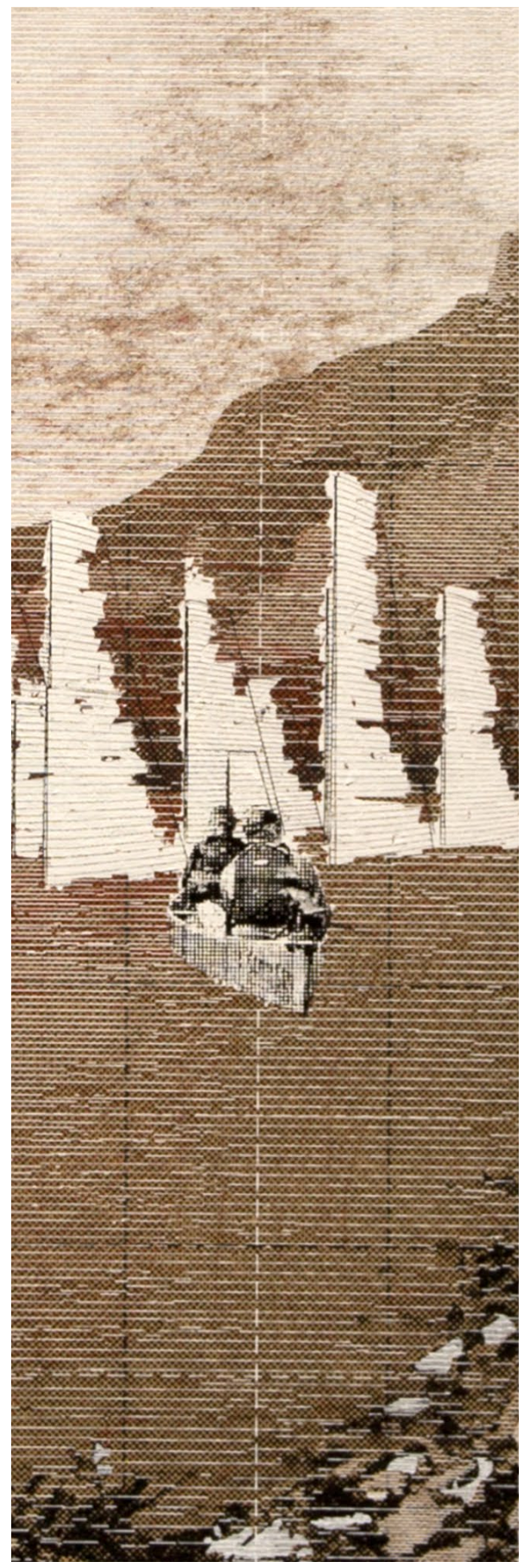




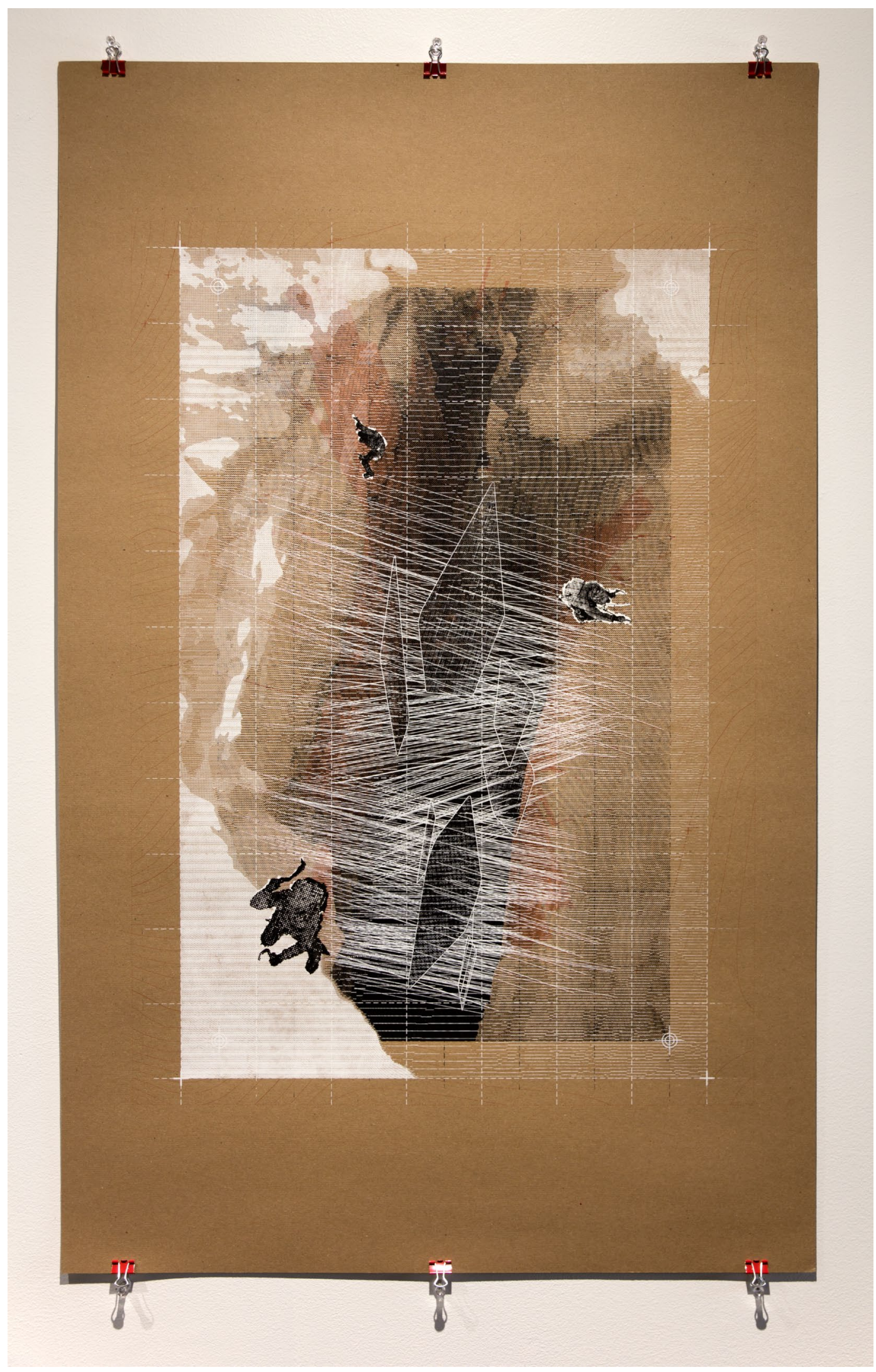

Fig. 72: Atmosphere Station 

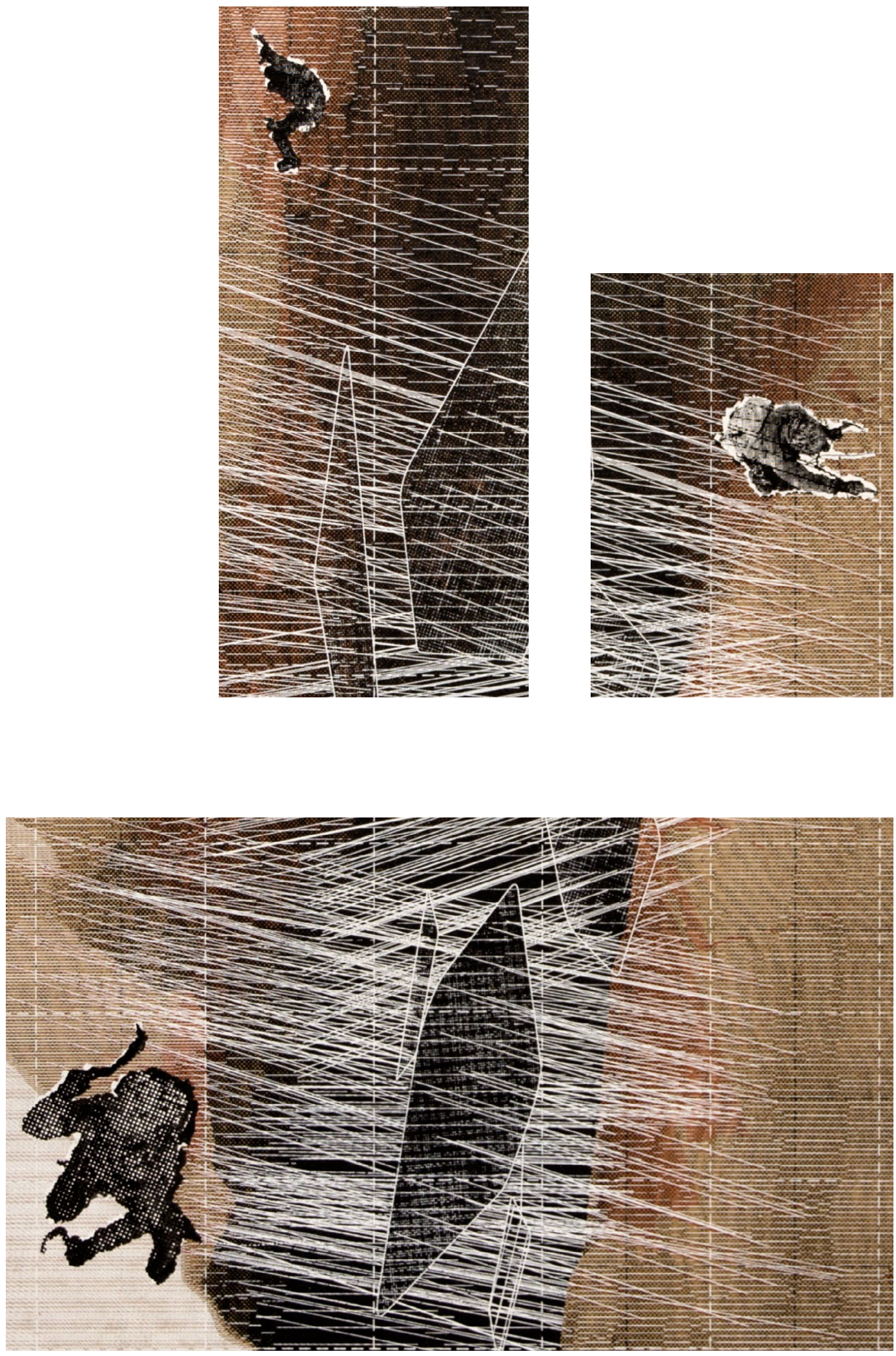

Fig. 73:

Details of Cryosphere

Station Print 


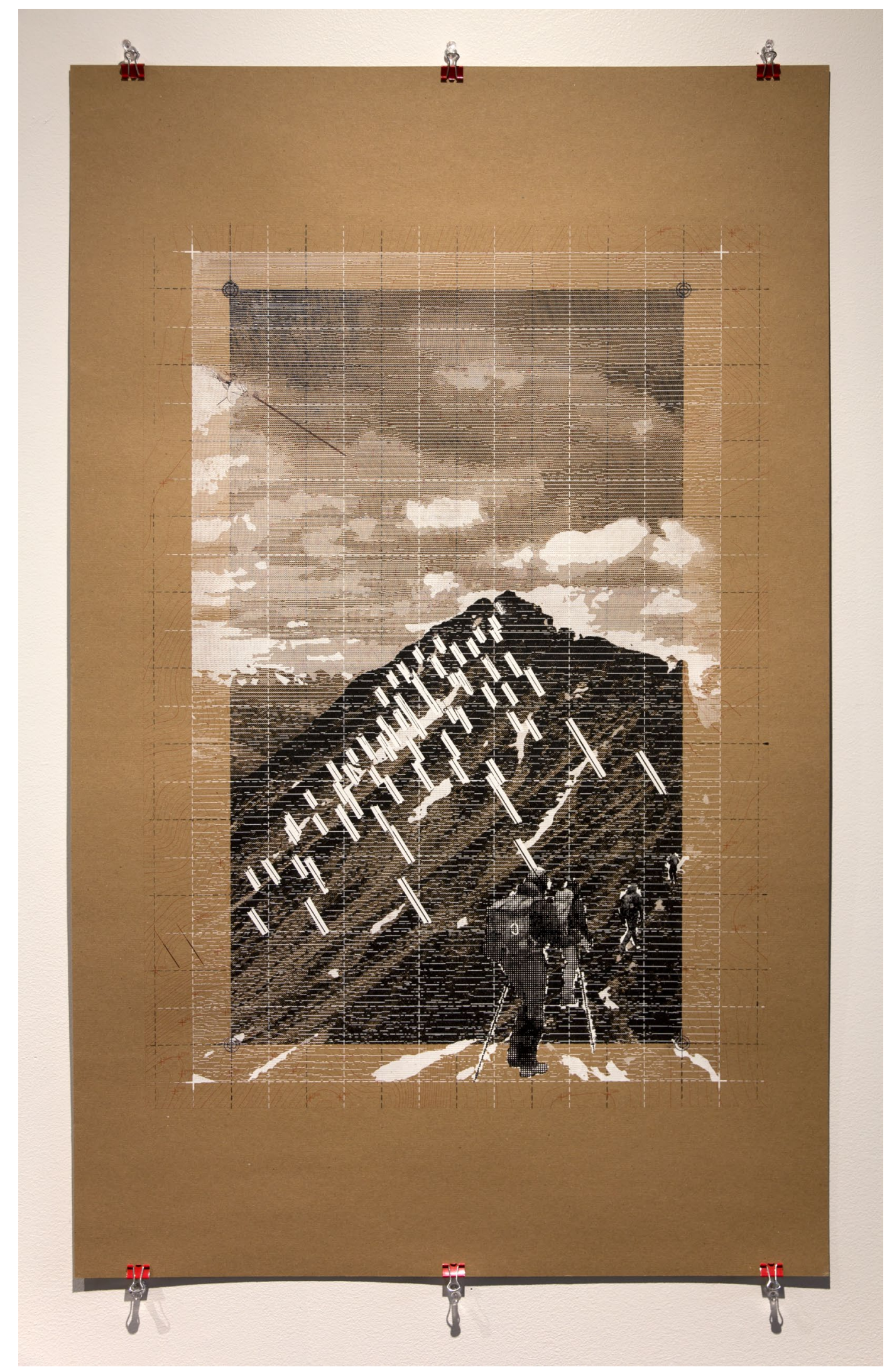

Fig. 74: Atmosphere Station 


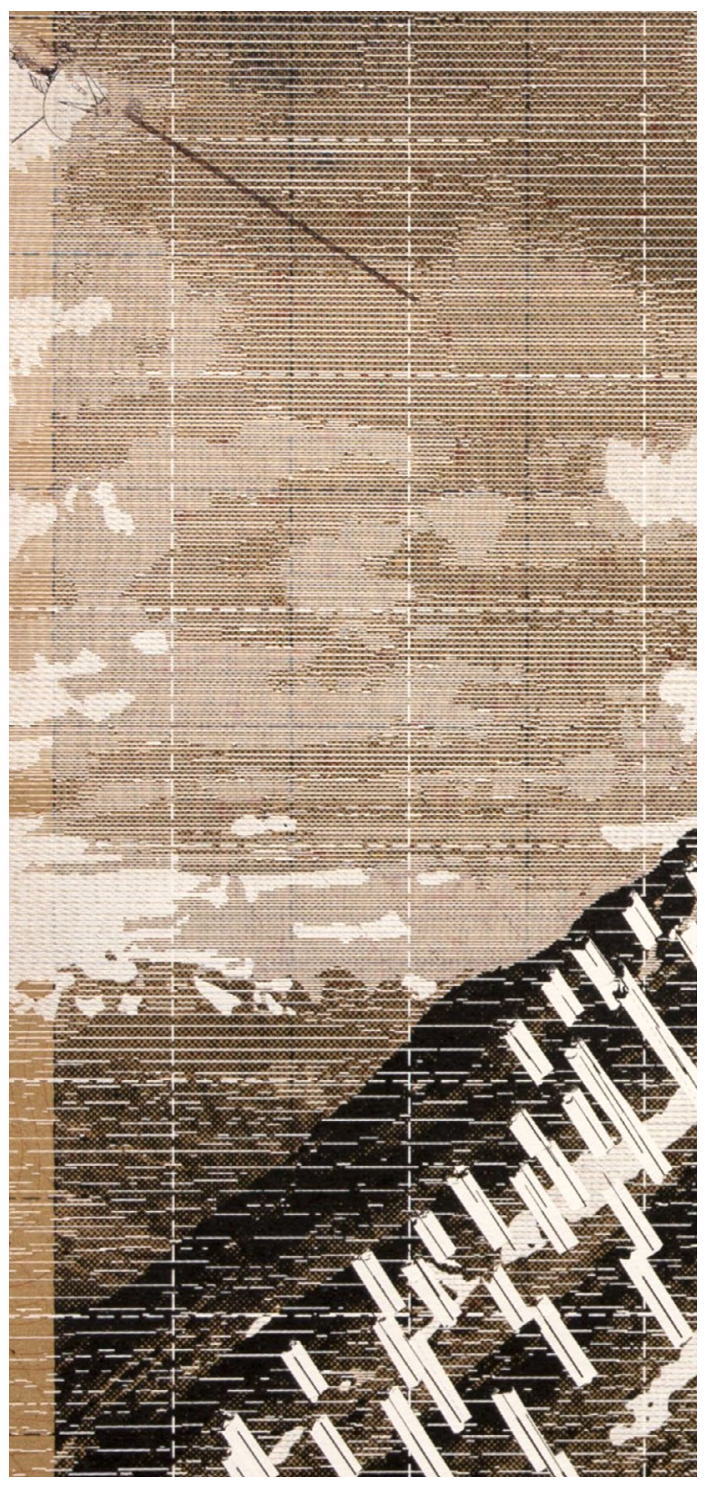

Fig. 75:

Details of Lithosphere

Station Print

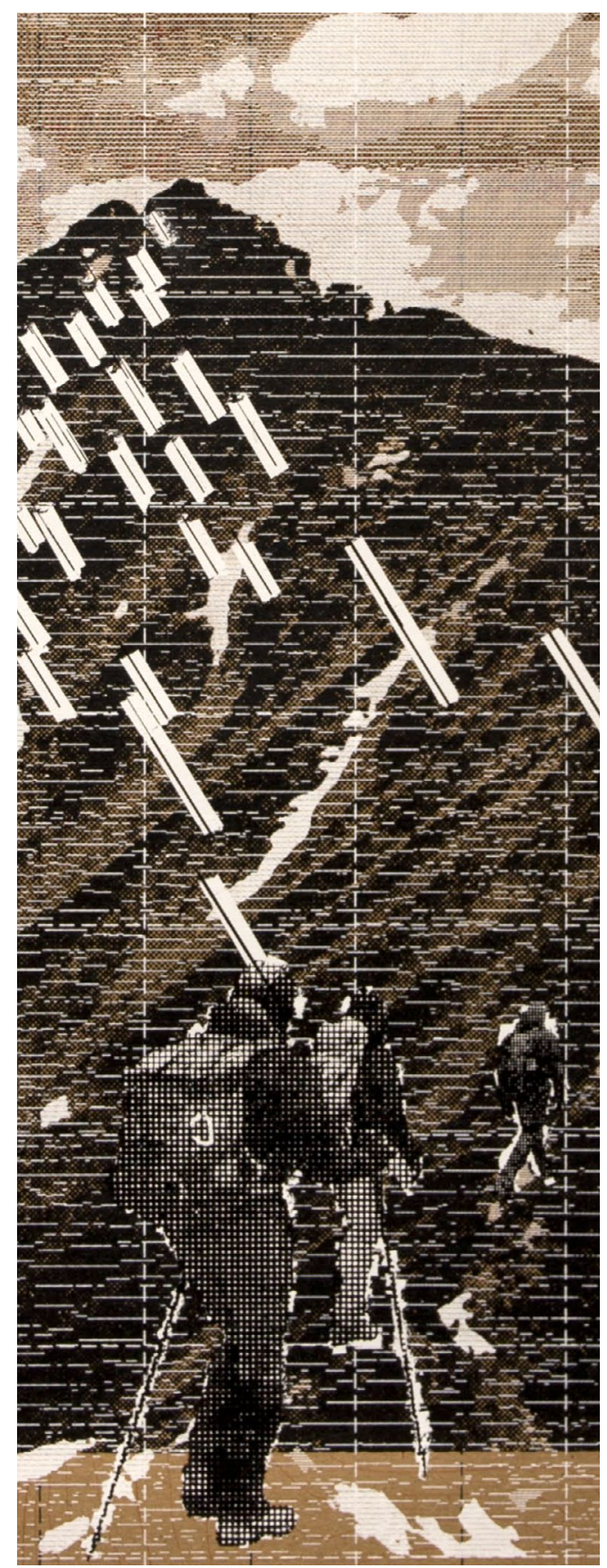


By making visible and interacting with the environmental conditions of the site the stations serve as the bridge between geosphere, biosphere, and the metaphysical realm of information. It is here where the data recorded and produced by all digital/technological entities, such as remote sensing surveying equipment used by citizen scientists, resides. This "infosphere" is a faction of the more encompassing noösphere, the theoretical conception of the sphere of human thought jointly introduced by French paleontologist Pierre Teilhard de Chardin, philosopher Édouard Le Roy, and Russian geochemist Vladimir Vernadsky in 1922. The theory proposes the existence of a collective entity of all consciousness generated by the biosphere that exists interwoven with the geosphere. ${ }^{68}$ Modern broadband technology used to connect people across the planet could be seen as the virtual manifestation generated by human activity in effect forming a part of the noösphere.

In the present state of information technology, connecting remote areas in the Canadian backcountry or northern regions to the global realm of information is extremely difficult and cost ineffective. ${ }^{69}$ The Canadian infoscape is therefore punctuated with voids and gaps due to the sheer vastness of the physical landscape. Regions rich in biological and geophysical diversity often remain in the "dark" or unrecorded. While broader misguided technological advancement has historically resulted in adverse effects on the environment, developments in geographical information systems (GIS) may also have the potential to generate data that has evaded western scientific understanding. Some of this ecological information was previsouly known to First Nations, which have inhabited the "wilderness" for thousands of years.

68 William L. Fox, "Dataland," in Landscape Futures: Instruments Devices and Architectural Inventions, ed. Geoff Manaugh (Spain: Actar Publishers, 2013), 13.

69 Dolby, Christine. Is High-Speed Internet a Basic Right? CRTC to Weigh in. The Globe and Mail, April 08, 2016, accessed April 23, 2017, http://www.theglobeandmail.com/report-on-business/ is-high-speed-internet-a-basic-right-crtc-to-weigh-in/article29576878/ 
Intimate Aboriginal connections with the landscape were severed with the displacement of first nations from their land through the establishment of Canada's National Parks. ${ }^{70}$ A loss of valuable ecological knowledge recorded only in the oral First Nations history, now posed to be rediscovered through modern science and technology. Ironically, the creation of the national parks which Canadians now seek to preserve has affected present western scientific understanding of our country's landscape. There is, however, an existent Canadian requirement to consult with First Nations prior to conducting scientific research and developing environmental assessment data. ${ }^{71}$ This could provide an interesting opportunity for the future citizen scientists to gain a multi-perspectival understanding of deep ecological histories and future projections. Through aboriginal involvement in the data collection and analysis process, a more holistic understanding of the environment could be achieved.

In an attempt to address these issues the proposed stations act as physical manifestations of the inanimate systems of the geosphere. By creating the possibility for interaction the devices network tourists with fluctuating environmental conditions. Human induced representation of these systems physically constructs the noösphere, substantiating the neo-nature of the current geological epoch. This leads to the genesis of a nature in which the human is consciously intertwined with the environment.

70 I.S. MacLaren, “Rejuvenating Wilderness: The Challenge of Reintegrating Aboriginal Peoples into the 'Playground' of Jasper National Park', ' in A Century of Parks Canada 1911-2011, ed. Claire Campbell (Calgary: University of Calgary Press, 2011), 340.

71 "Government of Canada and the Duty to Consult," Indigenous and Northern Affairs Canada, Government of Canada, last modified April 19, 2016, accessed April 25, 2017, https://www. aadnc-aandc.gc.ca/eng/1331832510888/1331832636303 


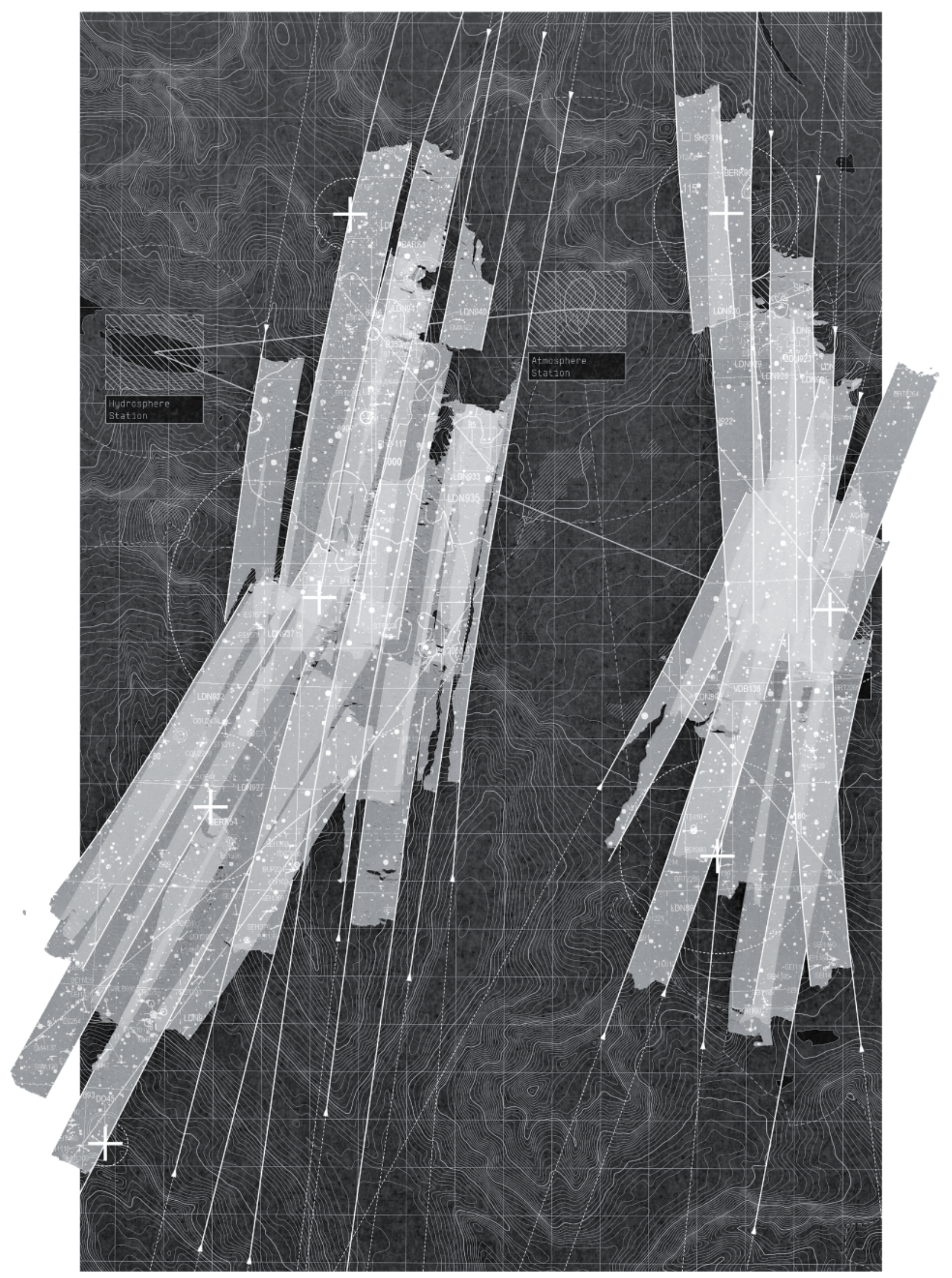

Fig. 76: Infosphere 

Bailey, Eric. Columbia Icefield: Ice Apex of the Canadian Rockies (Jasper: Parks Canada, 1987)

Ballantyne, Brian. ed., Survey, Parcels, and Tenure on Canada Lands, (Edmonton: Natural Resources Canada, 2010).

Boschman, Robert. "Bum Steer: Adulterant E. Coli and the Nature-Culture Dichotomy, " in Found in Alberta: Environmental Themes for the Anthropocene, (Waterloo: Wilfrid Laurier University Press, 2014).

Brado, Edward. Cattle Kingdom: Early Ranching in Alberta, (Victoria: Heritage House Publishing Co. Ltd., 2004).

Chakrabarty, Dipesh. "The Climate of History: Four Theses, Critical Inquiry, Vol. 35 (Winter 2009), 206-207.

Crutzen, Paul. "Geology of Mankind" Nature, Vol 415, (January 2002)

Forty, Adrian. Words and Buildings (New York: Thames and Hudson, 2000)

Freeman, Lewis Ransome. On the Roof of the Rockies: the great Columbia Icefield of the Canadian Rockies, limited ed. (New York: Dodd, Mead. 1925).

Fox, William L. "Dataland," in Landscape Futures: Instruments Devices and Architectural Inventions, ed. Geoff Manaugh (Spain: Actar Publishers, 2013)

Fullalove, Benedict. "Places, Desire, and Maps: Representing Wilderness at the Columbia Icefield, " in Found in Alberta: Environmental Themes for the Anthropocene, (Waterloo: Wilfrid Laurier University Press, 2014).

Heringman, Noah. "Deep time at the Dawn of the Anthropocene," Representations, Vol. 129, No. 1, (Winter 2015).

Higgs, Eric. Nature by Design: People, Natural Process, and Ecological Restoration (Cambridge and London: The MIT Press, 2003)

King James Bible: 400th Anniversary Edition (Oxford: Oxford University Press, 2010).

Klingan, Katrin. et al., Textures of the Anthropocene: Grain, Vapor, Ray (Boston: MIT Press, 2015).

Lam, Elsa. "Wilderness Nation: Building Canada's Railway Landscapes 1885-1929" (PhD diss., Columbia University, 2011)

Lord Smail, Daniel. On Deep History and the Brain (Berkley and Los Angeles: The University of California Press, 2008). 
Lothian, William F. A Brief History of Canada's National Parks

(Ottawa: Environment Canada, Parks, Canada, 1987).

MacLaren, I.S. "Rejuvenating Wilderness: The Challenge of Reintegrating Aboriginal Peoples into the 'Playground' of Jasper National Park', " in A Century of Parks Canada 1911-2011, ed. Claire Campbell (Calgary: University of Calgary Press, 2011)

Martell, Lynn. "Finding Answers in the Ice." Calgary Herald, July 3, 2011

Mumford, Lewis. Technics and Civilization (New York: Harcourt, Brace \& World, Inc., 1932; Reprint, New York: Harbinger Books, 1963).

Nixon, Rob. Slow violence and the Environmentalism of the Poor. (Cambridge, US: Harvard University Press, 2011).

Pendergast, Christopher. ed., Cultural Materialism: On Raymond Williams, (Minnesota: Minnesota University Press, 1995).

Scranton, Roy. Learning to Die in the Anthropocene: Reflections of the End of a Civilization, (San Francisco: City Light Books, 2015).

Stutfield, Hugh Edward Millington. Climbs and Explorations in the Canadian Rockies / by Hugh E.M. Stutfield and J. Norman Collie. (London: Longmans, Green. 1903).

Tavares, Paolo. "Stratoshield," in Textures of the Anthropocene: Grain, Vapor Ray, Vol. 2, (Cambridge and London: The MIT Press, 2015) .

Tennant, Christina and Brian Menounos. "Glacier Change at the Columbia Icefield, Canadian Rocky Mountains, 1919-2009," Journal Of Glaciology, Vol. 59, No. 216, (2013)

Thompson, E. P. "Time, Work-Discipline, and Industrial Capitalism." Past \& Present, No. 38 (1967). http://Www.jstor.org/ stable/649749.

Wang, J.Y. and Catherine M. M. Felton. Instruments for Physical Environment Measurements, Vol. 1 (Dubuque, Iowa: Kendall/ Hunt Publishing Company, 1983)

Weber, Bob. "Scientists Propose Vast Network of Wildlife Cameras," Calgary Herald, February 8, 2017.

Williams, Raymond. Keywords: A Vocabulary of Culture and Society, (USA: Oxford University Press, 1985). 
WEB SOURCES

"Alberta's Flood of Floods," Canada's Top Ten Weather stories for 2013, Environment and Climate Change Canada, last modified May 17, 2014, accessed January 14, 2017, https://WwW ec.gc .ca/meteo-weather/default. asp?lang=En\&n=5BA5EAFC-1\&offset $=2 \&$ toc $=$ show

Mortillaro, Nicole. "Fort McMurray Wildfire: Why the Fire Engulfed the City Within Hours." Global News, May 4, 2016, accessed January 14, 2017, http://globalnews.ca/news/2679397/ fort-mcmurray-wildfire-why-the-fire-engulfed-the-city-within-hours/

McDonald, Caroline. "The Insurance impact of the Fort McMurray fire. "Risk Management, September 2016, accessed January 14, 2017, proxy.library.carleton.ca/login?url=http:// go . galegroup.com/ps/i.do?p=AONE\&sw=w\&u=ocul_carleton\&V=2.1\&id=GALE\%7CA463401075\&it=r\&asid=64277e4922d93d50774caa32e8af9211.

Derworiz, Colette. "Canada's Mountain Parks Record Increase in Visitors During Early Summer. " Calgary Herald, September 2016, accessed March 3, 2017, http://calgaryherald.com/news/ local-news / canadas-mountain-parks-see-another-spike-in-tourism-numbers

Dolby, Christine. Is High-Speed Internet a Basic Right? CRTC to Weigh in. The Globe and Mail, April 08, 2016, accessed April 23, 2017, http://www. theglobeandmail.com/report-on-business/ is-high-speed-internet-a-basic-right-crtc-to-weigh-in/article29576878/

Drollete, Dan. "Citizen Science Enters a New Era." BBC News, March 2012, accessed March 5, 2017, http://Www.bbc.com/future/story/20120329-citizen-science-enters-a-new-era?selectorSection=technology

"National Parks of Canada, National Parks - Introduction," Parks Canada, last modified March 31, 2015, accessed March 28, 2017, http://WWw.pc.gc.ca/progs/np-pn/intro_e.asp

Arthur J. Ray, "The Hudson's Bay Company," The Encyclopedia of Canada, last modified June 22, 2015, accessed March 28, 2017, http://www. thecanadianencyclopedia.ca/en/article/hudsons-bay-company/

Stewart, Briar. "How 3D Maps of an Alberta Mountain Could Help Predict the Next Flood or Drought." CBC News, March 2017. accessed March 26, 2017, http://Www.cbc.ca/news/canada/edmonton/3d-mapping-fortress-ridge-1.4029656 
"Huts," The Alpine Club of Canada, accessed March 28, 2017. http: / / www. alpineclubofcanada.ca/facility/

"Orogeny, n.1," OED Online. March 2017. Oxford University Press. http://www.oed.com.proxy. library.carleton.ca/view/ Entry/132702?redirectedFrom=orogeny\#eid (accessed March 29, 2017)

"Climate Change and Agriculture," Alberta Agriculture and Forestry, last modified December 23, 2016, accessed January 14, 2017, http://www1.agric.gov.ab.ca/\$department/deptdocs.nsf/ all/cl9706

"Government of Canada and the Duty to Consult," Indigenous and Northern Affairs Canada, Government of Canada, last modified April 19, 2016, accessed April 25, 2017, https://WWw.aadnc-aandc.gc.ca/eng/1331832510888/1331832636303 
IMAGE SOURCES

Fig. 01: Ron Blakey, "Present." Source: Colorado Plateau Geosystems, Inc., Digital Image. Available from: http://jan. ucc.nau.edu/rcb7/namPres.jpg (accessed March 30, 2017)

Fig. 02: Ron Blakey, "Late Cretaceous." Source: Colorado Plateau Geosystems, Inc., Digital Image. Available from: http://jan.ucc.nau.edu/rcb7/namk100.jpg (accessed March 30 , 2017)

Fig. 03: Ron Blakey, "Late Jurrasic." Source: Colorado Plateau Geosystems, Inc., Digital Image. Available from: http://jan. ucc.nau.edu/rcb7/namJ150.jpg (accessed March 30, 2017).

Fig. 04: Ron Blakey, "Late Pennsylvanian." Source: Colorado Plateau Geosystems, Inc., Digital Image. Available from: http://jan.ucc.nau.edu/rcb7/namPP300.jpg (accessed March 30 , 2017)

Fig. 05: Ron Blakey, "Early Devionian." Source: Colorado Plateau Geosystems, Inc., Digital Image. Available from: http://jan.ucc.nau.edu/rcb7/namD400.jpg (accessed March 30 , 2017)

Fig. 06: Ron Blakey, "Late Cambrian." Source: Colorado Plateau Geosystems, Inc., Digital Image. Available from: http://jan. ucc.nau.edu/rcb7/namc500.jpg (accessed March 30, 2017)

Fig. 07: Richard Watkins, "Opening Page of Genesis" 1744, Microfilm, The British Library Archives, ESTC T230899, From: The Holy Bible, Containing the old and New Testaments (Edinburgh: 1744), Plate A3.

Fig. ๑8: James Hutton, "Page Exerpt," 1793, Scan, ETH-Bibliothek Zürich, Rar 3971, From: A Theory of the Earth: With Proofs and Illustrations (Edinburgh: 1795), Plate 311.

Fig. 09: Byron Harmon, "The Great Divide, " Source: Playle's Auctions, Inc., Digital Image. Available from: https:// playle.com/pictures/ISLANDDWELLER209.jpg (accessed March 30 , 2017)

Fig. 10: Arthur Oliver Wheeler, "Columbia Icefields No. 1, 290," 1918, Source: Mountain Legacy Project, Digital Image. Available from: https://mlplibrary.s3.amazonaws.com/ bfe809c4-75b2-11e2-abb9-c82a14fffed2.jpeg (accessed March $30,2017)$. 
Fig. 11: Arthur Oliver Wheeler, "Columbia Icefields No. 1,

291," 1918, Source: Mountain Legacy Project, Digital Image. Available from: https://mlplibrary.s3. amazonaws. com/bb1de7ba-75b2-11e2-abb9-c82a14fffed2.jpeg (accessed March 30 , 2017)

Fig. 12: Jenna Falk, "Columbia Icefields No. 1, 6183," 2011, Source: Mountain Legacy Project, Digital Image. Available from: https://mlplibrary.s3.amazonaws. com/5bbøe962-6ffe11e2-a556-c82a14fffed2.jpeg (accessed March 30, 2017).

Fig. 13: Jenna Falk, "Columbia Icefields No. 1, 6185," 2011, Source: Mountain Legacy Project, Digital Image. Available from: https://mlplibrary.s3.amazonaws.com/2b45656e-6ffe11e2-a556-c82a14fffed2.jpeg (accessed March 30, 2017).

Fig. 14: Unkown, "Table of Surveying Equipment," 1728, Source: Wikipedia, Digital Image. Available from: https://en.wikipedia.org/wiki/Surveying\#/media/File:Table_of_Surveying,_Cyclopaedia,_Volume_2.jpg (accessed January 18, 2017).

Fig. 15: Dominion Exhibition, "Dominion Exhibition Calgary 1908," 1908, Source: Canadian Design Resource, Digital Image. Available from: https://upload.wikimedia.org/wikipedia/ commons/5/51/Dominion_Exhibition_Calgary_1908.jpg (accessed March 30, 2017).

Fig. 18: Dominion Exhibition, "Dominion Exhibition Calgary 1908," 1908, Source: Canadian Design Resource, Digital Image. Available from: https://upload.wikimedia.org/wikipedia/ commons/5/51/Dominion_Exhibition_Calgary_1908.jpg (accessed March 30, 2017)

Fig. 19: NASA, "Athabasca Oilsands 1984," 1984, Source: NASA Earth Observatory. Digital Image. Available from: https:// earthobservatory. nasa.gov/Features/WorldofChange/images/ athabasca/athabasca_tm5_19840723_lrg.jpg (accessed March 30, 2017)

Fig. 20: NASA, "Athabasca Oilsands 2016," 2016, Source: NASA Earth Observatory. Digital Image. Available from: https:// earthobservatory. nasa.gov/Features/WorldofChange/images/ athabasca/athabasca_oli_20160715_lrg.jpg (accessed March 30 , 2017) 
Fig. 21: Lewis Ransome Freeman, "Wrangler Bob Baptie Doing His

Stuff on a Cliff of CastleGuard," 1925, Photograph. Whyte Museum and Archives. From: On the Roof of the Rockies: the great Columbia Icefield of the Canadian Rockies, limited ed. (New York: Dodd, Mead. 1925). Plate 147.

Fig. 22: Goolge Earth, "Bow River, Calgary, Alberta, 2013," 51 $2^{\prime} 39.29^{\prime \prime} \mathrm{N}$ and $114^{\circ} 0^{\prime} 54.31^{\prime \prime} \mathrm{W}$. (accessed Januuary 19, 2017).

Fig. 23: Goolge Earth, "Bow River, Calgary, Alberta, 2013," 51 $2^{\prime} 39.29^{\prime \prime} \mathrm{N}$ and $114^{\circ} 0^{\prime} 54.31^{\prime \prime} \mathrm{W}$. (accessed Januuary 19, 2017).

Fig. 24: NASA, "Fort McMurray Burn Scar," 2016, Source: NASA Earth Observatory, Digital Image. Available from: https:// eoimages.gsfc.nasa.gov/images/imagerecords/88000/88039/mcmurray_oli_2016133_lrg.jpg (accessed March 30, 2017).

Fig. 25: NASA, "Fort McMurray Fire Progress," 2016, Source: NASA Earth Observatory, Digital Image. Available from: https://eoimages.gsfc.nasa.gov/images/imagerecords/87000/87988/mcmurray_etm_2016125_swir_lrg.jpg (accessed March 30, 2017).

Fig. 26: Wang, J.Y. and Catherine M. M. Felton, "Control Recorder, C-577D/GMD-1," Photograph. From: Instruments for Physical Environment Measurements (Dubuque, Iowa: Kendall/ Hunt Publishing Company, 1983). Plate 281.

Fig. 27: Wang, J.Y. and Catherine M. M. Felton, "Barringer Correlation Spectrometer, " Photograph. From: Instruments for Physical Environment Measurements (Dubuque, Iowa: Kendall/ Hunt Publishing Company, 1983). Plate 428.

Fig. 28: Wang, J.Y. and Catherine M. M. Felton, "Triton Buoy," Photograph. From: Instruments for Physical Environment Measurements (Dubuque, Iowa: Kendall/Hunt Publishing Company, 1983). Plate 472.

Fig. 29: Wang, J.Y. and Catherine M. M. Felton, "The Airborner Unit of Vaisala RS 21-12C Radiosonde," Print. From: Instruments for Physical Environment Measurements (Dubuque, Iowa: Kendall/Hunt Publishing Company, 1983). Plate 291.

Fig. 30: Francis W. Reichelderfer, "Artist Rendering of Proposed Nimbus Weather Satellite," Drawing. From: Space Science aids the Weatherman (USA: United States Weather Bureau, 1962). Plate 19. 
Fig. 31: Wang, J.Y. and Catherine M. M. Felton, "Nimbus II

Spacecraft System," Print. From: Instruments for Physical Environment Measurements (Dubuque, Iowa: Kendall/Hunt Publishing Company, 1983). Plate 405.

Fig. 32: Francis W. Reichelderfer, "TIRos Photograph, " Photograph. From: Space Science aids the Weatherman (USA: United States Weather Bureau, 1962). Plate 13.

Fig. 33: Francis W. Reichelderfer, "TIRos Photograph," Photograph. From: Space Science aids the Weatherman (USA: United States Weather Bureau, 1962). Plate 11.

Fig. 34: Francis W. Reichelderfer, "Men Plotting Cloud Photos," Photograph. From: Space Science aids the Weatherman (USA: United States Weather Bureau, 1962). Plate 12.

Fig. 35: Francis W. Reichelderfer, "TIR0S Photograph," Photograph. From: Space Science aids the Weatherman (USA: United States Weather Bureau, 1962). Plate 12.

Fig. 36: Geosoft, "Subsurface 3D Tools." Source: Geosoft, Digital Image. Available from: http://www.geosoft.com/media/ uploads/products/arcgis/target-arcgis/subsurface-3d-tools. jpg(accessed March 30, 2017). 


\section{OTHER SOURCES}

Junior Bonner, DVD, directed by Sam Peckinpah (2004, USA: Solar Productions, 1972)

Paul Brandt, "Alberta Bound," in This Time Around, Orange Record Label, 2004.

Note: all images not included in this list are assumed to be the property of the author. 
